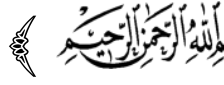

竞

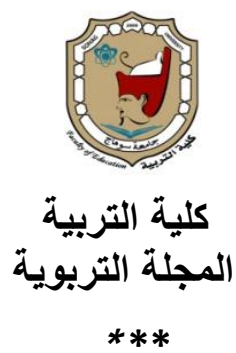

الجهود التزبوية لمركز هممد بن نايف للامناصهة والرعاية في هواجهة التطرف الفكري: رؤية هقترحة

إعداد

د. ـبد الله بن مزعل الحربي

أستاذ أصول التربية المشارك

جامعة حفر الباطن

المجلة التربوية.العدد الثامن والخمسون. فبراير 19+rم

Print:(ISSN 1687-2649) Online:(ISSN 2536-9091) 
الملاخص:

هافت الداسة إلى التعرف على الجهود التريوية لمركز محمد بن نايف للمناصحة والرعاية،

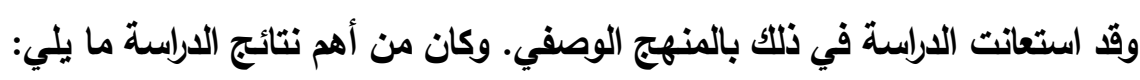

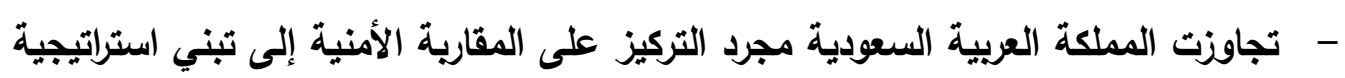

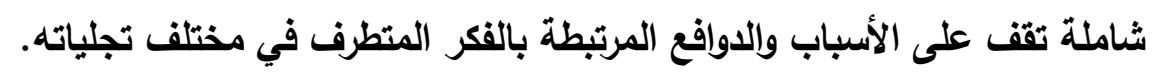

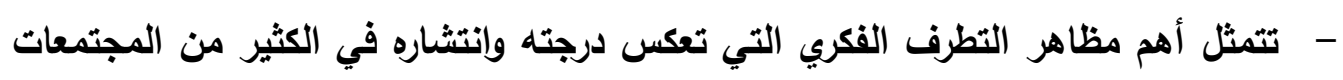

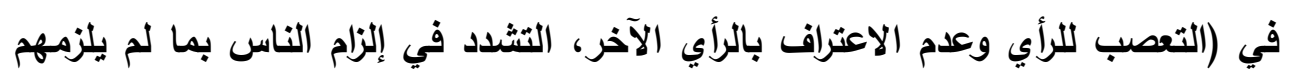

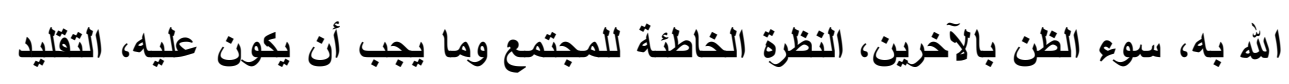
الأعمى، والسقوط في هاوية التكفير).

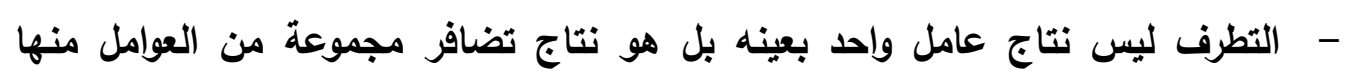

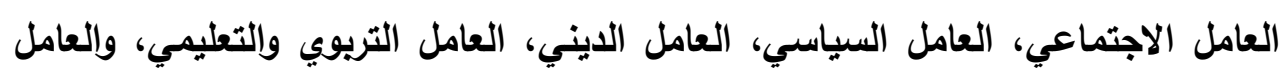
الإعلامي.

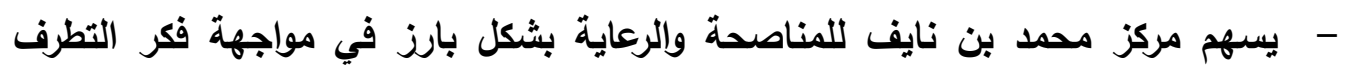

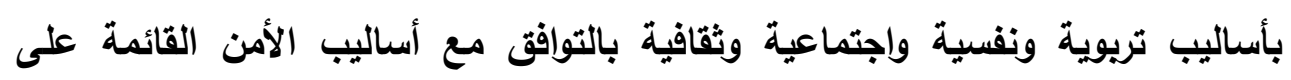
الضبط وتطبيق القانون.

- قامت الدارسة روئية مقترحة لتغزيز الجهود التربوية لمركز محمد بن نايف للمناصحة والرعاية في مواجهة التطرف الفكري بالمملكة العربية السعودية. الكلمات المفتاحية: الإرهاب، التطرف، الوقاية، المناصحة، التأهيل، الرعاية. 
الجهود التربوية لمركز محمد بن نايف للمناصحة والرعاية في مواجهة النطرف الفكري: رؤية مقترحة

The Educational Efforts of Mohammed Bin Nayef Center for

Counseling and Caring for the Elimination of Intellectual

Extremism: A Proposed Vision

Dr. Abdullah bin Muzil Al-Harbi

Associate Professor Fundamentals of Education

University of Hafr AlBatin

Abstract

The study aimed at identifying the educational efforts of Mohammed bin Nayef Center for Counseling and Care. The study used the descriptive approach. The most important results of the study were:

- Saudi Arabia has simply gone beyond focusing on the security approach to adopting a comprehensive strategy that stands on the real causes and motives of extremist ideology in its various manifestations.

- The most important aspects of intellectual extremism which reflect its degree and spread in many societies is represented in (intolerance of opinion and non-recognition of the other opinion, the strictness of committing people to what God did not require., the bad thinking of others, the wrong view of society and what it should be like, blind imitation, and the fall in the abyss of thinking).

- Extremism is not the product of one particular factor but rather the product of a combination of many factors including the Social, Religious, Educational, Political and Media factors.

- Mohammed Bin Nayef Center for Counseling and Care contributes significantly to the elimination of extremist ideology through educational, psychological, social and cultural methods besides security methods based on discipline, and law enforcement.

- The study presented a proposed vision to reinforce the educational efforts of Mohammed Bin Nayef Center for Counseling and Care in the Elimination of Intellectual Extremism in Saudi Arabia.

Keywords: terrorism, extremism, prevention, counseling, habilitation, care. 


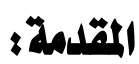

يعد التطرف في الآراء والأفكار تجاه بعض القضايا الاجتماعية والسياسية واللينية ظاهرة

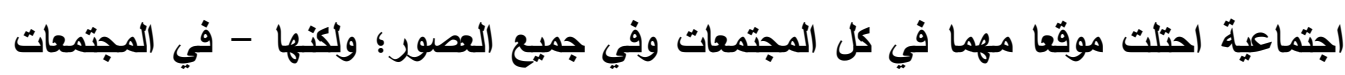

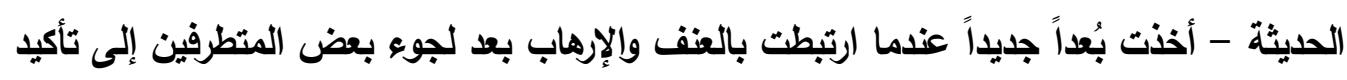

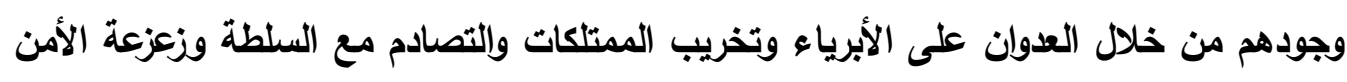

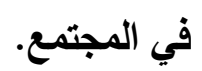

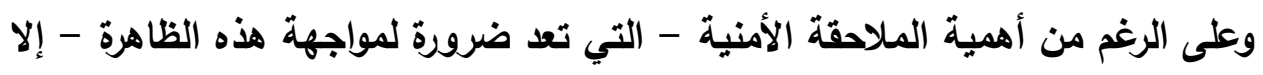
أنها ليست كافية؛ لأن التطرف الفكري مشكلة لها أبعادها النفسية والاجتماعية والاقتصادية الإنية

$$
\text { والسياسية وغيرها (عيسى، 1991 199). }
$$

كما أن لها أهمية قصوى كإعدى قضايا العصر، ومن ثم ثم فهناك ضرورة لمواجهنها

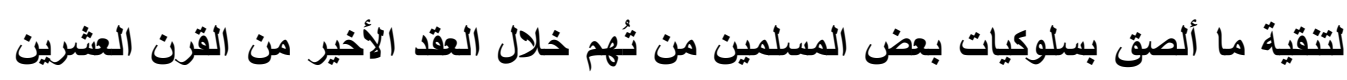

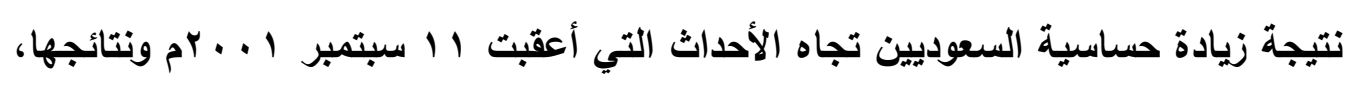

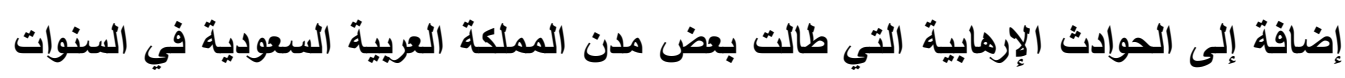

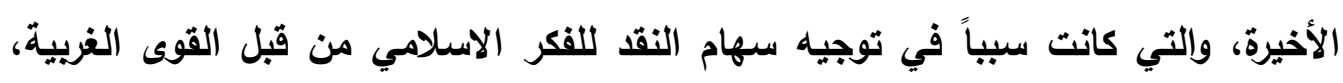

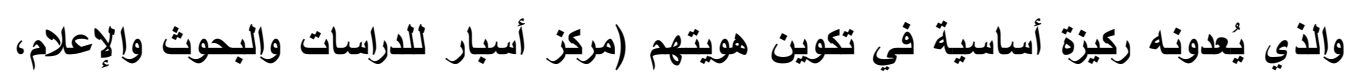

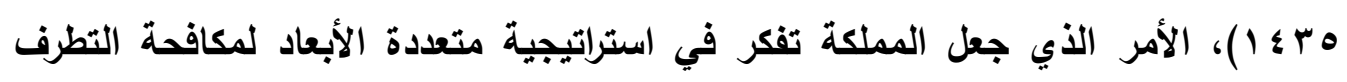

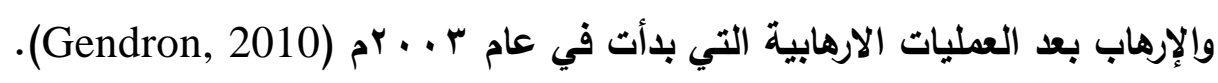

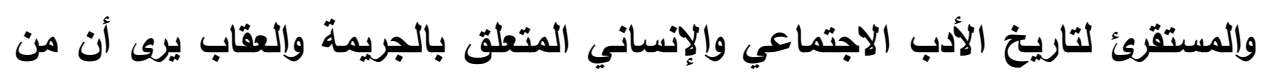

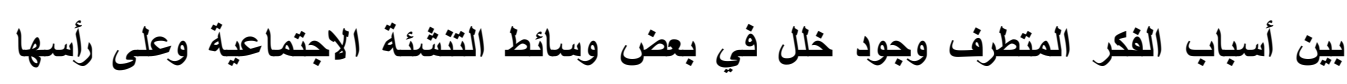

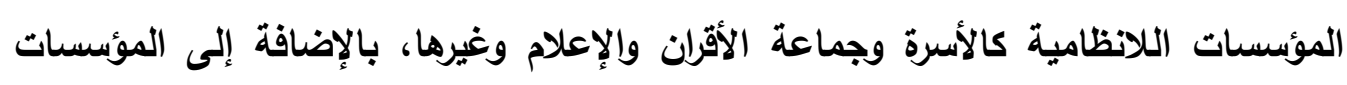

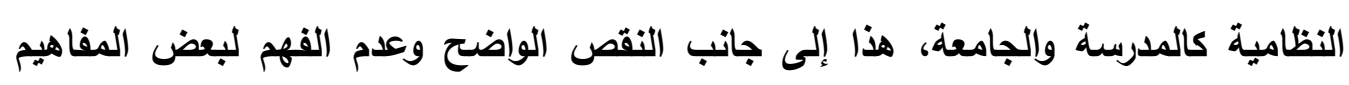
الثقافية ويخاصة الاينية منها.

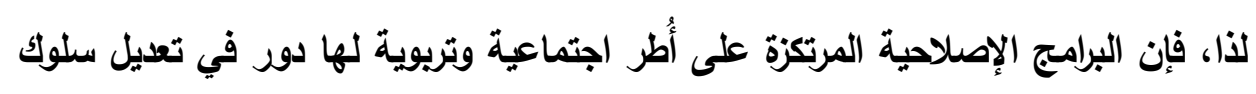

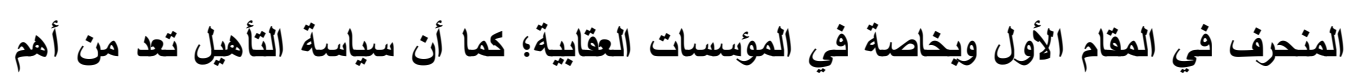

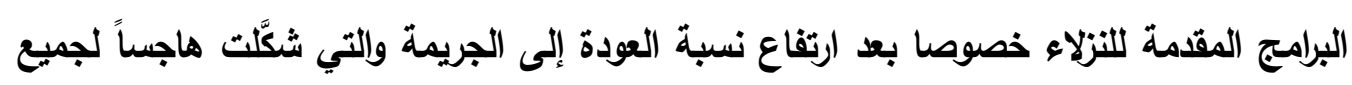
المهتمين بقضية الإصلاح. 
وحقيقةُ الخطر لا تكمن في وجود بعض الأفراد من أصحاب الفكر المتطرف، فهؤلاء لا

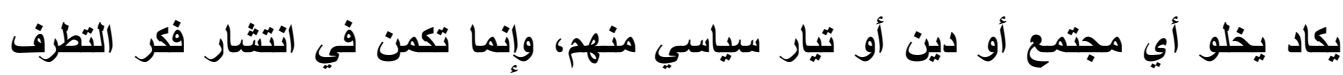

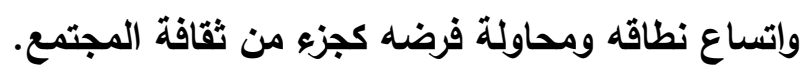

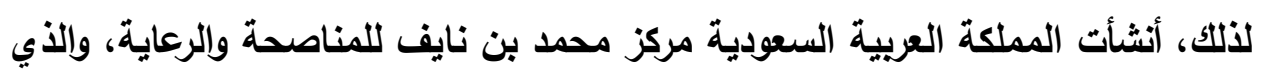

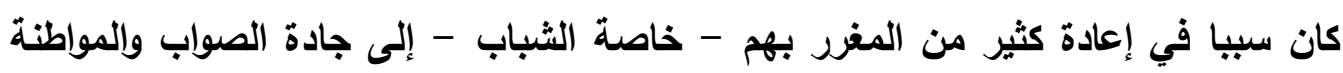
الصالحة وإلى المشاركة الفاعلة في بناء الوطن وتصحيح ما لايهم من أفكار من خلال استهلاف البُنى التحتية لفكر التطرف.

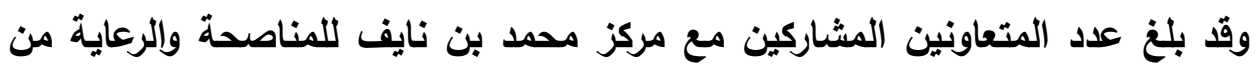

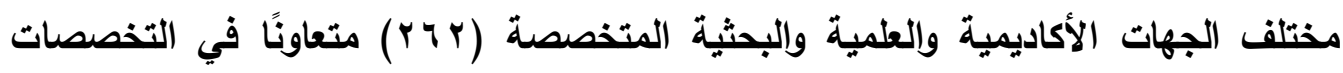

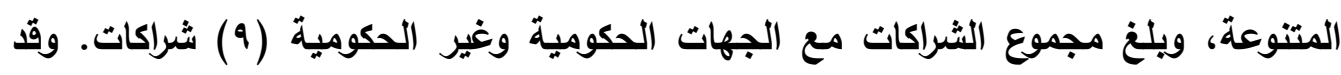

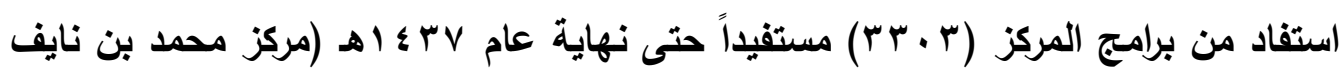

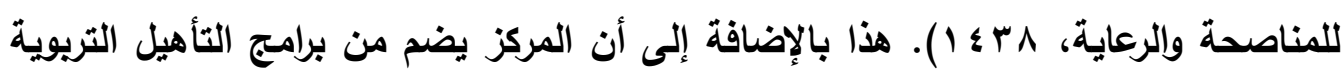

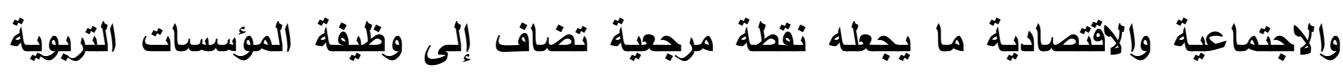

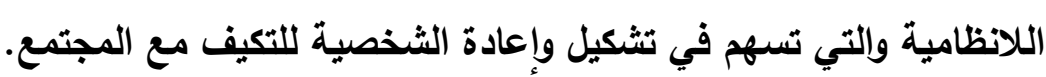

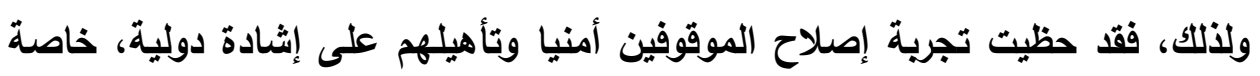

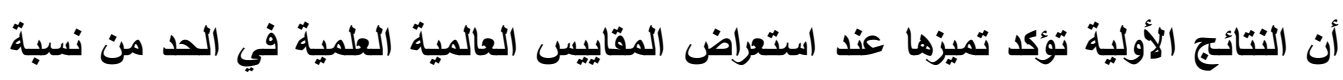

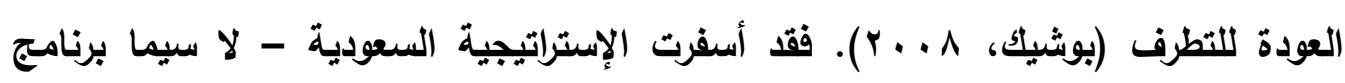

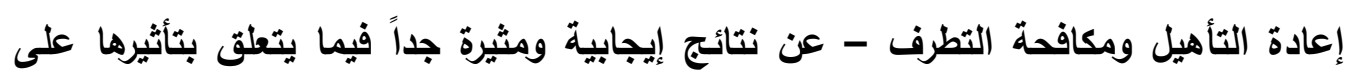

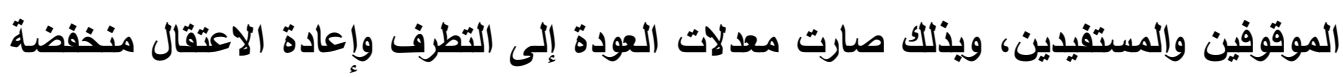

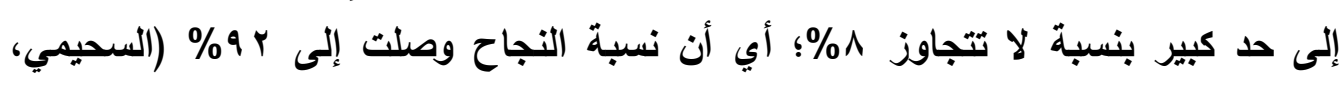
( $1 \leqslant$ ro

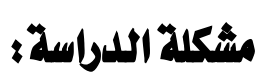

تدور مشكلة الدراسة حول فكرة الإنسانية في تطبيق العقوية والانتقال من فكرة الانتقام من

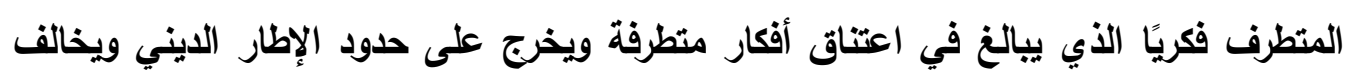

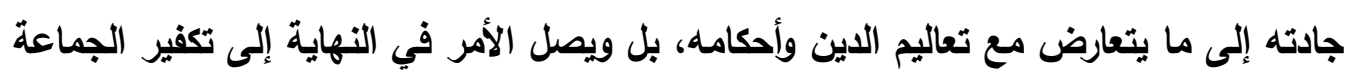

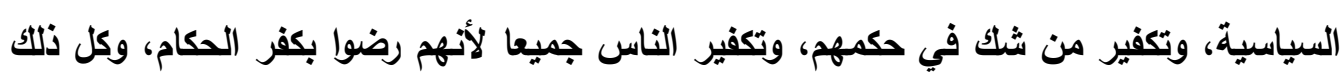


يتطلب العمل الجاد الهادف إلى استئصال الأسباب الموضوعية التي أدت به إلى ذلك الجرم

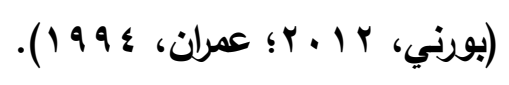

ومن هنا بأ فكر الإصلاح، حيث يرى البعض أنّا إنسانية العقاب تخدم أهداف العدالة أكثر

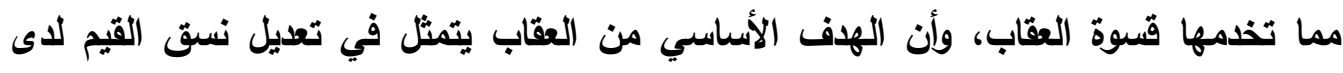

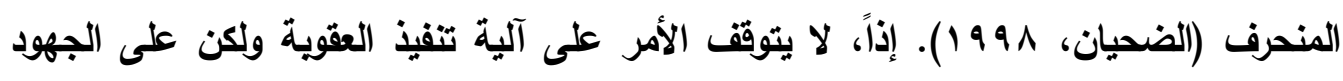

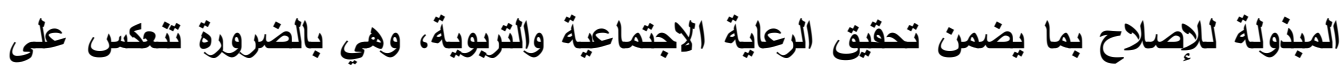
الموقف الفكري للاولة.

ويطبيعة الحال فإن جميع محاولات الإصلاح والعلاج التي قامت بها المثلكة العربية

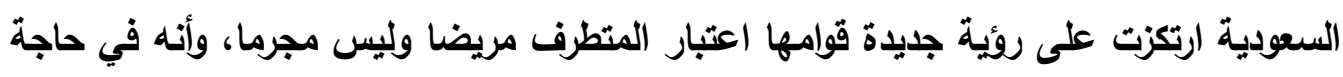

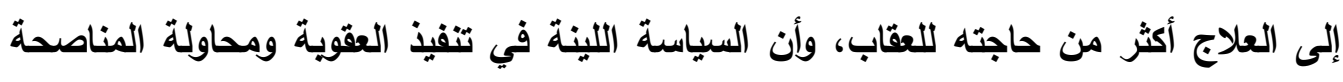

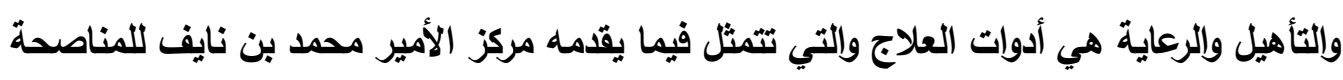
والرعاية (Saba \& Shagufty, 2009)، حيث إنه يخدم فلسفة وأهداف السياسة الإنسانية

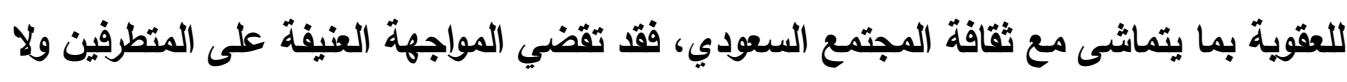

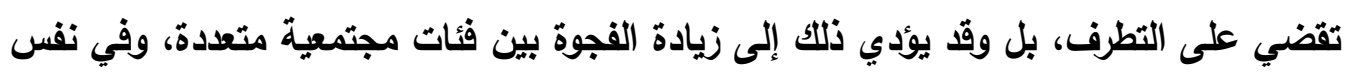
الوقت قد يؤدي ذلك إلى وجود تنافر اجتماعي.

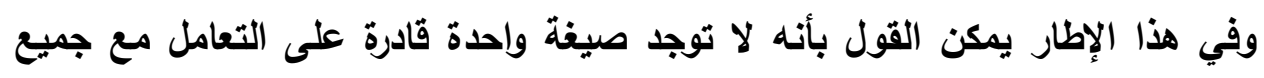

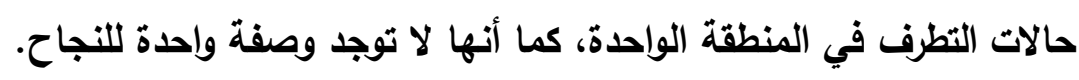

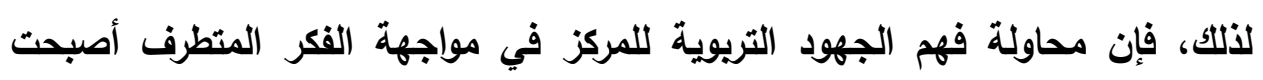

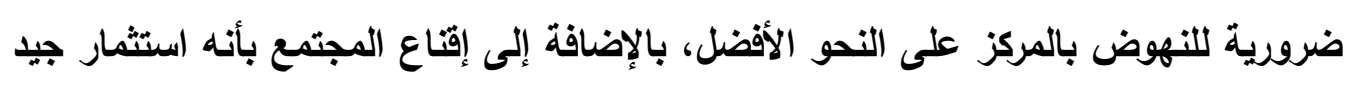

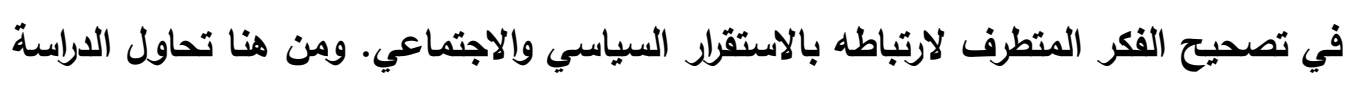
إجابة الأسئلة الآتية:

1 - ما مفهوم التطرف الفكري؟ وما أهم مظاهره؟

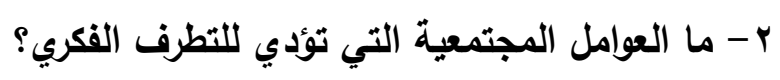

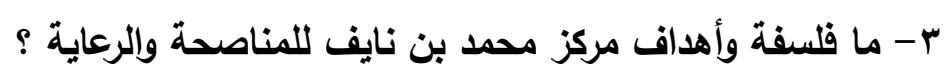

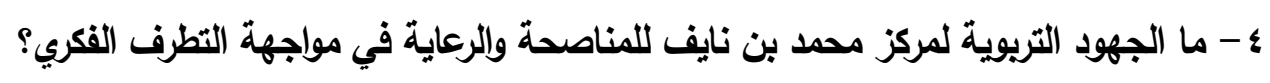

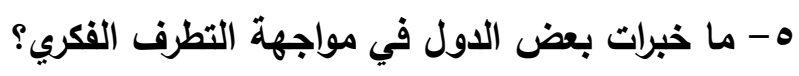




\section{الجهود التربوية لمركز محمد بن نايف للمناصحة والرعاية في مواجهة التطرف الفكري: رؤية مقترحة}

צ- ما الروئة المقترحة لتعزيز الجهود التريوية لمركز محمد بن نايف للمناصحة والرعاية في

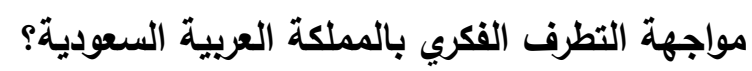

\section{أهداف الدراسة:}

يمكن عرضها على النحو الآتي:

- تحاول الدراسة فهم قضية التطرف الفكري وإلقاء الضوء على على أهم مظاهره. - التعرف على العوامل المجتمعية التي تؤدي إلى التطرف الفية الفكري.

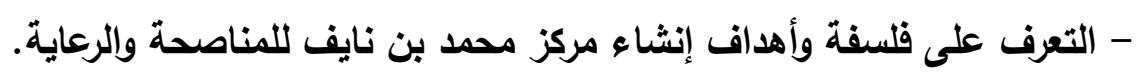

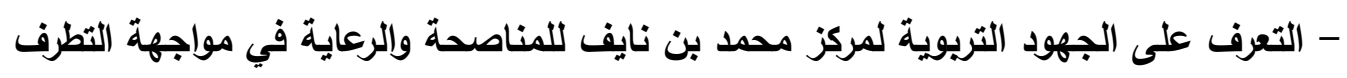
الفكري.

- رصد خبرات بعض الدول في مواجهة التطرف الفكري.

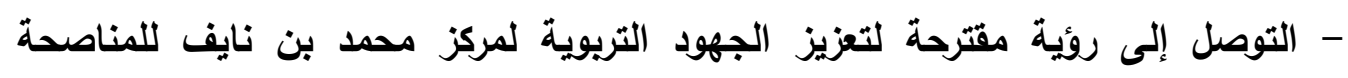
والرعاية في مواجهة التطرف الفكري في المملكة العربية السعودية.

\section{أهية الدراسلة:}

\section{يمكن عرضها على النحو الآتي:}

- - إنها تعد من الدراسات الكاثشفة التي توضح دور الاني: المملكة العربية السعودية غير التقليدي

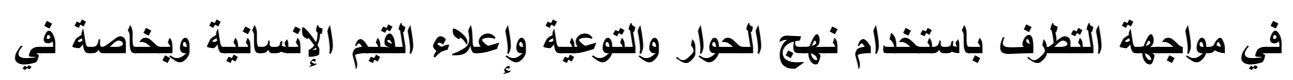
إحدى مؤسساتها التريوية والاجتماعية.

- تعد إحدى الداراسات التي تمهر للكثير من الدراسات الميدانية في مرحلة لاحقة للمراجعة والإضافة في ظل التطورات المستقبلية.

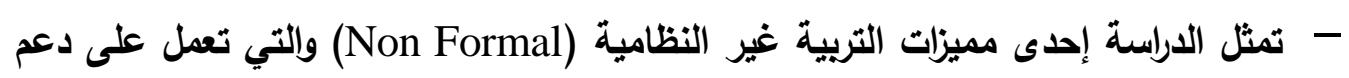

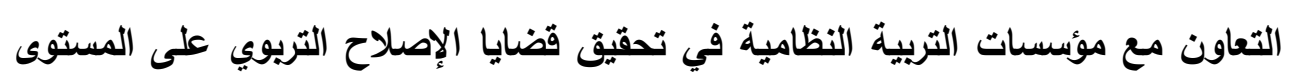

الاجتماعي.

\section{منهج الدراسة:}

تستخدم الدراسة المنهج الوصفي (Anderson \& Arsenault, 2000) من خلال إجراء دراسة نظرية وصفية لتوضيح قضية التطرف الفكري وإلقاء الضوء على أهم مظاهره، 
وتحديد العوامل المجتمعية التي تؤدي إليه، وعرض لنثأة مركز محمد بن نايف للمناصحة والرعاية وفلسفته وأهدافه، ورصد خبرات بعض الدول في مواجهة التطرف الفكري، بالإضافة إلى إجراء دراسة تحليلية للجهود التريوية للمركز.

\section{مصطاحات الدراسة ؛}

$$
\text { يمكن عرضها على النحو الآتي: }
$$

- الجهود التريوية Educational Efforts: هي مجموعة من المفاهيم والحقائق والمعارف

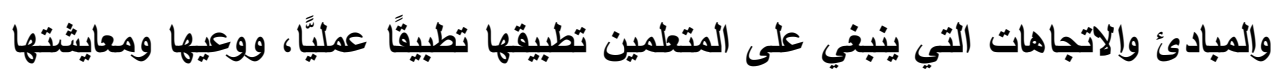

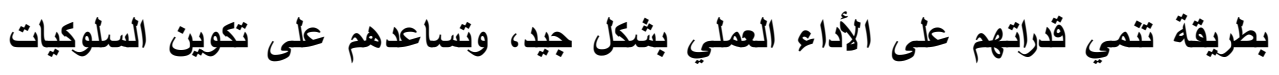

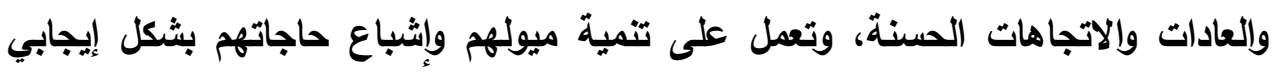

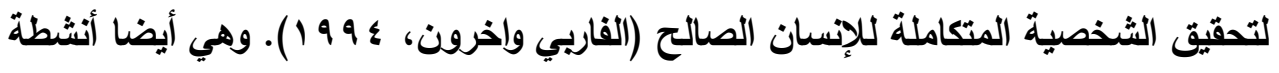

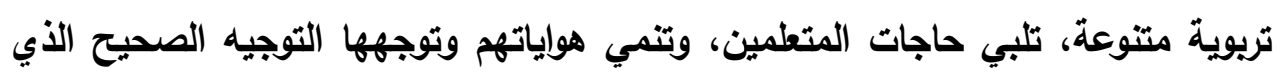

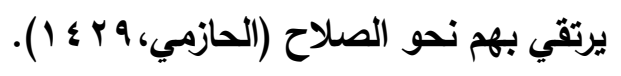

ويقصد بالجهود التريوية في هذه الدراسة "مجموعة من البرامج والأنشطة التريوية التي يقوم بها مركز محمد بن نايف للمناصحة والرعاية في مواجهة الفكر المتطرفي".

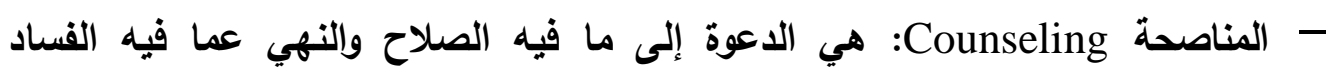

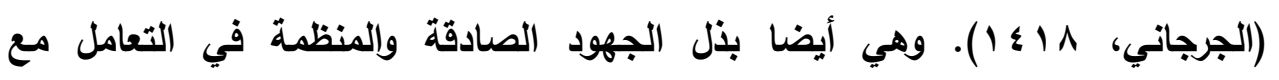

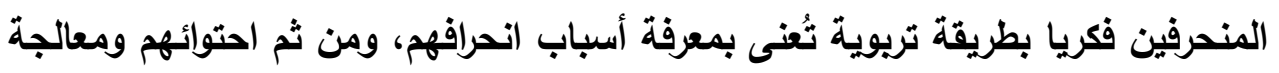

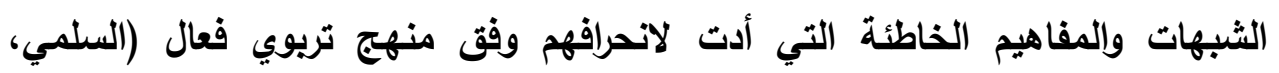

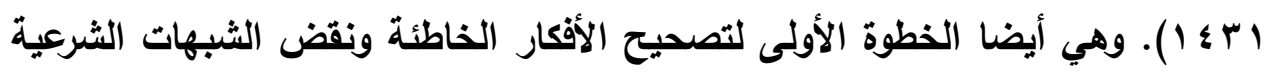

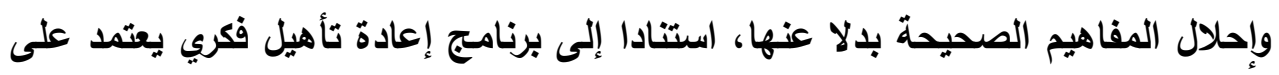

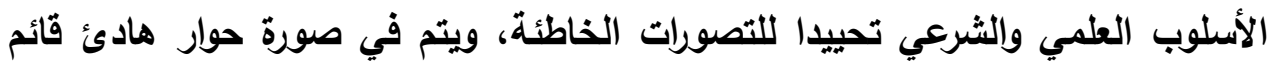

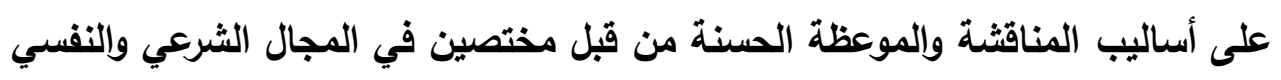

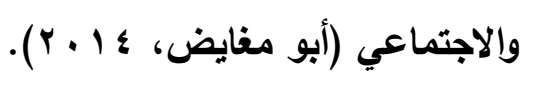

ويقصد بالمناصحة في هذه الدراسة "تلك العملية التربوية التي تقوم على أسس

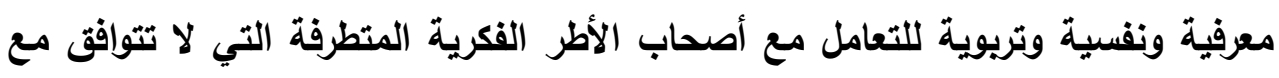

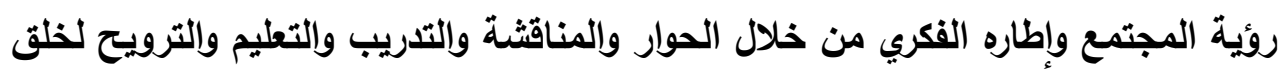


بنية فكرية ونفسية لهم تتسم بالانفتاحية والتسامح والقدرة على التعامل إيجابيا مع الأطر المجتمعية والانتماء والولاء للأمة".

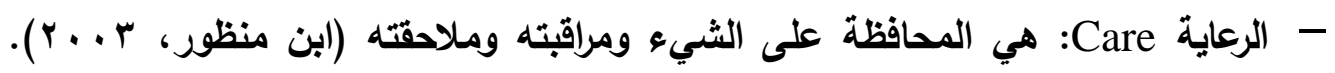

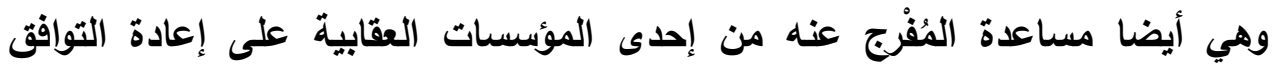

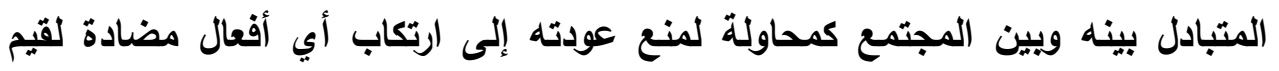
المجتمع وقوانينه وليمارس حياة سوية كمواطن شريف (عبد العال، 1 ـ ـ 1 ).

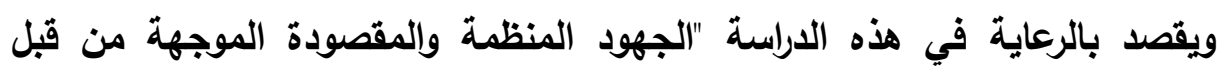

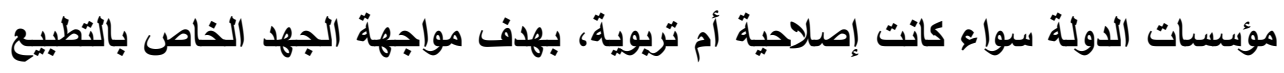

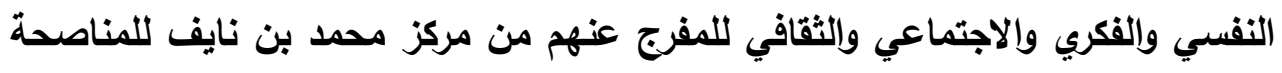

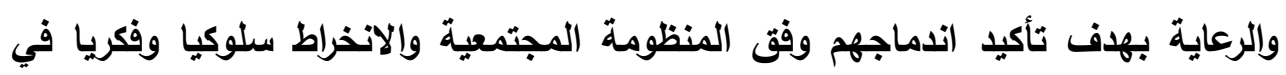

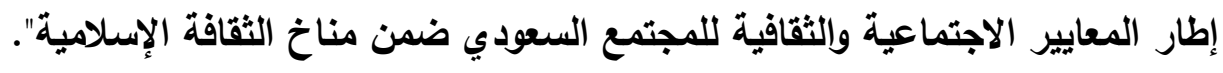

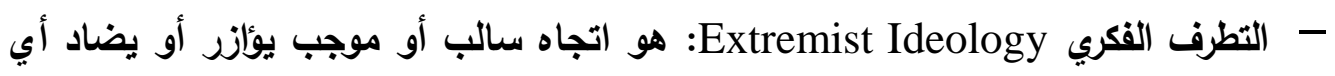

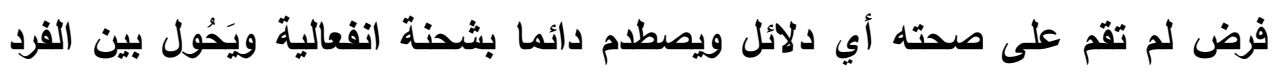

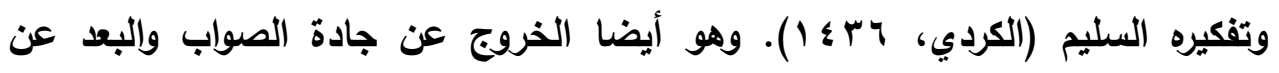

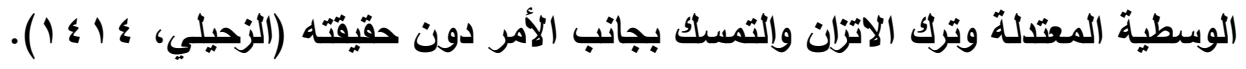

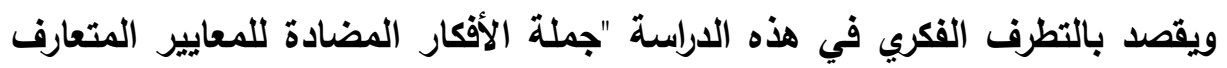

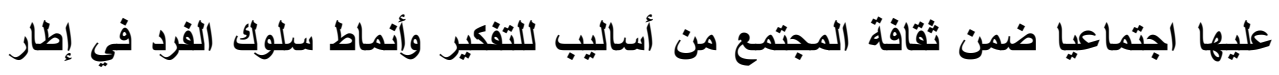

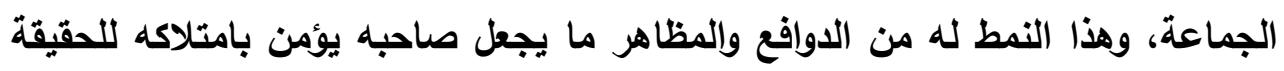

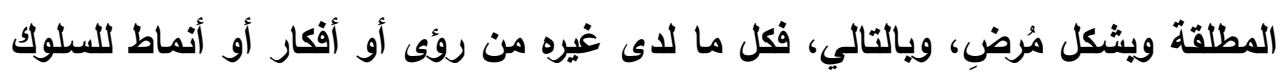
خطأ. وعليه، فهو دائما في صدام مع مجتمعه ويالتالي هو خارج عليه".

\section{حدود الدراسة:}

يمكن عرضها على النحو الآتي:

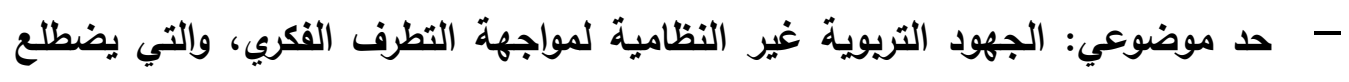
بها مركز محمد بن نايف للمناصحة والرعاية.

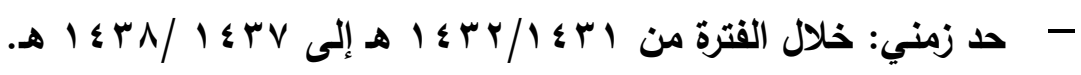


- - حد مكاني: مركز محمد بن نايف للمناصحة والرعاية في المملكة العربية السعودية.

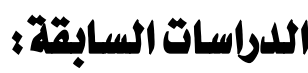

تم انتقاء أكثر الدراسات ارتباطاً بالموضوع، نعرضها وفق التسلسل التاريخي لإجرائها

$$
\text { من الأقدم إلى الأحدث على النحو الآتي: }
$$

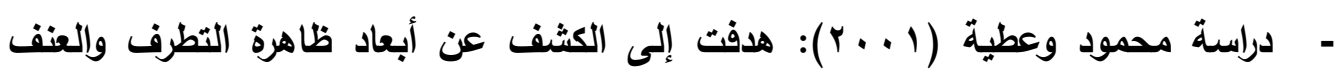

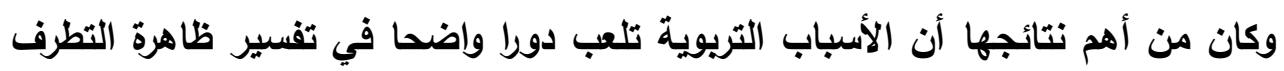

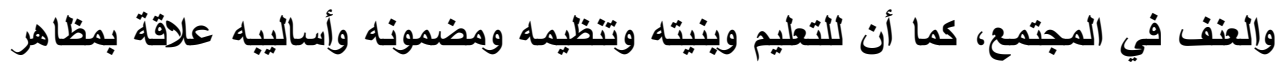
التطرف والعنف، تجسدت هذه العلاقة في القصور في تحقيق التنمية المتكاملة

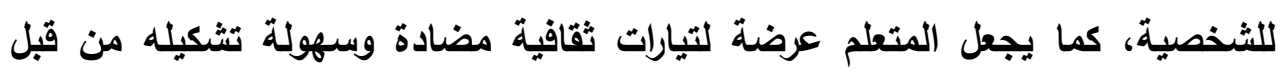

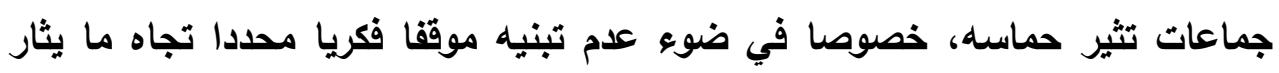
حوله. - دراسة هورجان ويرادوك (Horgan \& Braddock, 2010): هدفت إلى تقييم فعالية برامج اجتثاث التطرف في أيرلندا الثمالية وكولومبيا وإندونيسيا واليمن والسعودية. وكان التيان

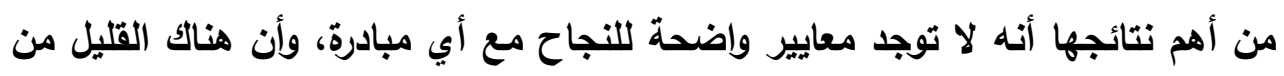
البيانات المرتبطة بأي من هذه المبادرات التي من الممكن أن تكون موثئوقة بثكل كبير ،

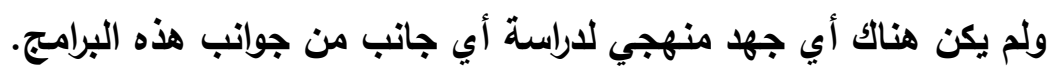

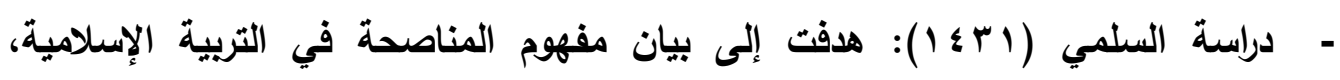

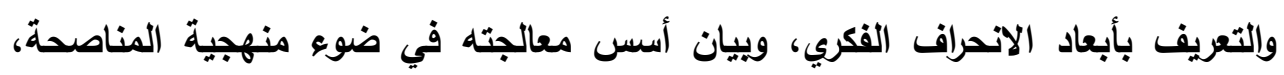

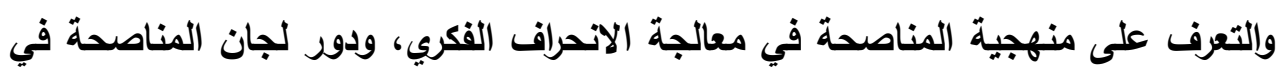
تطبيقها. واستخدمت الاراسة المنهج الوصفي، وكان من أهم نتائجها أن عملية المناصحة الهاصة

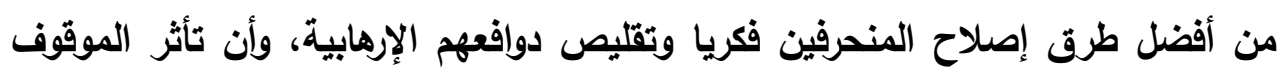

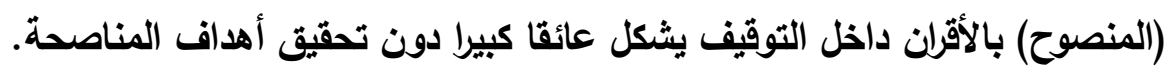

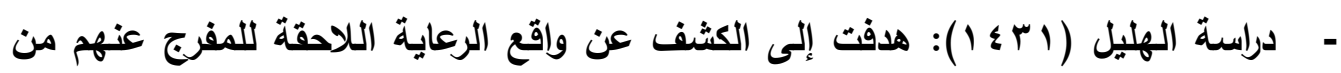

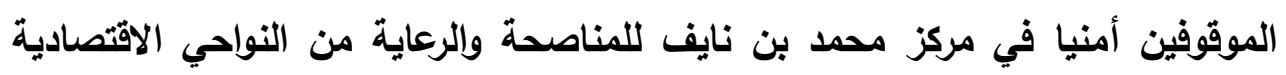

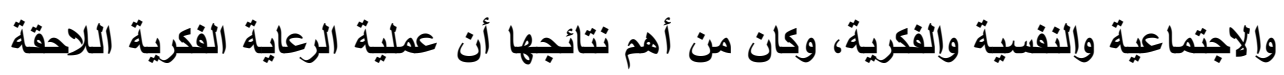


هي الأقلّ من بين مجالات الرعاية اللاحقة، بالإضافة إلى عدم معرفة المفرج عنهم بالكثير من الخدمات والمساعدات التي تقدم لعموم المفرج عنهم.

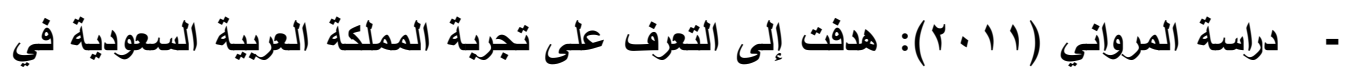

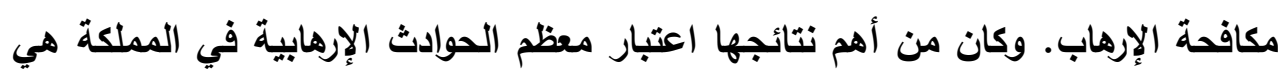

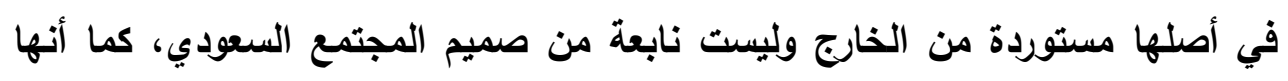

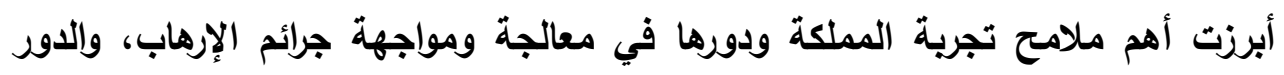

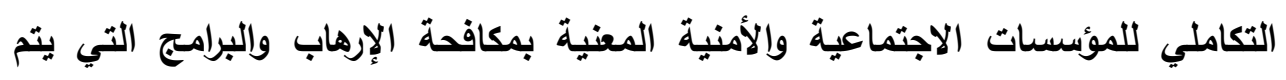
تنفيذها لإعادة تأهيل ومناصحة ذوي الفكر المتطرف. - دراسة جونس (Jones, 2013): هدفت إلى التعرف على الطرق الأكثر فاعلية في تعديل

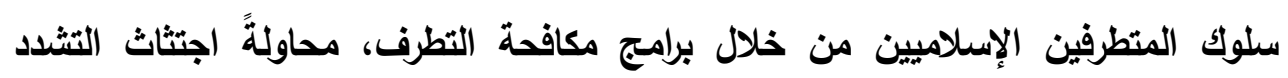

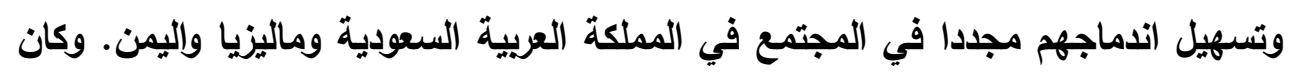

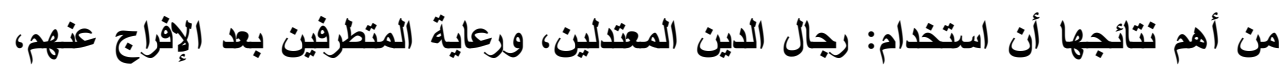

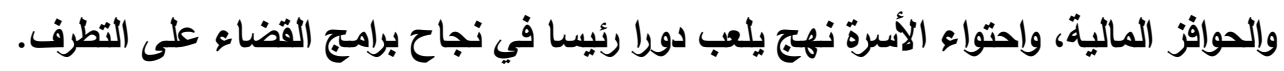

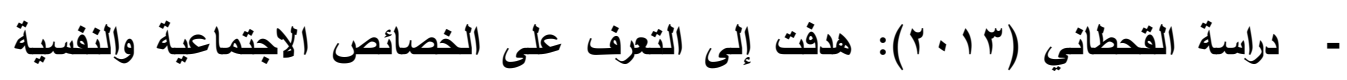

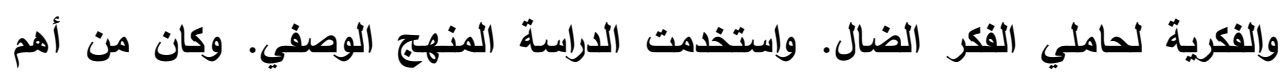

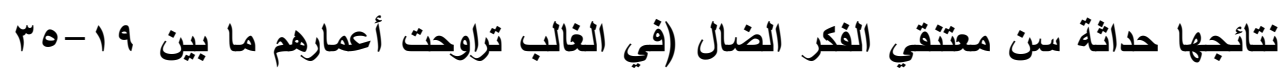

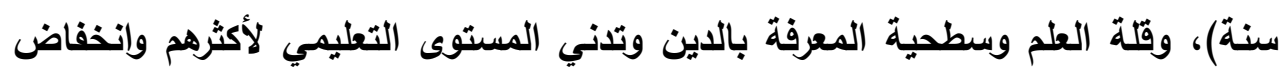

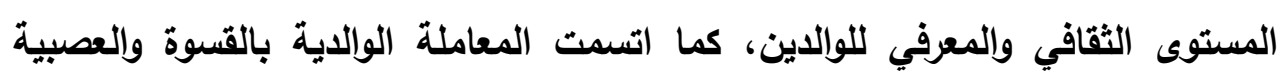

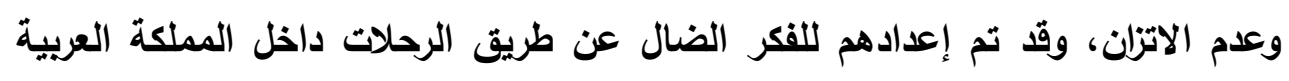

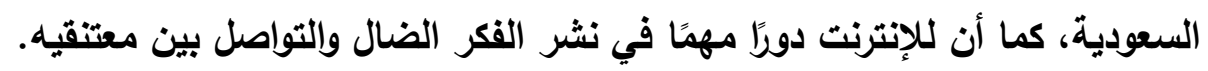

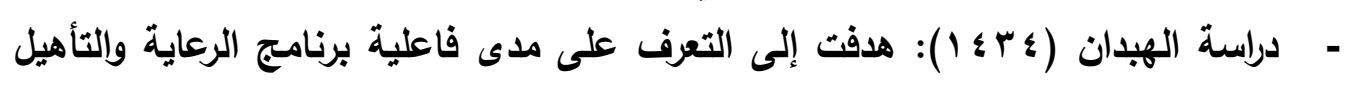

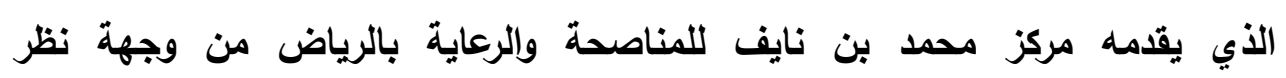

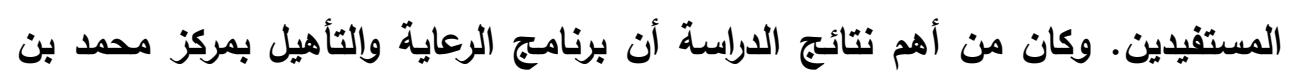
نايف للمناصحة والرعاية يسهم بثكل كبير في تصحيح سلوكيات المستفيدين.

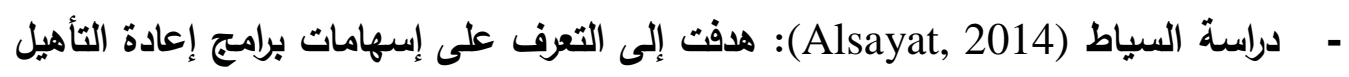

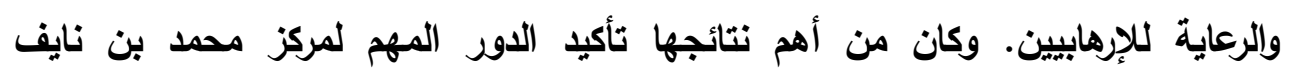


للمناصحة والرعاية بسبب نجاحه في مساعدة الإرهابيين على تغيير سلوكهم ليصبحوا أفرادا منتجين في المجتمع.

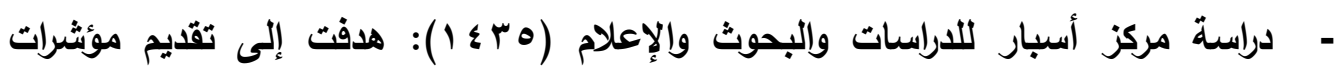
تعكس درجة تَديُن السعوديين، والتعرف على موقف الثباب من مشكلة الغلو والتطرف

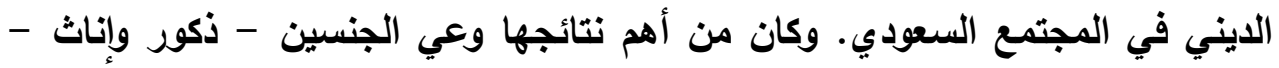

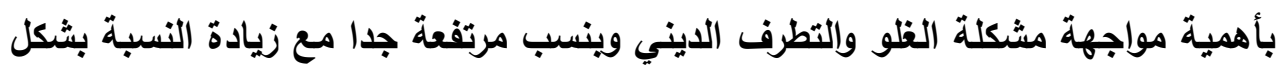
طفيف لاى الإناث، وضرورة توجيه جهود الدولة في الحاضر والمستقبل القريب لمعالجة هذه المشكلة.

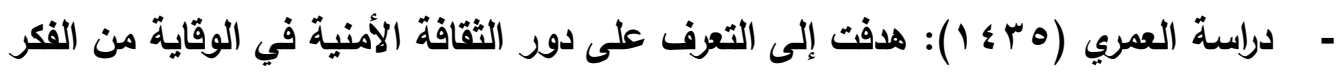

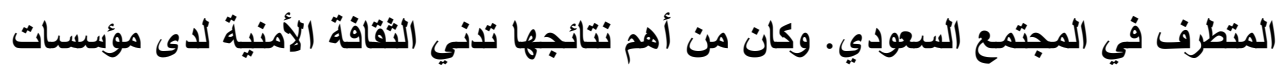

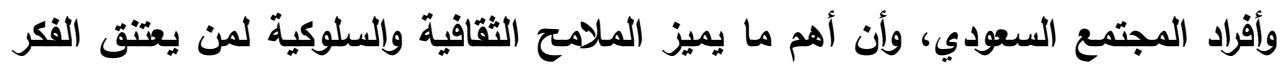

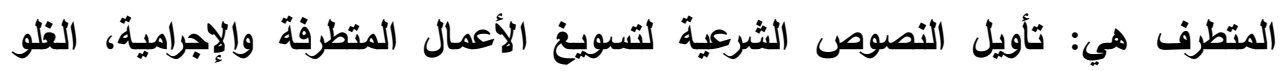

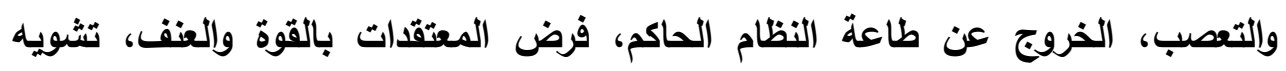

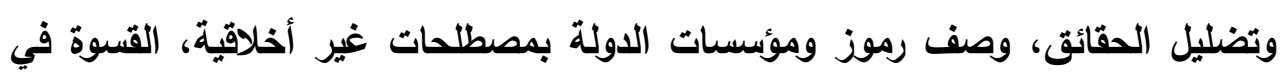

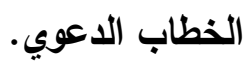
- دراسة أسلم وآخرون (Aslam et al., 2016): هافت إلى التعرف على برامج القضاء على التطرف وإعادة تأهيل المتطرفين في ماليزيا وتايلاند وإندونيسيا وسنغافورة. وكان التان

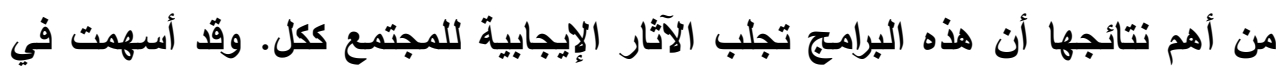

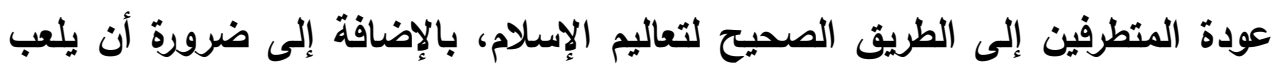
المجتمع دورا في تحفيز المتطرفين السابقين حتى لا ينتكسوا.

\section{التمايق العام على الدراسات السابقة:}

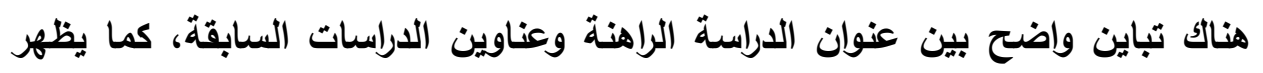

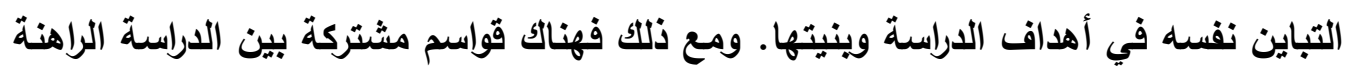

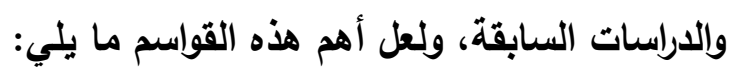

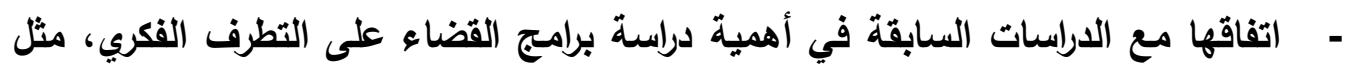
دراسة هورجان و برادوك (Horgan \& Braddock, 2010)، ودراسة السياط 


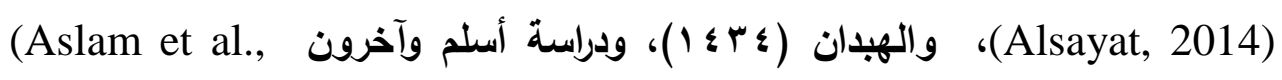

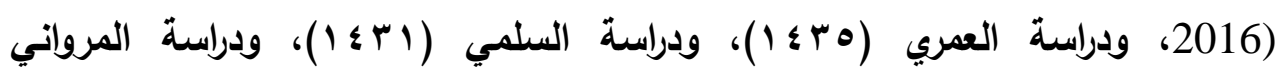

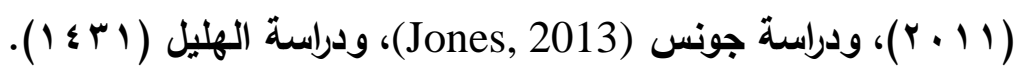
- واضحا في تفسير ظاهرة التطرف والعنف في المجتمع، وأيضا في استخدامها للمنهج

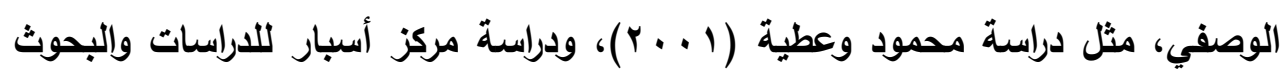

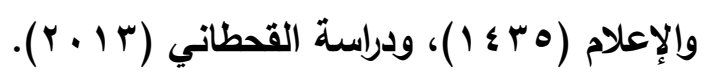

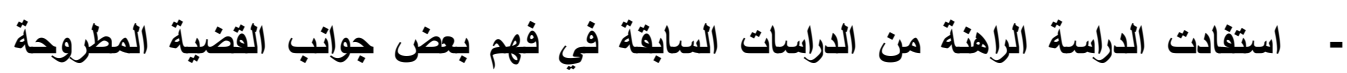

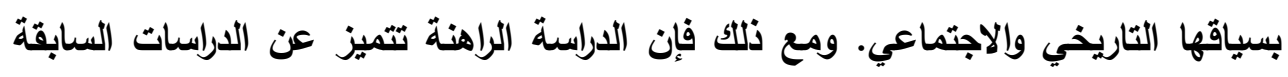

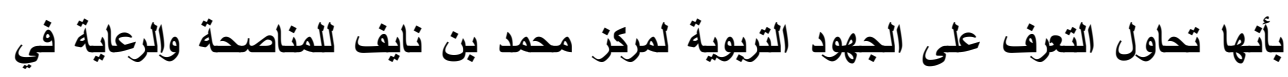
مواجهة التطرف الفكري.

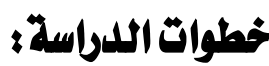

تحاول الدراسة الإجابة عن أسئلتها وتحقيق أهدافها، وذلك باتباع مجموعة من

الخطوات يتم من خلالها تناول الموضوعات الآتية: - - التطرف الفكري: المفهوم - المظاهر.

-

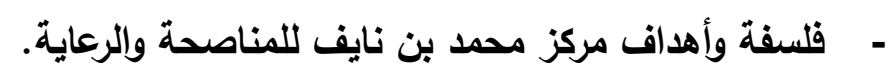

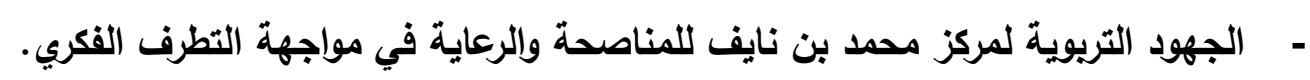
- الجبرات بعض الدول في مواجهة التطرف الفكري والسمات المشتركة بينها.

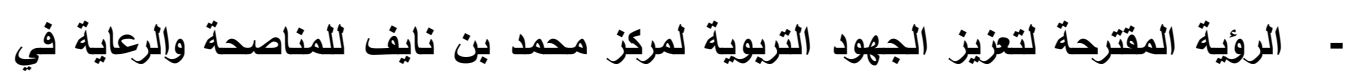
مواجهة التطرف الفكري بالمملكة العربية السعودية. 


\section{أولاً: التطرف الفكري: المفهوم - المظاهر}

ا

يحاول علم اجتماع التربية فهم الفعل الإنساني وتأويله داخل بنية مجتمع ما، وذلك برصد مختلف الالالات والمعاني والمقاصد التي يعبر عنها هذا الفعل أثناء عملية التفاعل والتواصل الاجتماعي. ومن ثم كان التفسير والفهم والتأويل من أهم الخطوات الرئيسة لاراسة

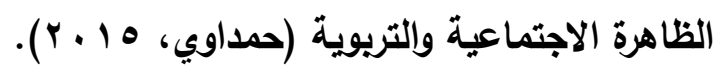

ولذا، فقا ركزت بحوث علم اجتماع التربية على الجواتب الاجتماعية للأنظمة التريوية

في المؤسسات التعليمية كنتائج محتملة لطبيعة المشكلات العامة في أبعاد التركيبة البنائية للمجتمع، وليس كنتيجة حتمية للممارسات التريوية في تلك المؤسسات بعيدة عن قولبتها الاجتماعية المختلفة والمتباينة في جوهرها وتركيبتها السياسية والاقتصادية والثقافية

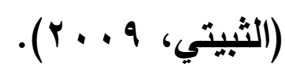

ولقد أشار تورين (11 + ب) إلى أن المقولات الاجتماعية التي سيطرت على الاراسات الفكرية والاجتماعية خلال العقدين المنصرمين والمتمثلة في الدولة والطبقية والمدرسة والأسرة والمجتمع والمعايير الاجتماعية والنست الاجتماعي لم تعد كافية وحدها لتفسير الظواهر في في

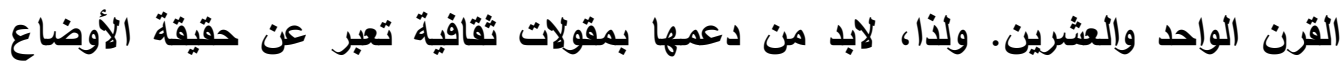
والأزمات المجتمعية. وتأتي في مقدمة هذه المقولات: الصراعات الثقافية، والتطرف الدايني والفئات المهمشة، والتمزقات العرقية والدينية، وإنتشار العنف والنزعة الطائفية.... إلخ. وسواء اقتنع البعض بالتفسير الاجتماعي والتربوي لظاهرة التطرف باعتبارها مقولات اجتماعية أو اعتبرها البعض من المقولات الثقافية، فهي في نهاية الأمر تفسيرات لها مبررات

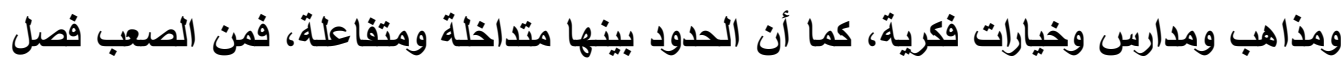
ما هو اجتماعي عما هو ثقافي. ولعل الإثكالية المطروحة حول تفسير مقاومة التطرف ترتبط في هذا البحث تحديدا بفكرة العقاب والتقويم الاجتماعي والتريوي، وهذه القاعدة مهمة عند التفسير، لأن فكرة الإنسانية في فلسفة العقاب لها من الضوابط الاجتماعية والتريوية، والتي يعتقد الباحث أنها ولها ضرورة منهجية لنجاح هذا التفسير والمعالجة في مؤسسات الإصلاح المختلفة. ولذا، فهناك بعض الملاحظات التي يمكن الانطلاق منها في هذا السياق، وهي: 
- أن الهلف من المناقثة والتفسير هنا هو محاولة البحث عن أطر ومداخل تريوية

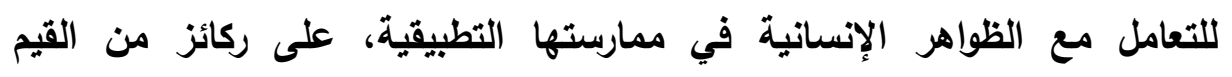

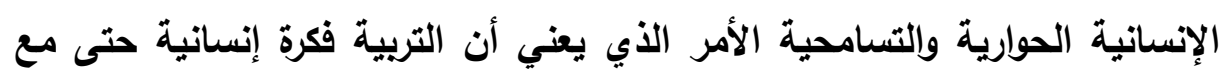
تطبيق القانون. - أن الهاف الأساسي هو التمييز بين نزعة تريد مواجهة روح الدين وأخرى تعتقا

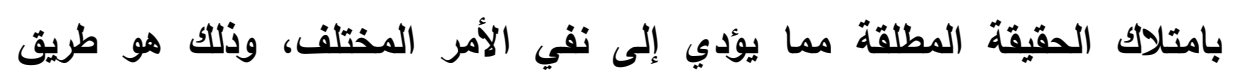
التطرف. وعليه، فالذين يعدون كل تدين تطرفا ليسوا طرفا في المناقثنة الآن.

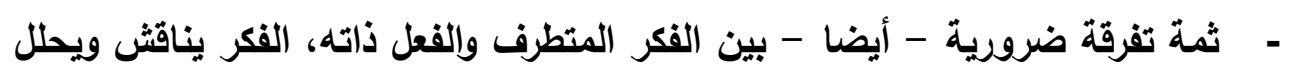

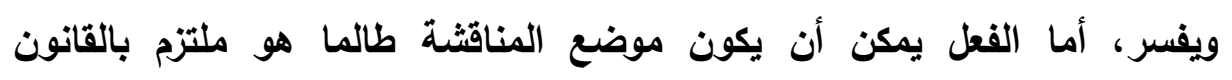

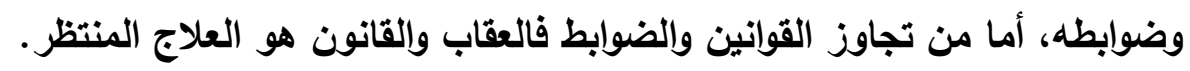

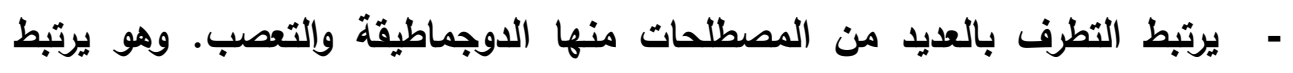

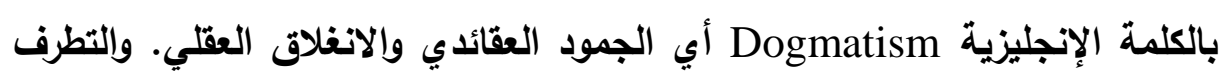

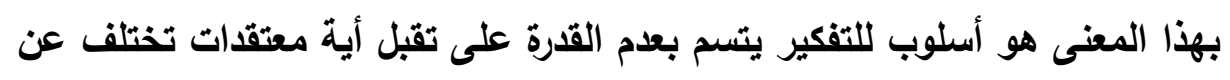

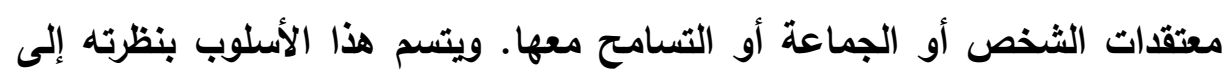

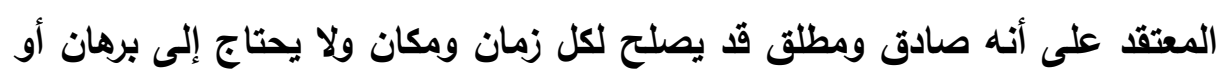

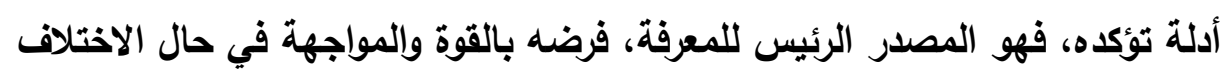

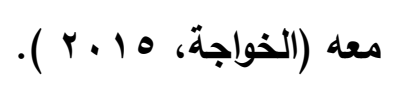

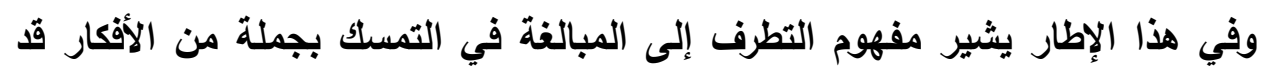

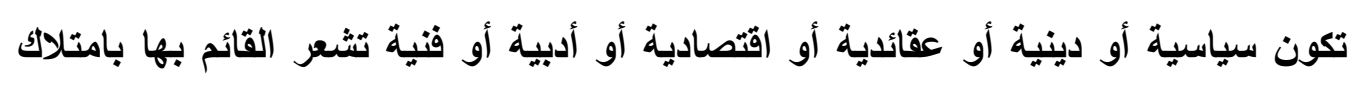

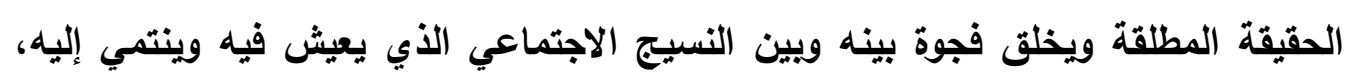

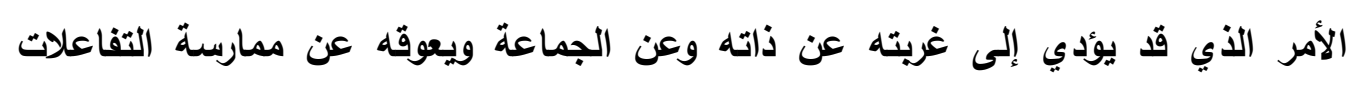

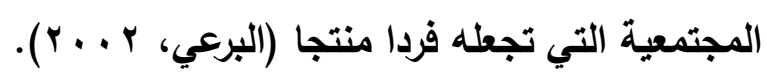

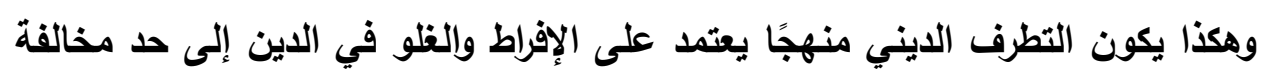

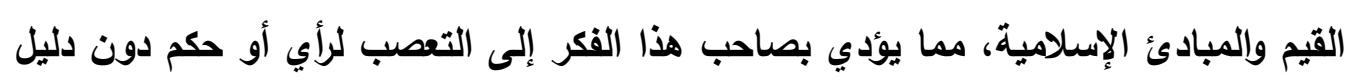

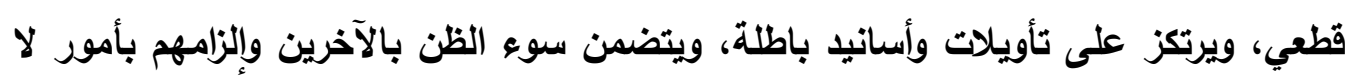


مرجعية لها سواء في الثرع أو النظام، والحكم على من يخالفها بالكفر وإهدار الدم دون

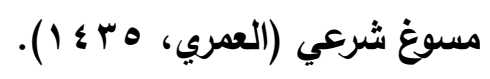

ويصفة عامة يفسر التطرف على أنه كل تفكير خرج عما هو مألوف من معايير المجتمع في سلوكه وفكره عند تعامله مع الآخرين، ويسعى إلى فرض أفكارئ أفكاره على الآخرين

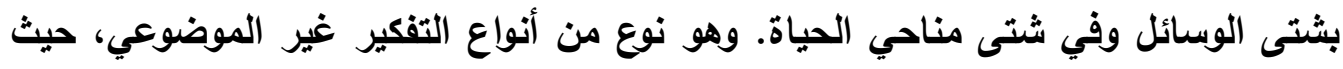

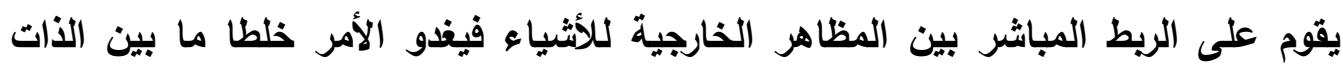
والموضوع (الطريف، هب ع 1).

وفي تطور لتفسير ظاهرة التطرف، والذي يعكس العلاقة بين الجاتب الاجتماعي والتطرف، يرى البعض أن المتطرف لا يولد متطرفا بالفطرة بل يصير كنلك عبر مؤسسات التتشئة

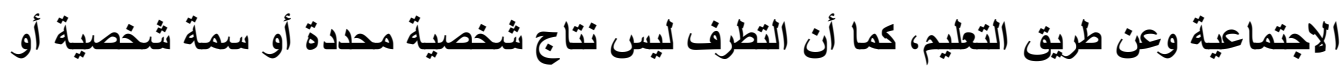
نفسية أيضا، ولا يمكن لأي أحد الجزم بأن هذه الثخصية أو تلك ستصبح منطرفة أو إرهابية

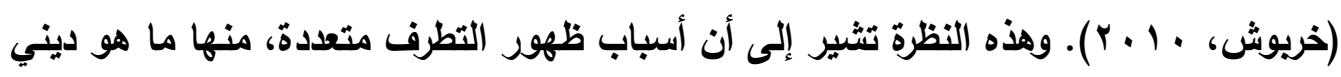

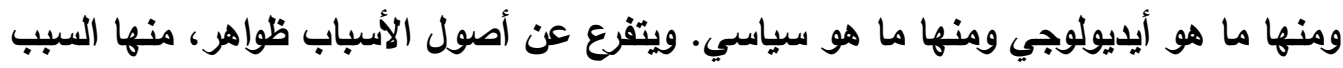
الاقتصادي والاجتماعي وإلثقافي. كما أن التطرف ظاهرة تمس الأديان كلها كما تمس المواقف الأيديولوجية والسياسية،

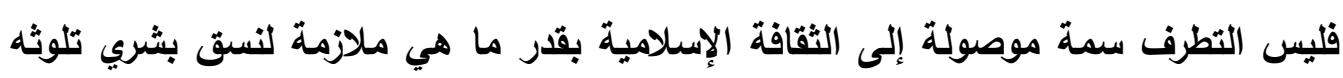

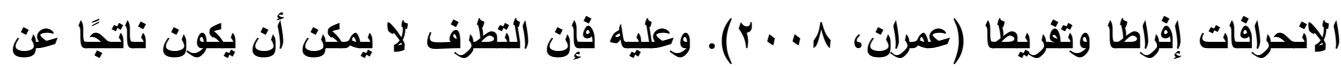

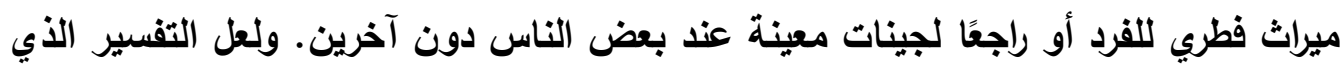

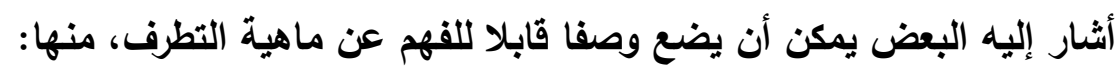

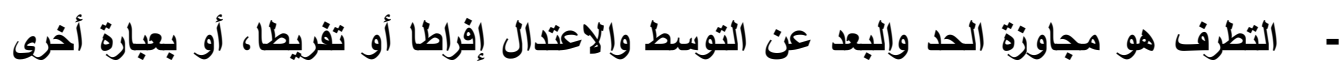

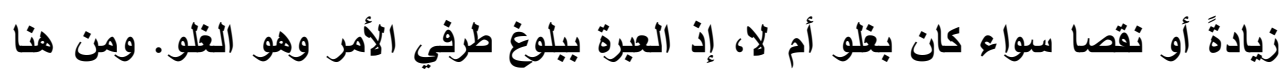

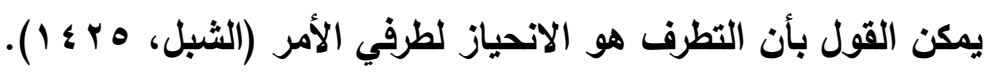

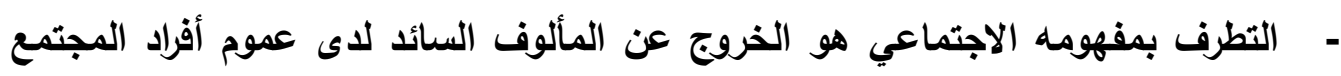

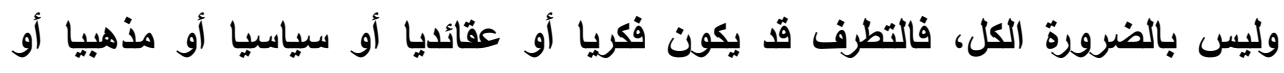

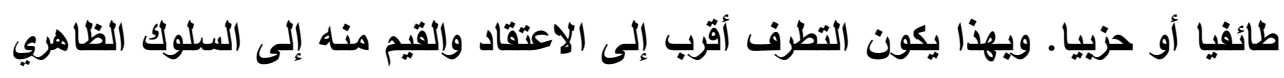

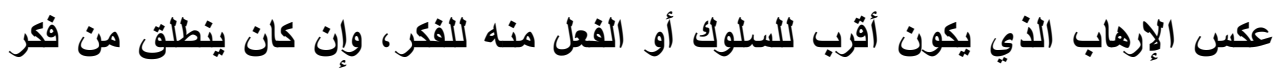


متطرف ومنحرف عن المألوف والمتوقع في المجتمع، فلا إرهاب أيًا كان إلا وله منطلق

$$
\text { تطرفي (عبدالله، } 17 \text { ـ ب). }
$$

ومن خلال العرض السابق يمكن القول إن التطرف الفكري هو جملة الأفكار المضادة

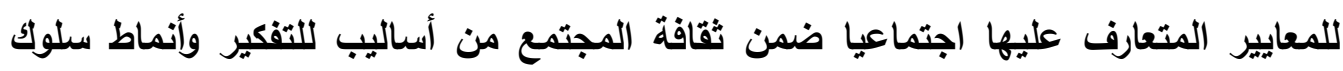

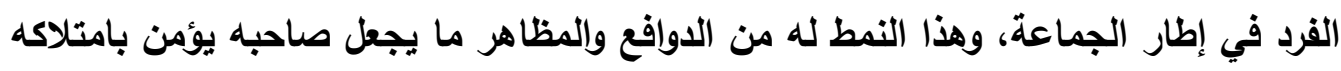

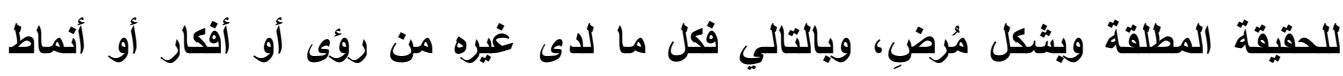

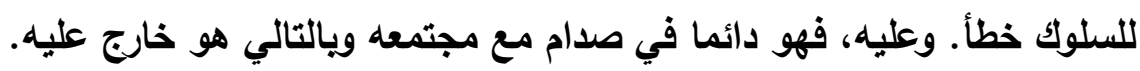

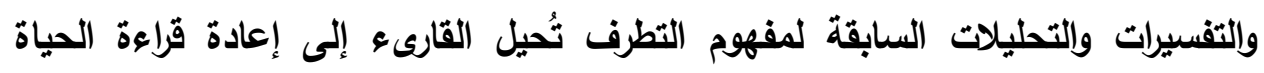

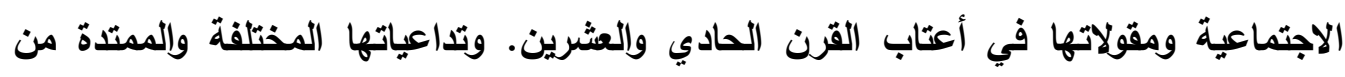

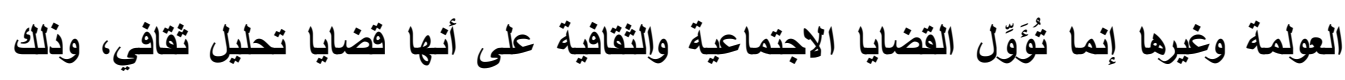

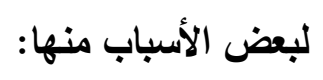

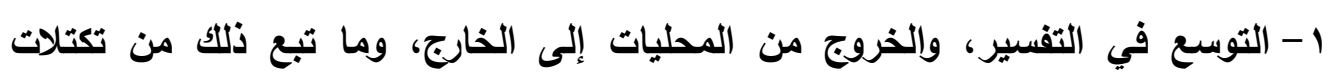

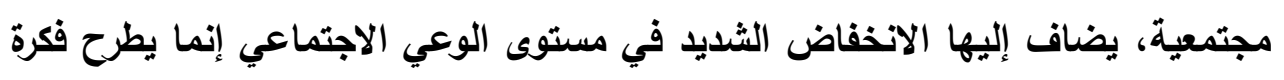

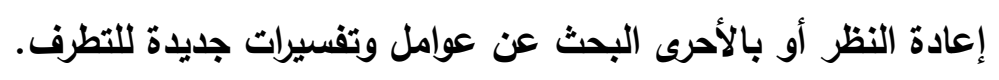

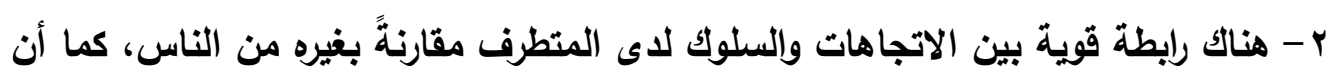

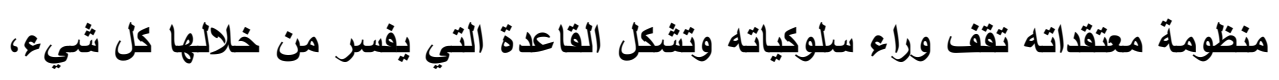

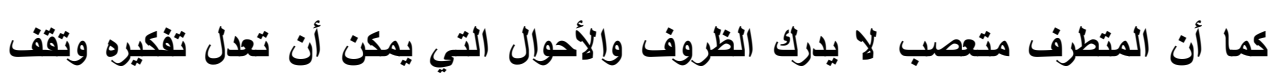

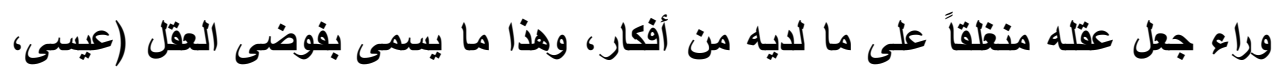
(1991 r- يفسر التطرف كظاهرة اجتماعة من خلال مؤثراتها الدالة على هذه الروئية ومنها: الفجوة

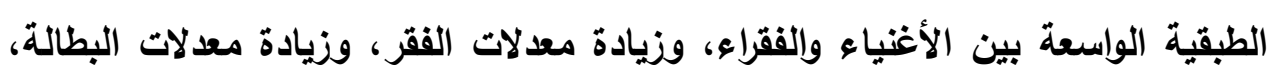

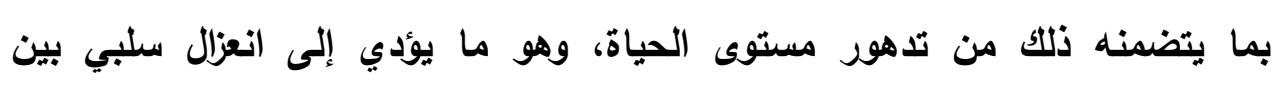

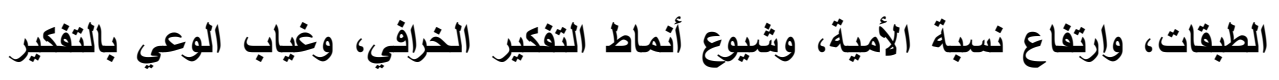

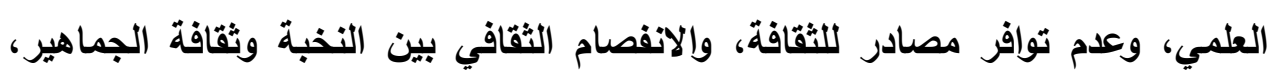

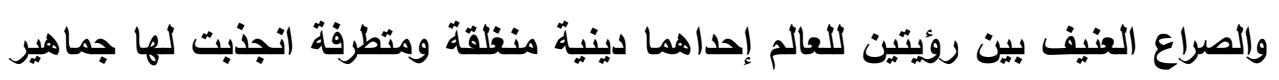

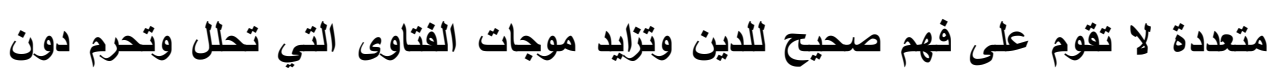


مراعاة لروح العصر، وأخرى ليبرالية منفتحة مشتتة عجزت عن إنتاج خطاب جماهيري

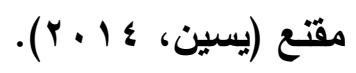

ع - تفسير التطرف له دلالة قوية على وجود بيئات حاضنة اجتماعية وثقافية لاستقبال

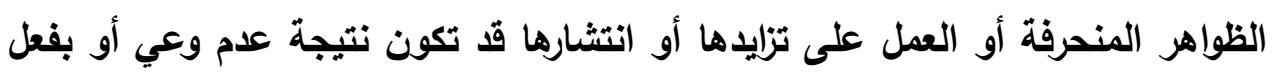

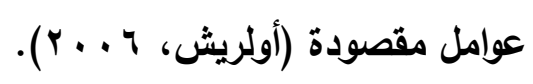

ه- وينظر الى التطرف كأزمة مجتمعية في تحليلاته وتفسيراته إلى الملاعمة التامة بين

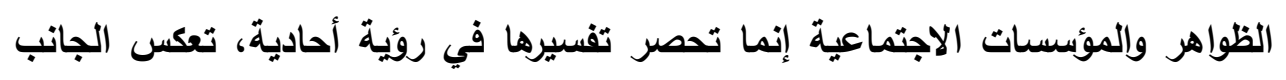

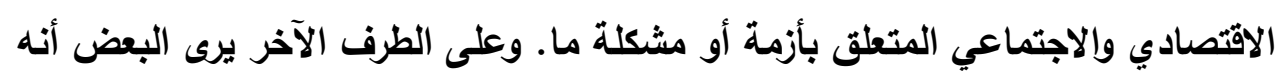

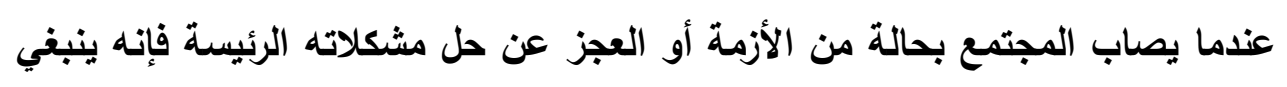

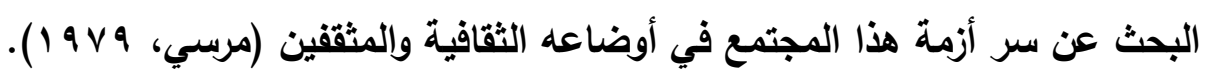

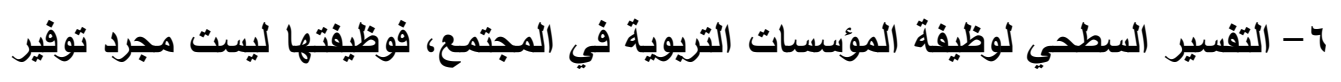

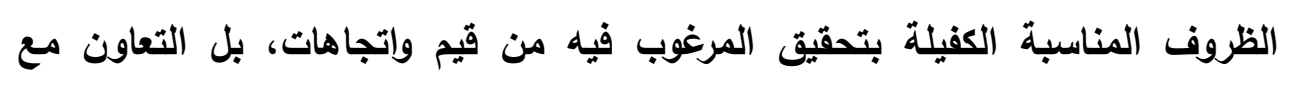

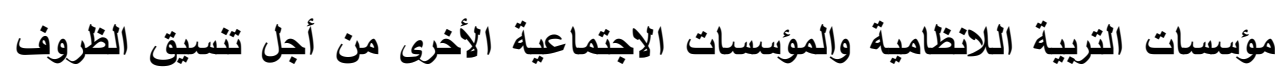

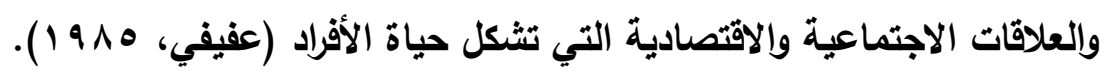

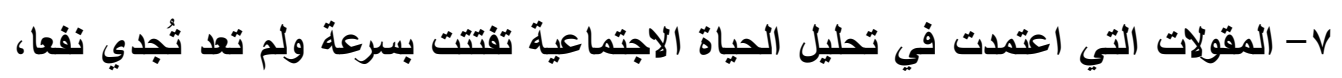

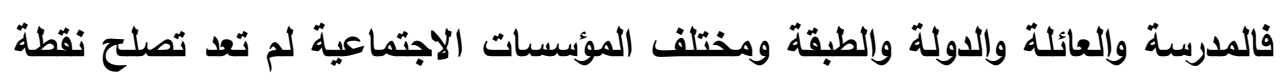

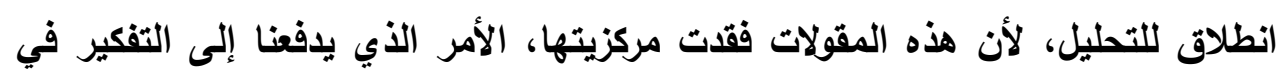

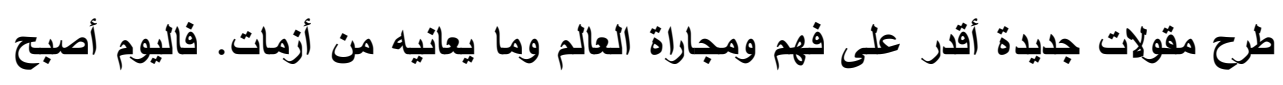

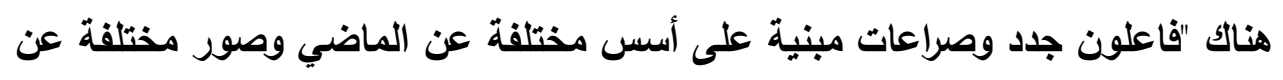

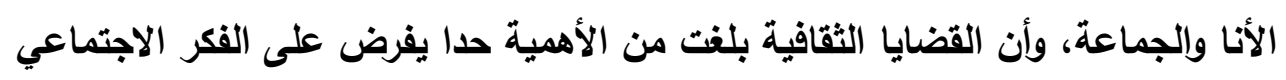

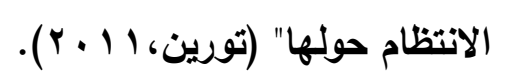

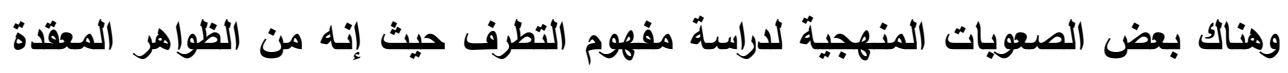

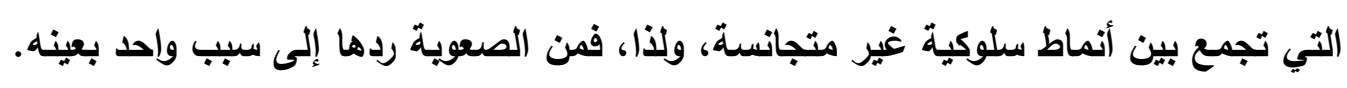

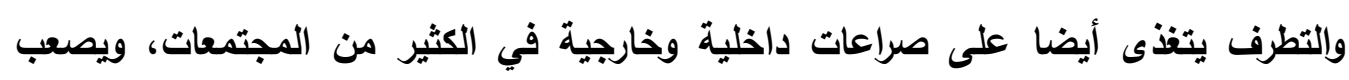
قراءة المشه بمعزل عن الصراع بأثكاله وتحالفاته الإقليمية والدولية. 
r

هناك عدة مظاهر للتطرف الفكري تعكس درجته وإنتثاره في الكثير من المجتمعات، منها: - التعصب للرأي وعدم الاعتراف بالرأي الآخر: وهو جمود الثخص على فهمه جمودا لا

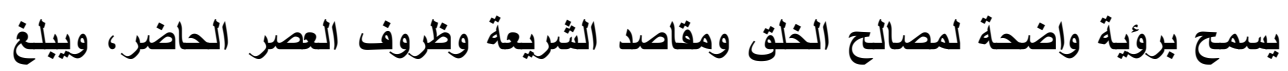

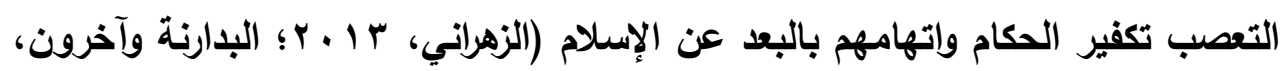
$\cdot(r \cdot 1)$ - التثدد في إلزام الناس بما لم يلزمهم الله به: هذا الجهل ناتج عن غياب الوعي الايني والفهم

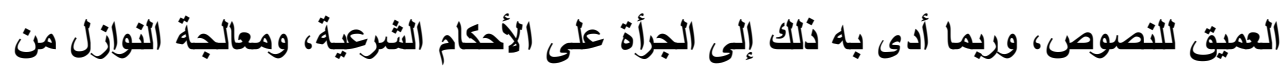
غير أهل الاختصاص دون فهم للنصوص الثرعية ومعرفة مقاصد الأحكام (البدارنة وآخرون، $\cdot(r \cdot 1)$ - سوء الظن بالآخرين: هو النظر للآخرين نظرة تشاؤمية، لا ترى أعمالهم الحسنة وتضخم من سيئاتهم، فلا يلتمسون الأعذار للآخرين. فالأصل عند المتطرف الاتهام والإدانة

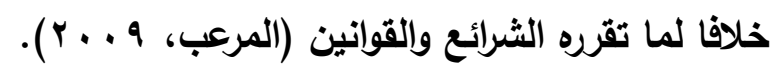

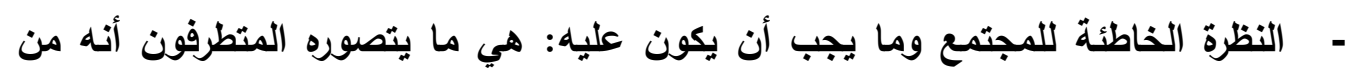

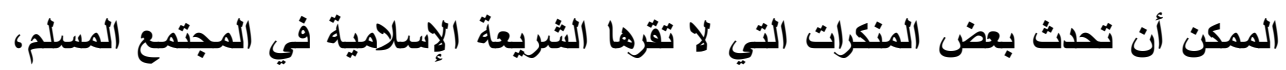

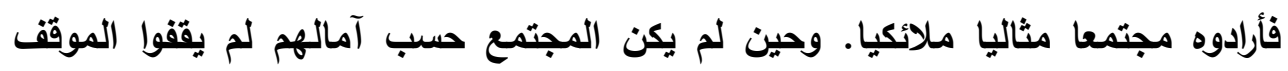
الشرعي الصحيح تجاهه بل وققوا موقف الهروب والعزلة والانطوائية والنظرة التشاؤمية له

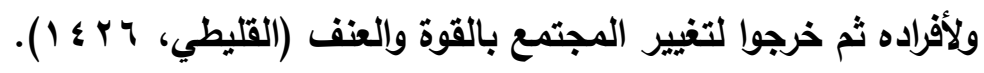

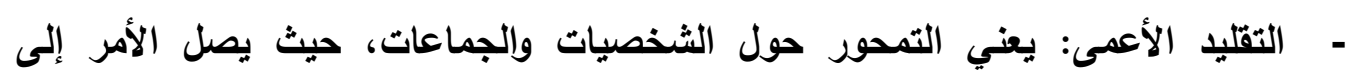
تقديس بعض القيادات والرموز، ومن ثم يمنح المقلد ثقته لشخص أو رمز معين يقلده بثقة عمياء ويلزمه برأيه ومنهجه دون تمحيص (الدهاش، ، بـ ـ 1).

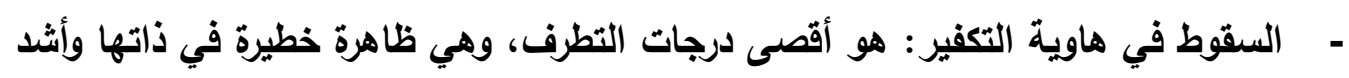

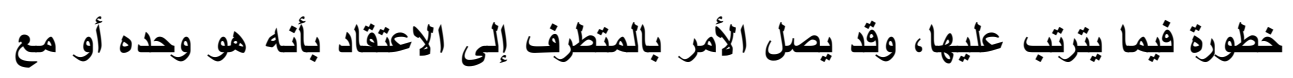

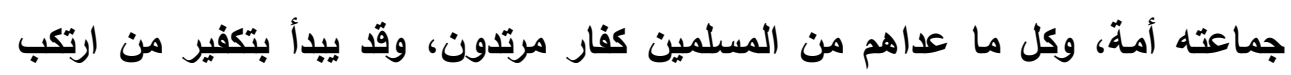

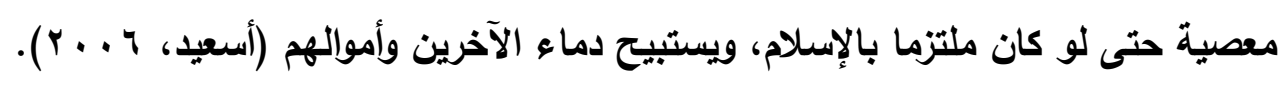


ولذا، فإن دراسة العوامل المجتمعية لفكر التطرف - بنظرة ثقافية متعمقة مع تحليل

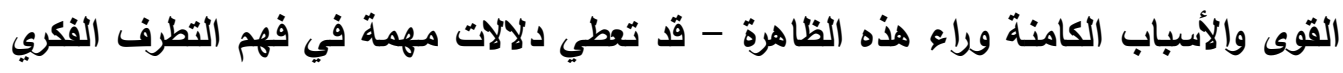

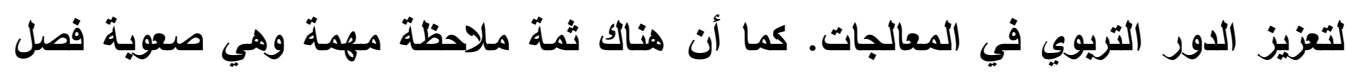
القوى والعوامل عن بعضها، لأن الكثير منها متثابك ومتداخل ويؤثر في بعضه البعض.

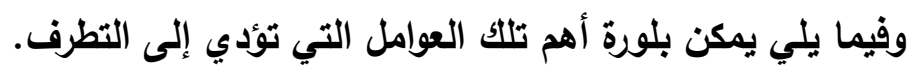

\section{ثانياً : العوامل المجتمعية التي تؤدي للتطرف الفكري}

الملفت للنظر أن انتشار ظاهرة التطرف يعد أخطر من التطرف في حد ذاته، لذا، كاتت الدول

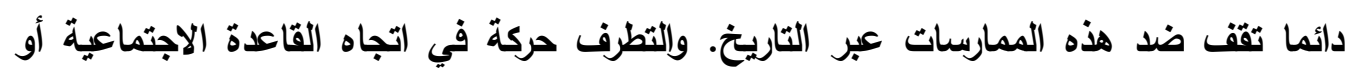

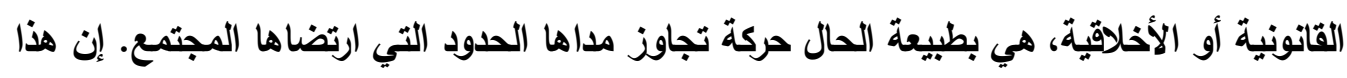

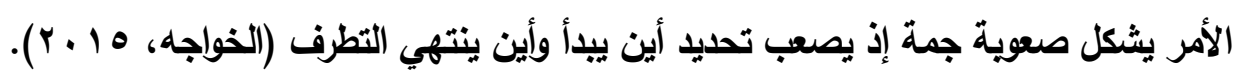

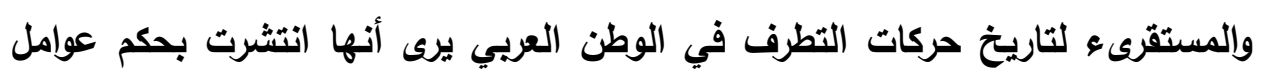

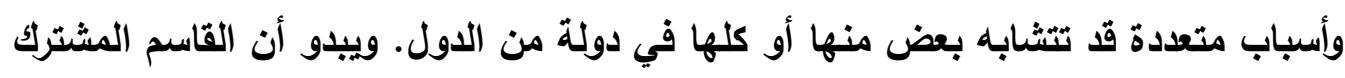

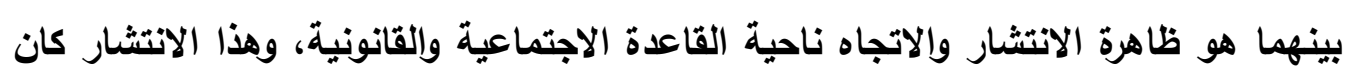

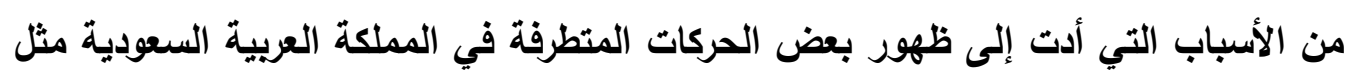

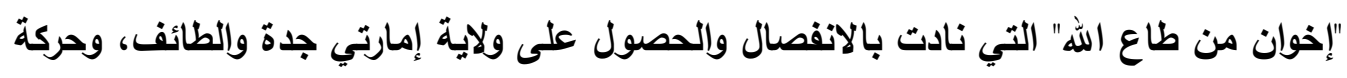

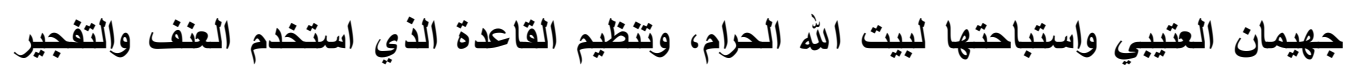

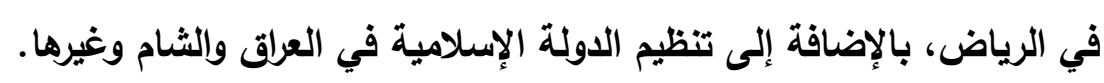

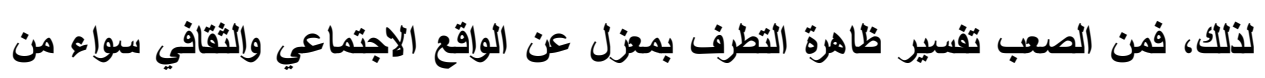

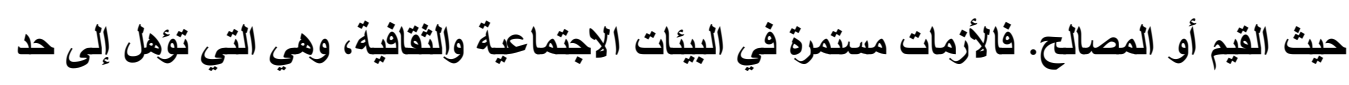

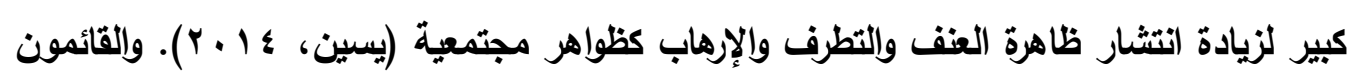
على التحليل الثقافي للظاهرة تتجه تفسيراتهم لها نحو العليد من العوامل والأسباب منها:

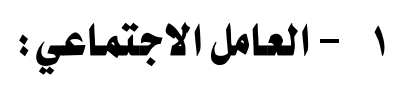

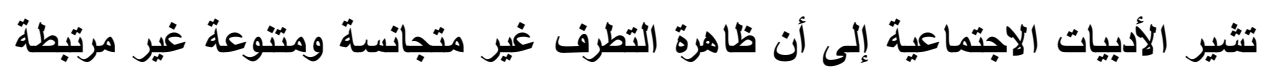

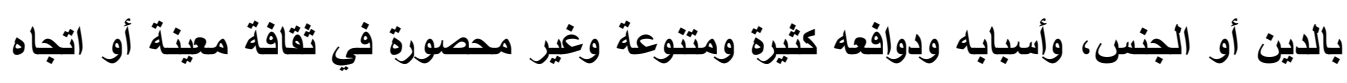

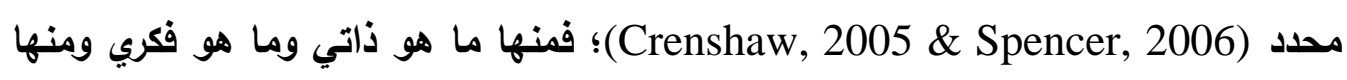


ما ينتج عن البيئة التي يعيش فيها المنطرف، ومنها ما ينتج عن ضغوط مختلفة كالظلم

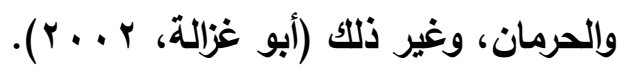

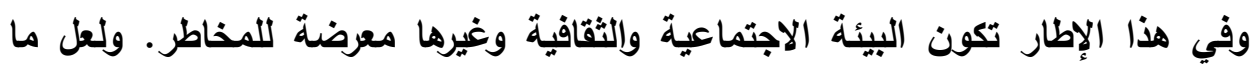

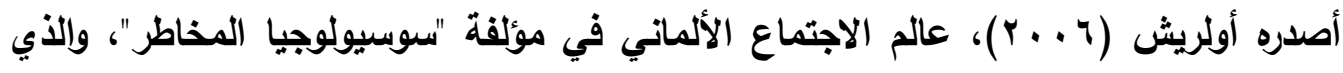

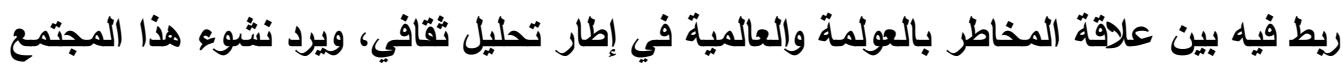

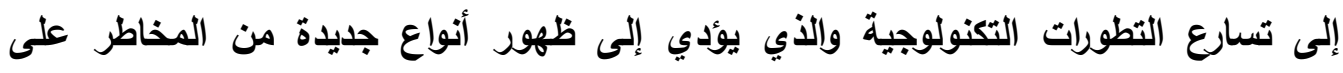

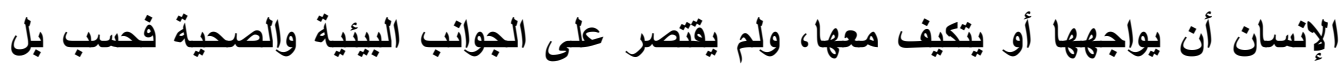

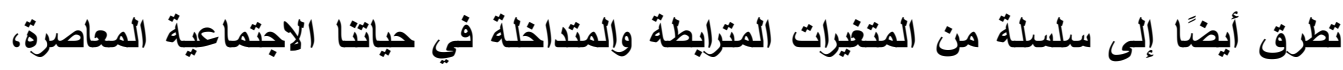

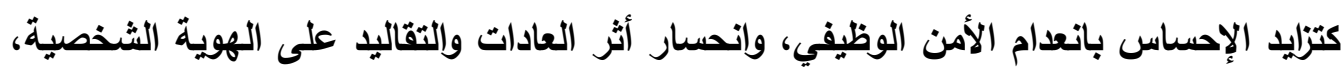

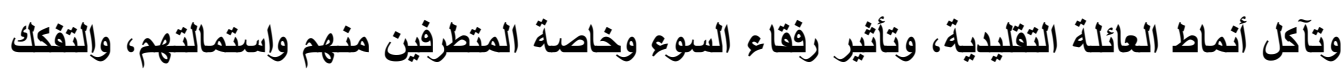

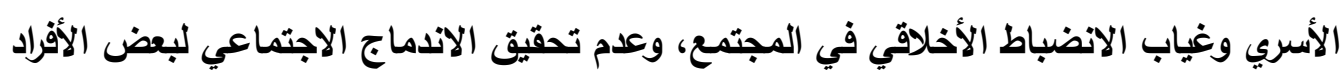

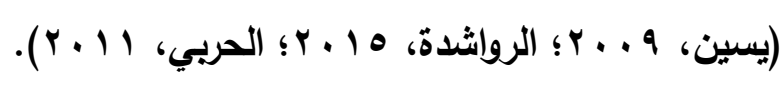

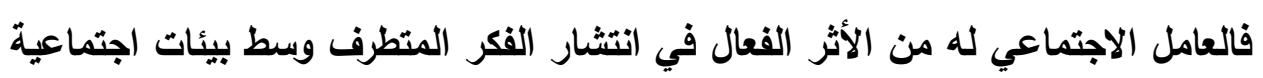

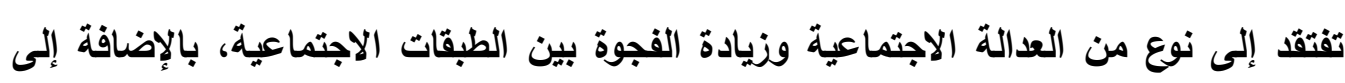

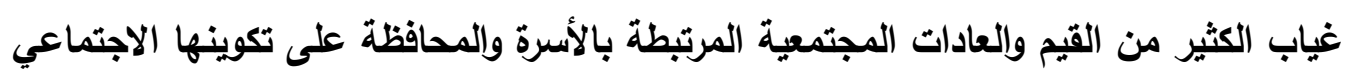
وتماسكها المجتمعي.

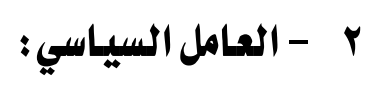

ينطلق هذا العامل من روية ترى أن الفكر المتطرف استجابة لظروف سياسية قاهرة للأفراد

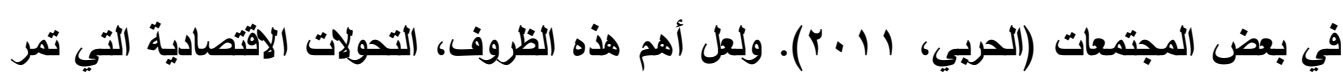

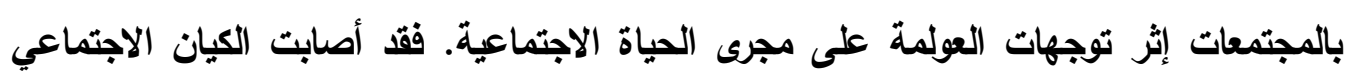

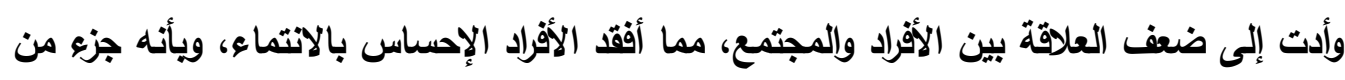

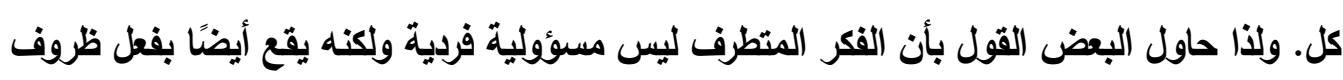

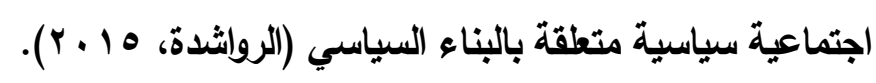

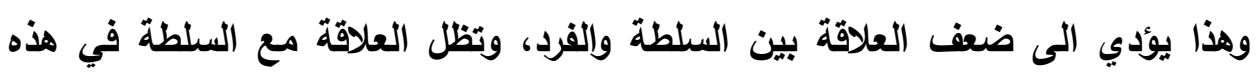

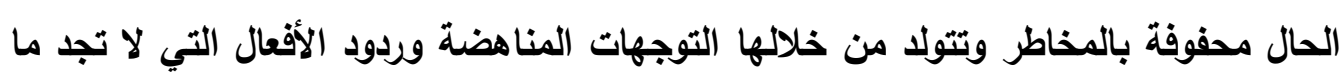
تصب فيها غضبها وتفريغ شحنات عواطفها إلا امتطاء صهوة الفكر المتطرف (السدلان، 
ه ؟ \& ). بالإضافة إلى تدني مستوى المشاركة السياسية لاى الشباب - ومن مختلف الطبقات - في اتخاذ القرارات التي تمس حياة المواطنين بما في ذلك الحياة اليومية، بالإضافة إلى دالى تجاهل مطالب الأقليات واستخدام القسر لبعض الجماعات. ولعل تجرية المملكة العربية السعودية في إنثاء مركز الحوار الوطني كانت مهمة لاستيعاب الثباب وتعليمهم أساليب الحوار وتوضيح ما تقوم به الدولة من جهود في هذا الصدد في الوقت الراهن (اليوسف،

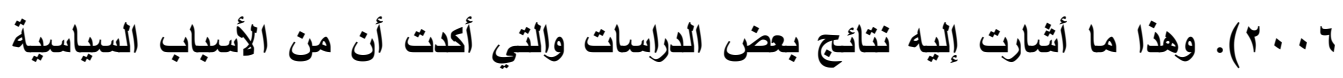

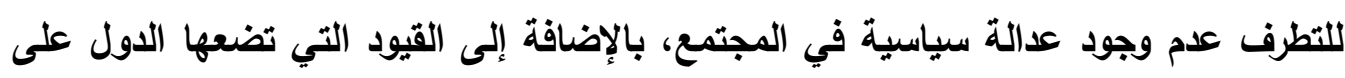

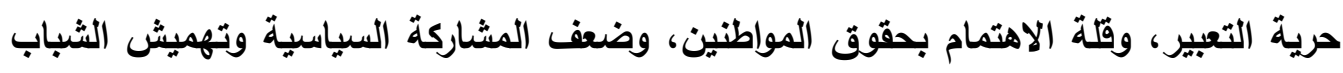

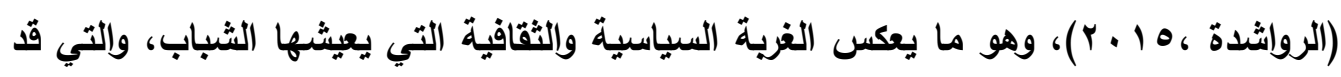

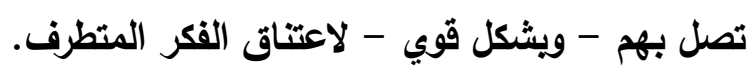

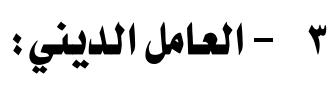

يمثل النهج الإسلامي الأصالة في حياة الأمة المسلمة، بل في حياة البشرية جميعاً،

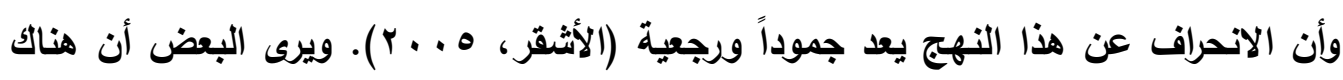
عوامل أثرت على ذلك مثل سوء الفهم والتفسير الخاطئ لأمور الثريعة، ومعاناة العالم

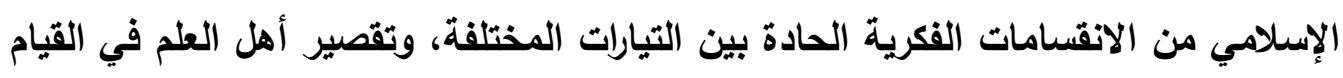

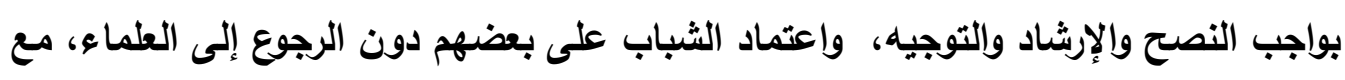
تلقي الفتوى من غير المتخصصين، مع فراغ الوسط الثقافي من الأكْفاء، ووجود جرأة من

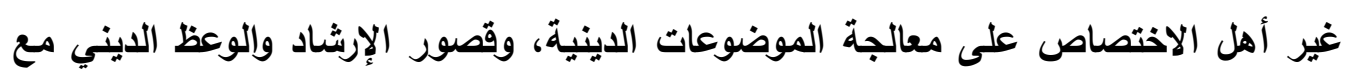

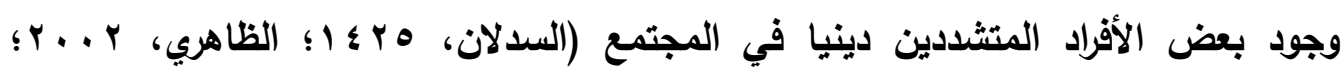

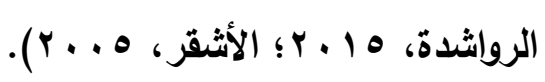

ولهذه المبررات وغيرها يتجه فكر المتطرف إلى الغلو والانغلاق الذي قات يهذد، استقرار

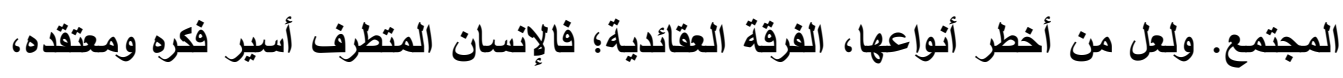
وما عملُ الإنسان وسلوكه وتصرفاته في واقع الحياة إلا صدى لفكره وعقيدته. ومن هنا كان بث الفكر المنحرف وغرس العقائد الضالة في قلوب المسلمين موجباً لاختلاف المسلمين في والإني

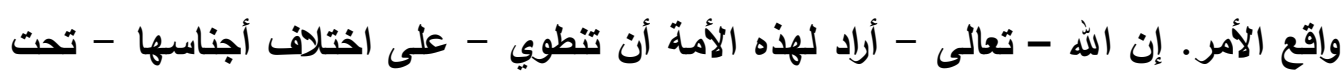

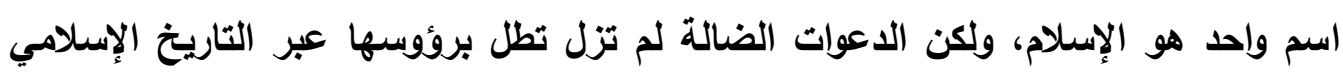


لتجزئ المسلمين إلى فرق وجماعات، تخالف الإسلام مخالفة كلية أو جزئية (الأثقر، $\cdot(r . .0$

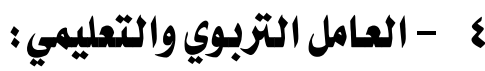

ثمة تزايد للضغوط التي تجمل المسألة التربوية والثثافية واحدة من أهم القضايا التي تأخذ

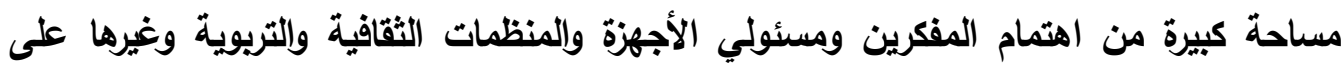
الصعيدين المحلي والعالمي، إلا أن هذه الضغوط تزداد حدتها على الدول النامية التهية بحكم ظروفها

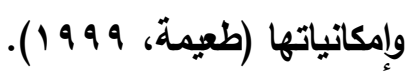

كما أن هذه الدول بها بعض البيئات التي تعمل كحاضنات مهيأة لاستقبال الظواهر

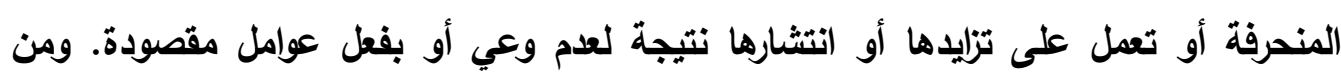

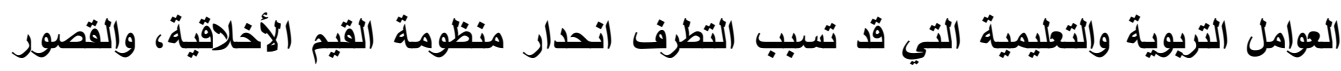

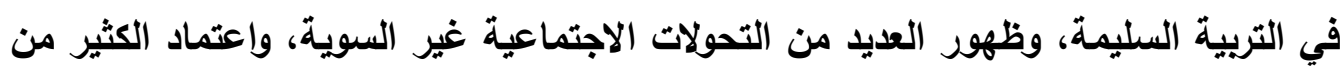

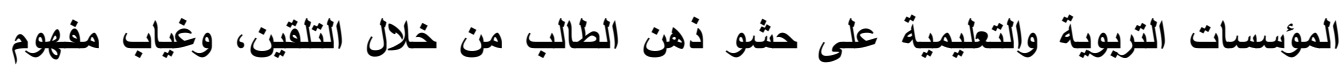

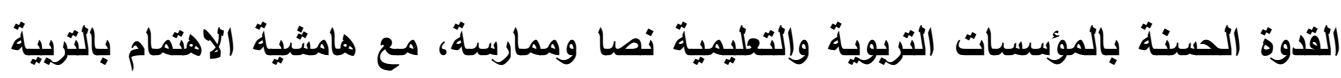

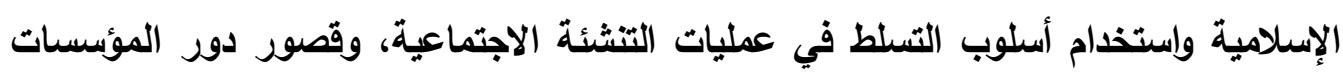

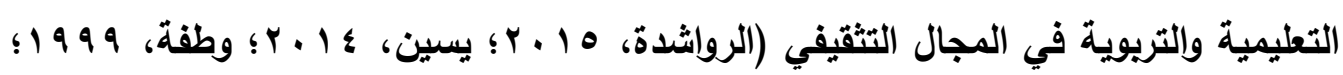

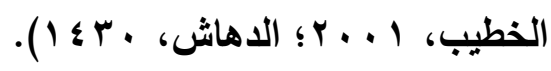

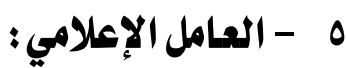

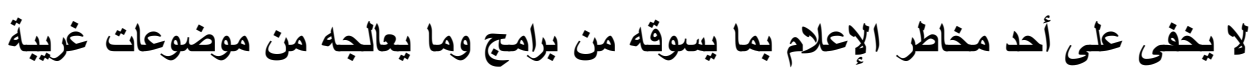

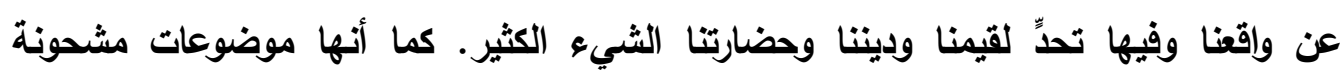

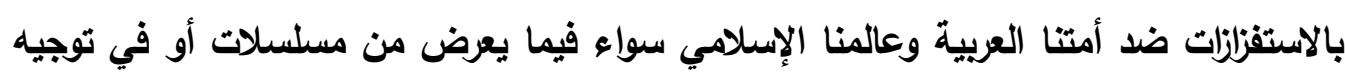

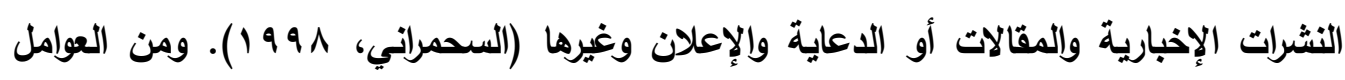

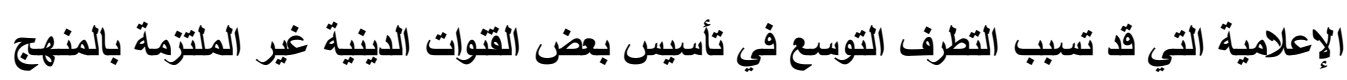

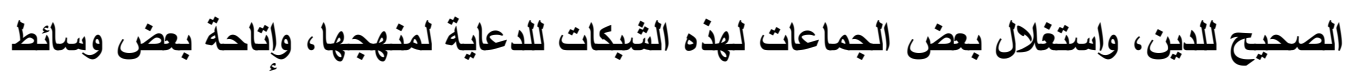

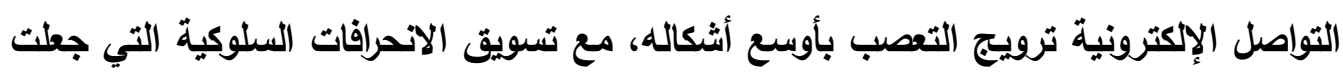

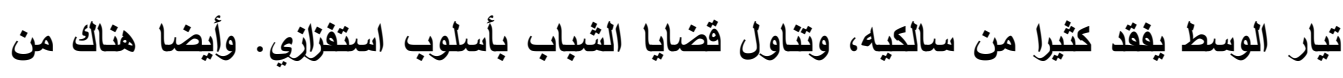


يضيف إلى ذلك غياب دور وسائل الإعلام في بيان حقيقة التطرف ومحاريته، واستخدام أساليب

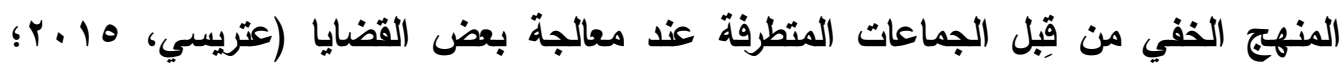

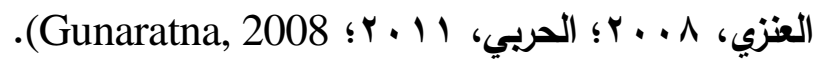

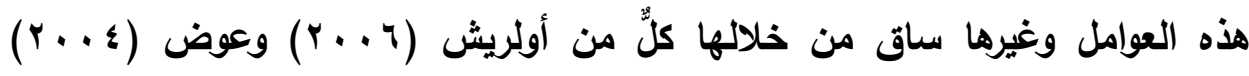

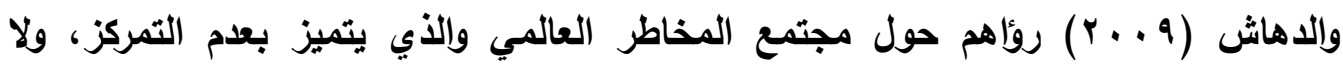

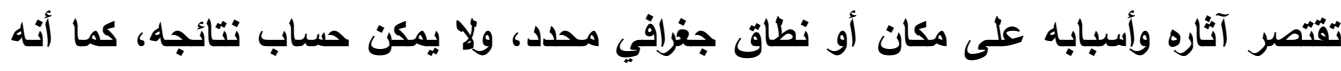

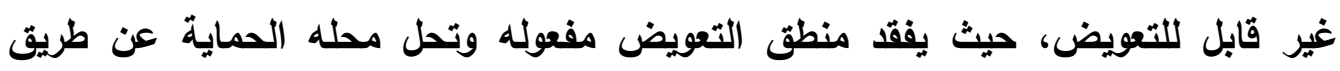

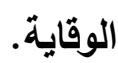

وهذا ما أدى بدول الظليج العربي إلى الدعوة إلى استراتيجية أمنية موحدة لمكافحة ظاهرة الاتحراف الفكري والآثار المترتبة عليها في إطار المسئولية التضامنية لأجهزة الدولة في

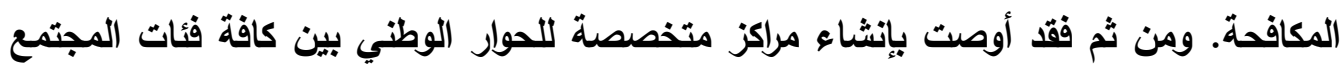

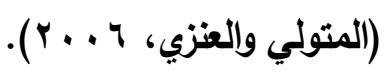
والحقيقة أن تنامي هذه التحديات - بصورة تتؤثر على أمن وسلم المملكة العربية

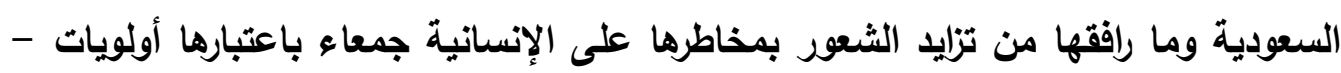

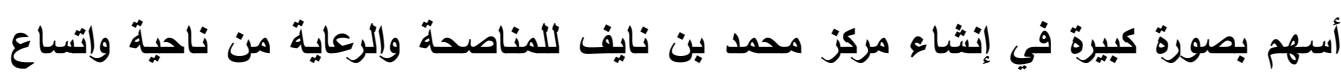

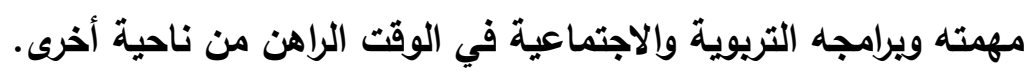

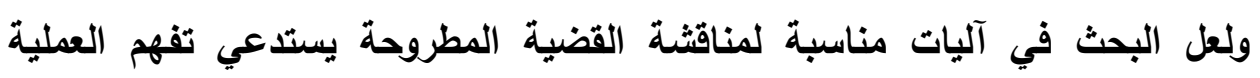

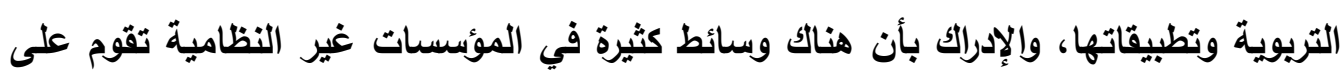

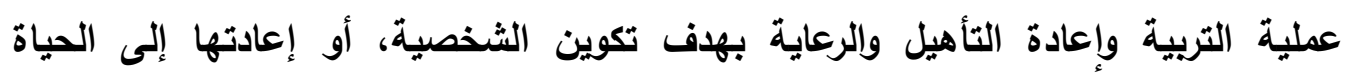

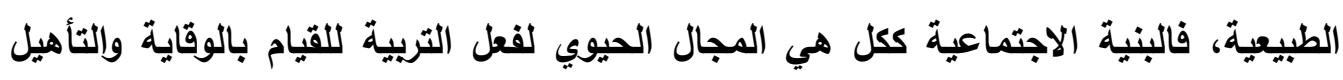

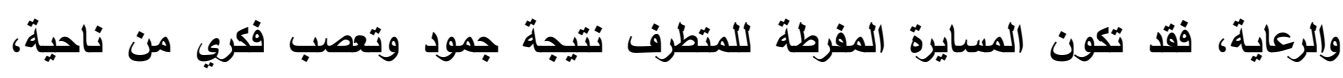

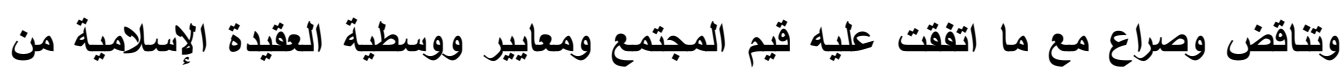

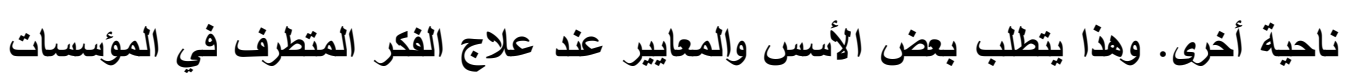

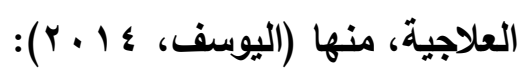


- وجود إطار (فلسفي - سياسي - اجتماعي- تريوي - مهني) يتم الاعتماد عليه في تحديد أهداف المؤسسة، والحاجات المطلوية، وأساليب التنفيذ والإنجاز، وعناصر التذخل والتطوير والمتابعة والتقويم، وضبط مختلف آليات التدبير. - مجود فلسفة للتمية الاجتماعية تعتمد عليها برامج الإصلاح، وأن ينظر إلى المستفيد كثخص في حاجة للرعاية والاندماج الاجتماعي، وربط البرامج بالخطط التنموية في

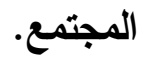
- وجود برامج احترافية مناسبة لظروف المستفيل وأسباب انحرافه، ومحاولة تذليل الصعويات التي تواجهه، وريط المستفيد بالأسرة والعالم الخارجي. - أن يخطط للبرامج على أسس علمية وفنية تساعد على إثباع الاحتياجات النفسية

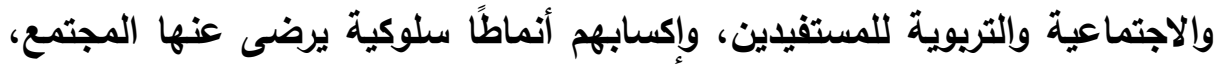
مع صقلهم بمهارات اجتماعية تساعدهم على التكيف مع أنفسهم والآخرين، وأن تحقق البرامج التأهيل والرعاية المهنية والاجتماعية لهم.

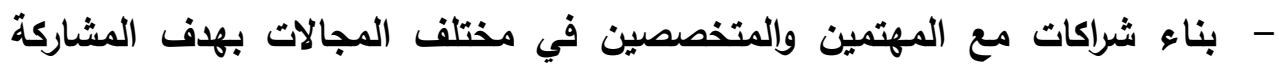

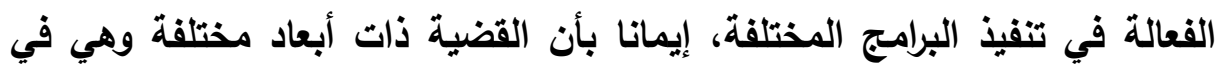
حاجة لجهود كافة أطراف الجهات المعنية للإسهام في تحقيق البرامج من أجل

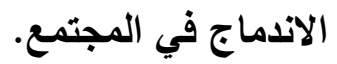
ولذا حاولت الدراسة التطرق إلى إحدى مؤسسات التربية غير النظامية بالمملكة العربية السعودية للتعرف على بنيتها ووظيفتها التريوية في مواجهة التطرف الفكري. ثالثاً : فلسفة مركز محمد بن نايف للمناصحة والرعاية وأهدافه تبنت الملكة العربية السعودية استراتيجية فكرية في مواجهة الإرهاب تتألف من ثلاثة برامج رئيسة ومترابطة تتمثل في كلمة (وتر)، وهي عبارة عن الأحرف الأولى من الكلمات

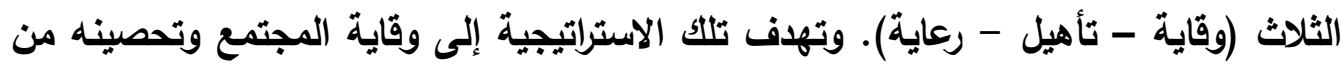

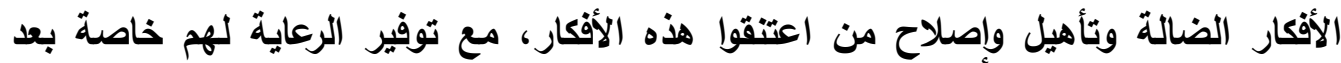

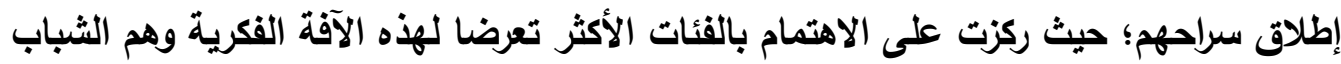

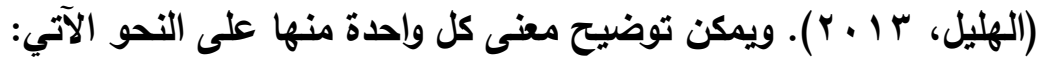


- الوقاية: هي العناية بالبنية الفكرية لأبناء المجتمع - خاصة الثباب منهم - أثناء

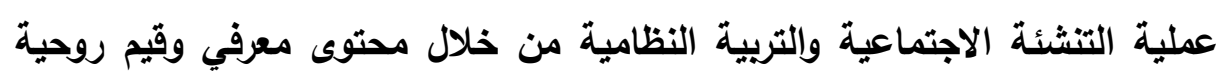
ومهارات معرفية تتسم بالوسطية والاعتدال.

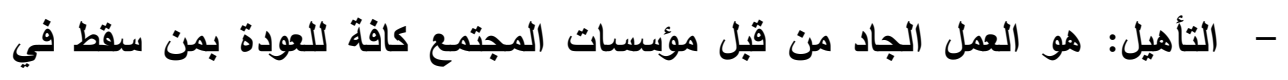

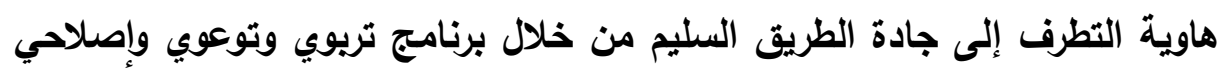

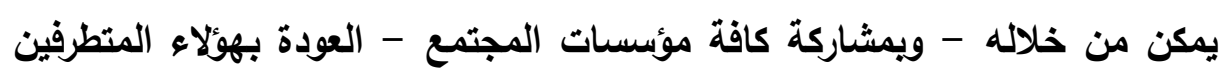

$$
\text { إلى طريق الاعتدال وسواء الفكر وسلامة الوجدان. }
$$

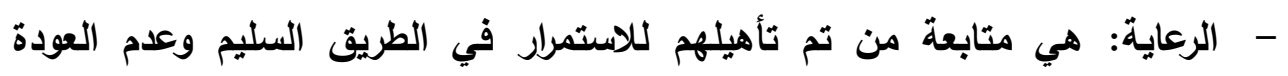

$$
\text { للتطرف ببرامج رعاية شاملة. }
$$

وتثمل الاستراتيجية بعض الإجراءات التي قامت بها كثير من الدول إضافة إلى تجفيف منابع

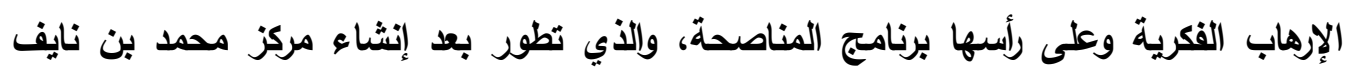

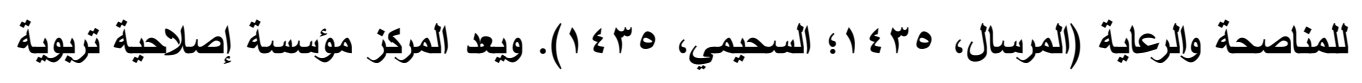

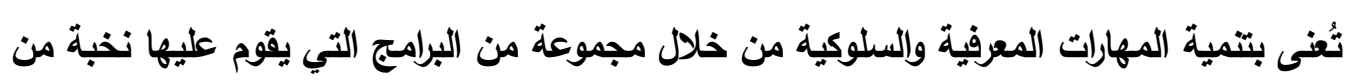

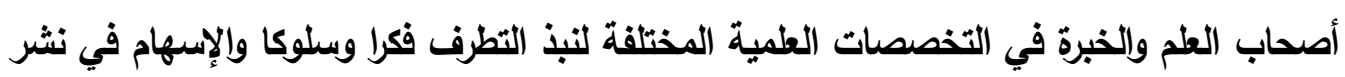

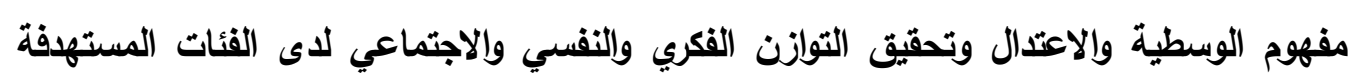

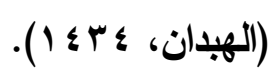

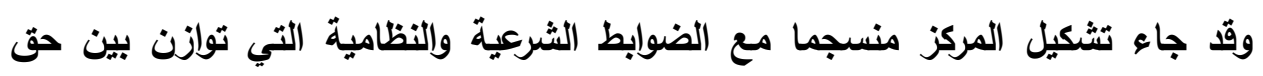

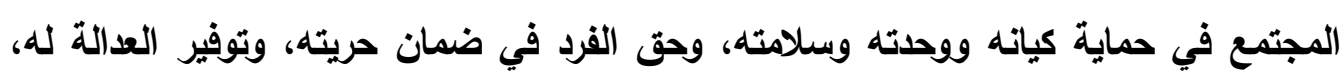

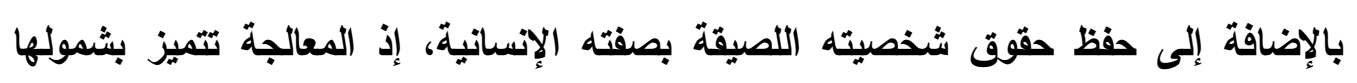

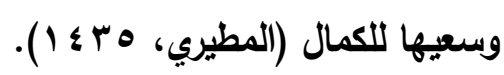
ويوجِّه المركز جهوده - بثكل كبير - لفئات محددة تعد محور برامج المركز . وتتمثل تلكت

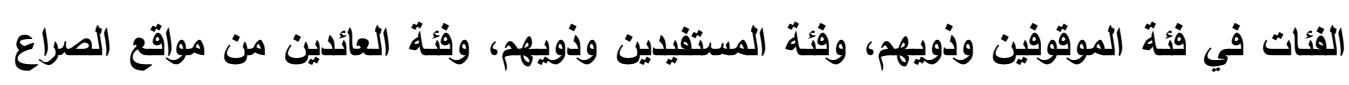

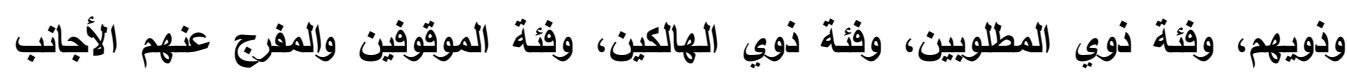

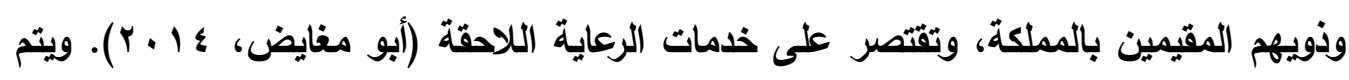

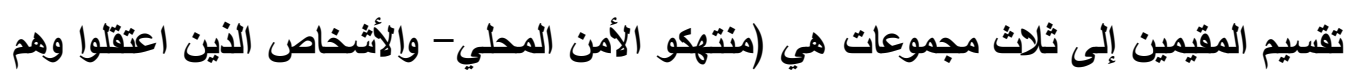

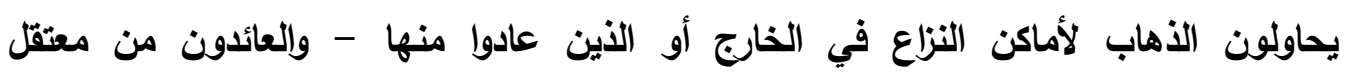


غوانتامو). ويتم الفصل بين هذه المجموعات الثلاث من خلال إسكان كل مجموعة منها في

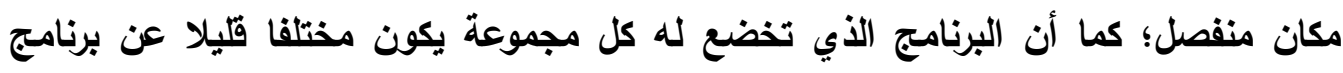

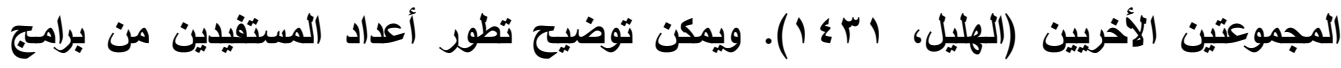

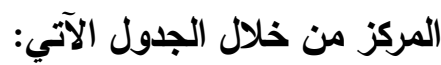

\begin{tabular}{|c|c|c|c|c|c|}
\hline العدد & الافعـة & العـام & العدد & الافعـة & العـام \\
\hline $1 \leq 11$ & rq_ro & بr آهـ & $\mu \wedge$ & $0-1$ & A ا هـ \\
\hline$\neg \wedge \wedge$ & rr_r. & ع إ إ & $\varepsilon \wedge$ & $9-7$ & هـ $1 \leqslant$ Y \\
\hline Irr & $r \varepsilon-r r$ & هـ ا هـ & iv & $1 \leq-1$. & . \\
\hline 179 & ס ס r-r & דr إهـ & ro & $17-10$ & اسب إهـ \\
\hline Tr & rA_rv & 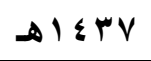 & $r v \leq$ & $r \leq-1 V$ & هـ \\
\hline \multicolumn{5}{|c|}{ Y Y T مستفيدا } & غو انتنامو \\
\hline \multicolumn{5}{|c|}{ r • rس مستفيدا } & المجموع \\
\hline
\end{tabular}

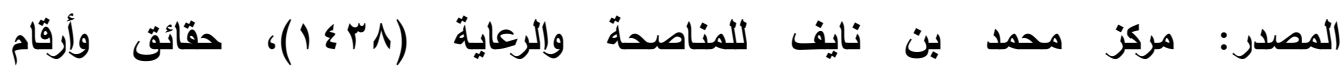
http://www.mncc.org.sa (21-9-1438)

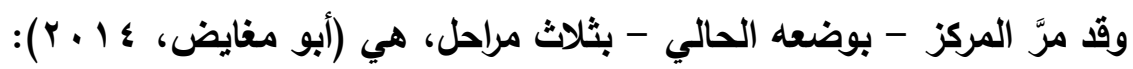

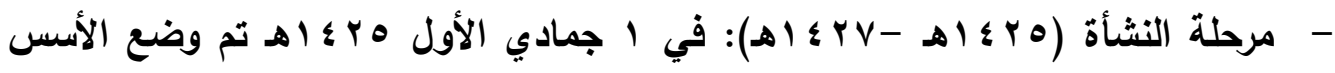

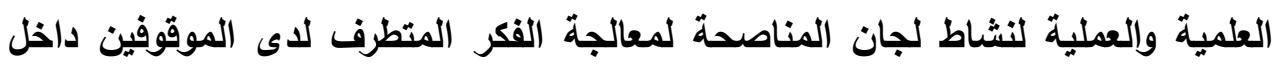

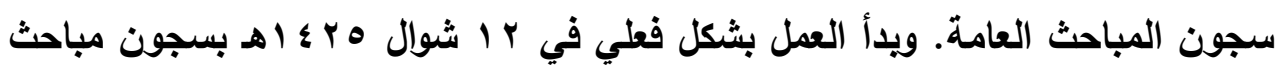
الرياض، ثم عمت الفكرة على بقية سجون المناطق استنادا لنتائجها الإيجابية.

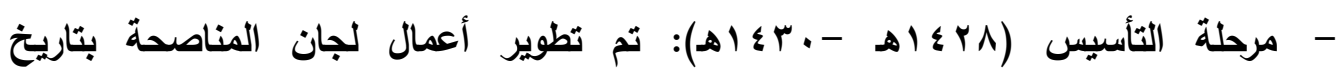

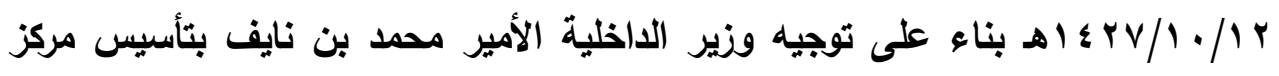
محمد بن نايف للمناصحة والرعاية إلى جاتب لجان المناصحة. وقد انطلق نثاط المئ المركز

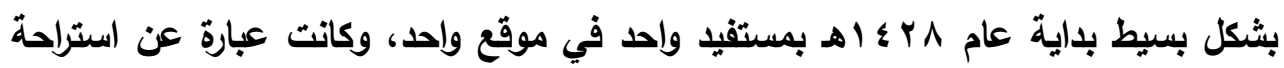

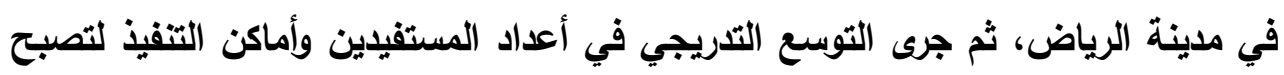
(1) موقعا للتنقيذ. 


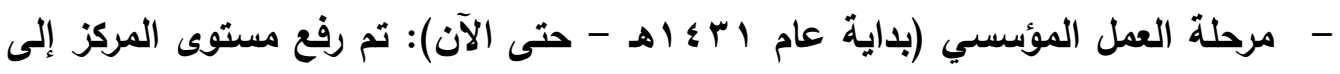

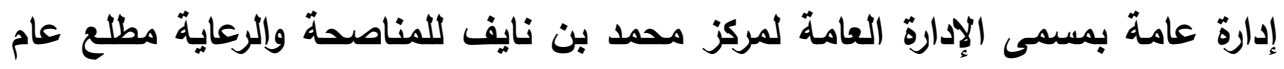

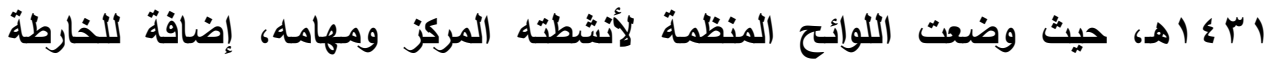

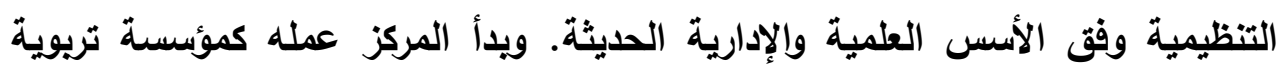

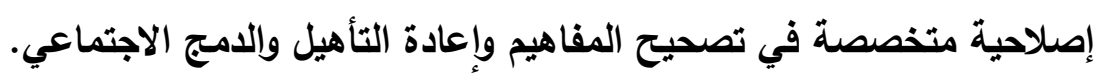

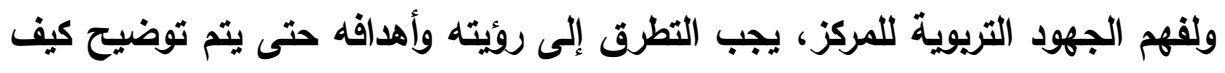

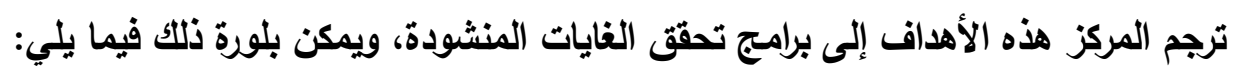

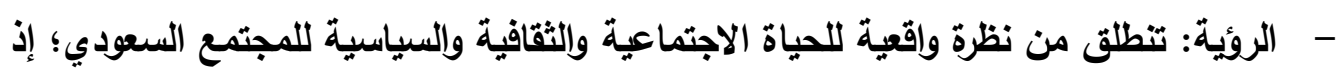

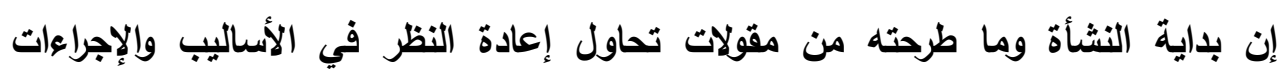

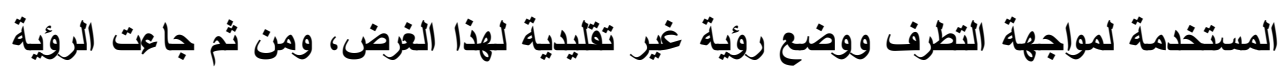

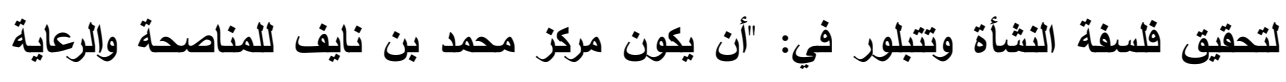

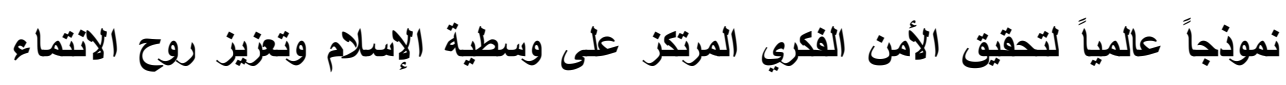

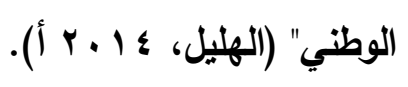

- الرسالة: تحقيق الأمن الفكري وصولاً إلى مجتمع يطبق الوسطية والاعتدال فكراً وسلوكًا،

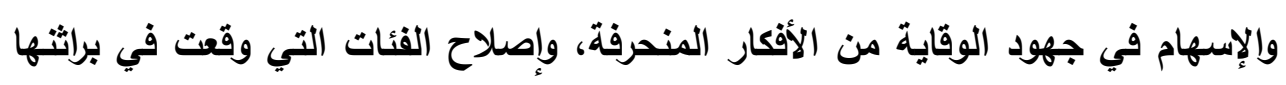

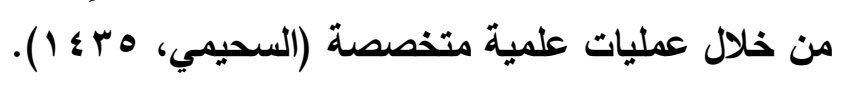

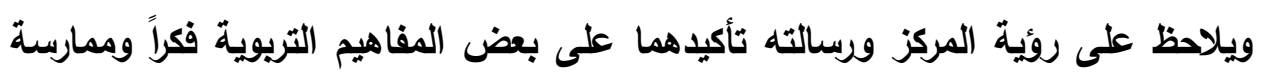

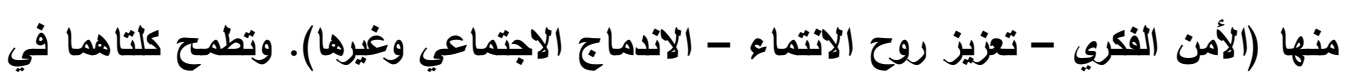

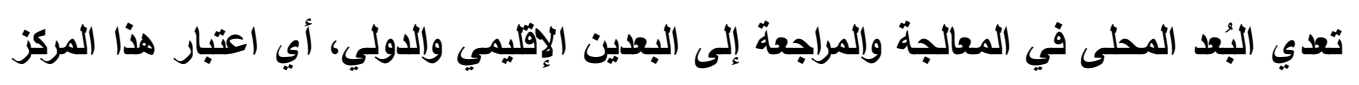

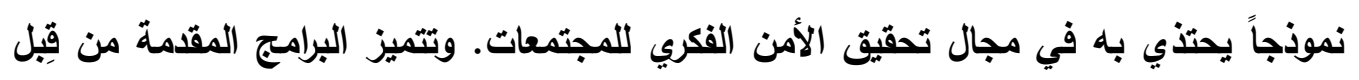

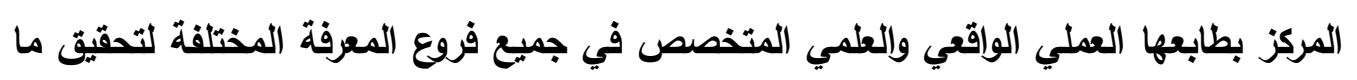
هو قانوني وما هو اجتماعي تريوي.

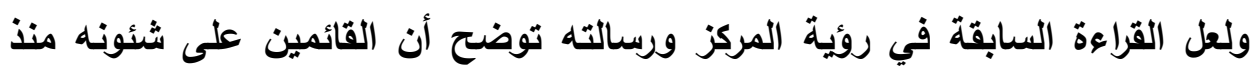

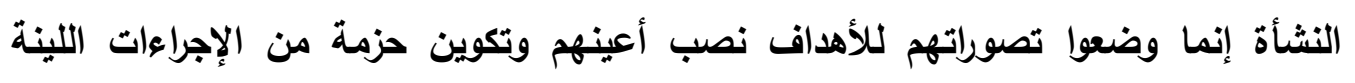

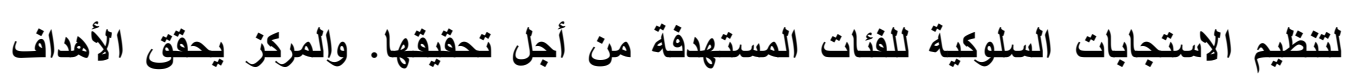

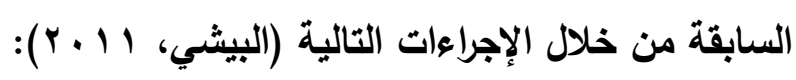




\section{الجهود التربوية لمركز محمد بن نايف للمناصحة والرعاية في مواجهة التطرف الفكري: رؤية مقترحة}

- القيام بأعمال المناصحة للموقوفين لتصحيح أفكارهم المظوطة والثبهات لايهم والعمل على تنقيذها بالاليل من الكتاب والسنة.

- تصحيح قناعات الموقوفين الخاطئة بقتاعات صحيحة تتوافق مع وسئة وسطية الإسلام وسماحته.

- تنفيذ برامج شاملة توعوية وقائية في الأماكن المرشحة للفكر المتطرف تستهدف جميع الفئات الاجتماعية مع التركيز على فئة الثباب.

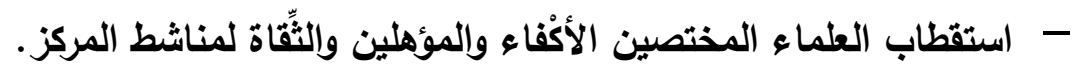
- إيجاد الآليات التي تعمل على توسيع مدارك ومعارف من انتهت محكوميته، وتوعيته بالأخطار التي يترتب عليها نهجه الخاطئ.

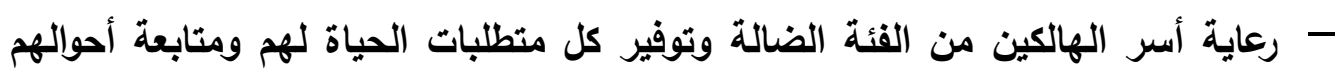
الاراسية والصحية والاجتماعية.

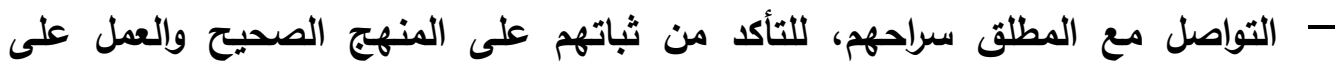
دعمهم بكل ما يخدم مصلحة الوطن. - - إجراء الدراسات والأبحاث العلمية الدقيقة عن الحالات التي تمت مناصحتها داخل السجن

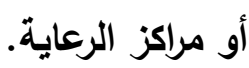

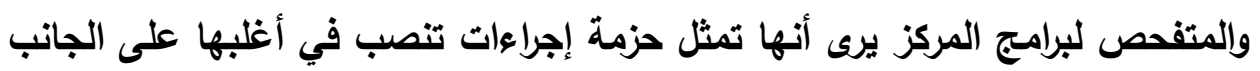

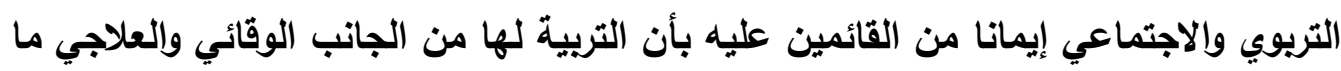

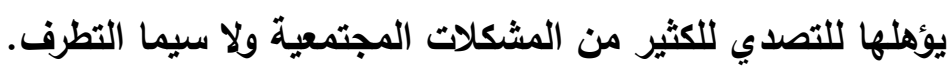

\section{رابعاً : الجهود التربوية لمركز محمد بن نايف للمناصحة والرعاية في مواجهة التطرف}

\section{الفكري}

تعد التربية ضرورة فردية واجتماعية، فالتربية تسمو بالفرد لتكوين السلوك المرغوب

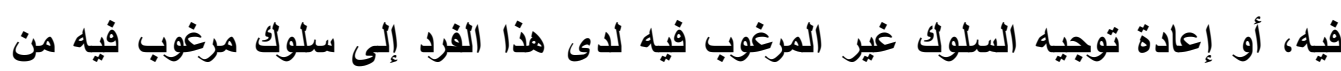

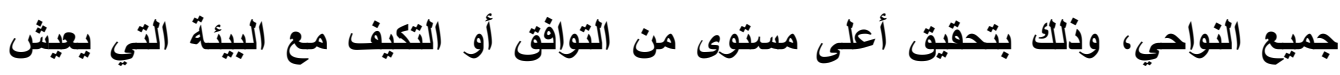
فيها. كما أن المجتمع الإنساني في حاجة ملحة إلى التربية ومؤسساتها المختلفة كي يحافظ التها على التراث الثقافي وعاداته وقيمه ومعاييره لكي ينقلها للأجيال. 
وتعد الأهداف التريوية جوهر الإنسانية ما دامت تتسم بالطابع الأخلاقي. وحتى في

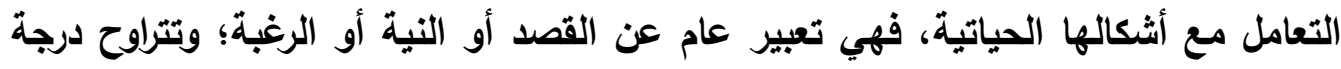

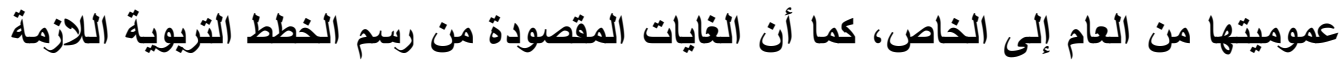

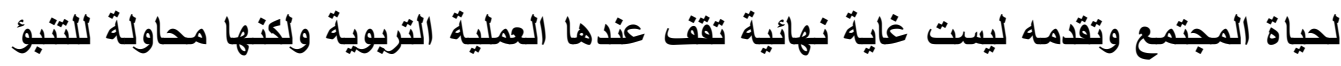
بما تتنهي إليه المجهودات التريوية الحاضرة أو ما يجب أن تتنهي إليه، أي أنها استبصار سابق للنهاية المأمولة في ظل الظروف الحاضرة. وبهذا المغنى يوجه النثاط ويؤثثر في

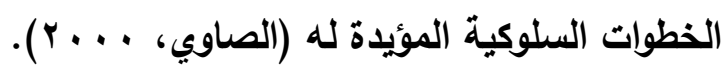

ومن خلال هذه الروئية يككن القول بأن تتفيذ العقوية لا يتوقف فقط على تنفيذ حكم القضاءواء وإنما أيضاً على الجهود المبذولة للإصلاح بما يضمن تحقيق الرعاية الاجتماعية والتربوية وغيرها للمذنب. والمملكة العربية السعودية كدولة إسلامية استمدت شرعية نظامها السياسي من أربعة

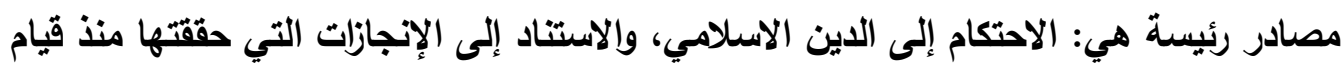

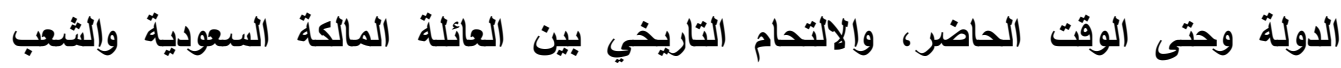

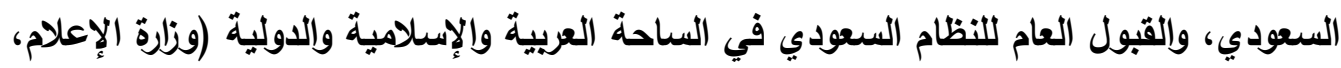
ه9 99 1). ومع ذلك واجهت المملكة أخطر التحديات المتعلقة بعملية التقريب والتوفيق ما بين القيم الدينية باعتبارها مصدراً رئيساً لشرعية النظام وما بين القيم الحضارية والاجتماعية

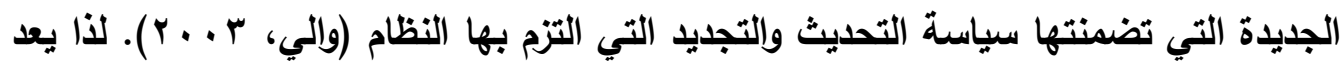
مركز الأمير محمد بن نايف للمناصحة والرعاية مؤسسة إصلاحية تريوية تهتم بتنمية المهارات المعرفية والسلوكية من خلال مجموعة من البرامج التي يقوم عليها نخبة من

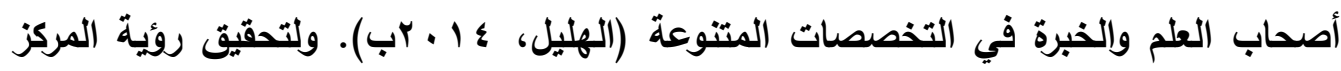
ورسالته وأهدافه تم اعتماد ثلاثة برامج اجتماعية وتربوية تتمثل في الآتي:

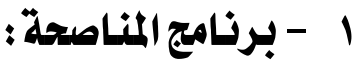

اهتم مركز محمد بن نايف للمناصحة والرعاية بتعديل الاتجاهات وتصحيح المعتقات والمفاهيم الخاطئة وتعديل الفكر المنحرف للوصول إلى الوسطية والاعتدال المنشود (المورعي،

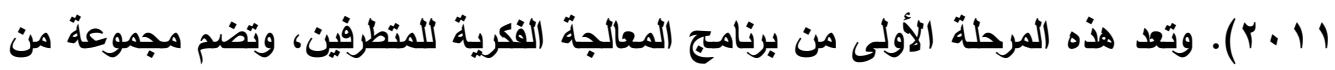


البرامج التي تتفذ داخل دور التوقيف وخارجها وتقوم على الأسلوب الطلمي والمفهوم الثشرعي لمنهج الوسطية والاعتدال، إضافة إلى الجاتب النفسي والاجتماعي (مركز محمد بن نايف للمناصدة

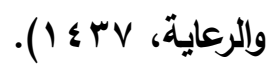

وكان من أهم ما يحسب للجان المناصحة أنها تمكنت - من خلال حوار شرعي علمي

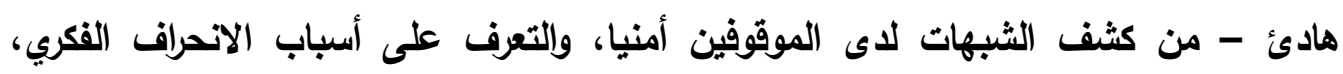

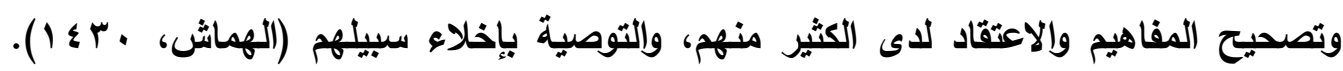

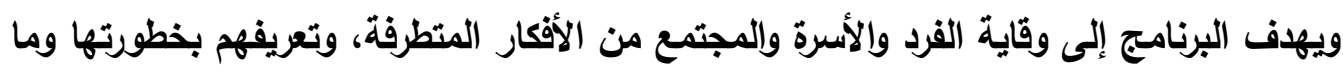
يترتب عليها من آثار، وتصحيح أفكار نزلاء السجون من الثبهات الثيات الفكرية (الأحمدي، هب أ ). ويقدم البرنامج خدماته من خلال مسارين هما (مركز محمد بن نايف للمناصحة

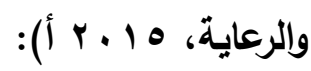

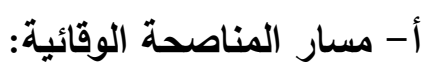

- برنامج المناصحة التوعوية: ومن خلاله يتم القيام بحملات توعية وقائية توجه إلى التى بعض المناطق والمحافظات والمدن والهجر، وتستهاف كل مكونات المجتمع

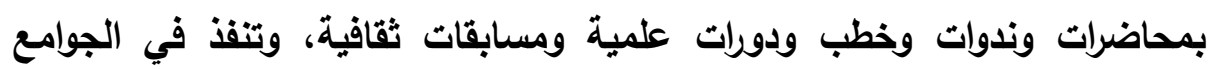
والمساجد وفي المدارس للجنسين وفي النوادي والساحات العامة.

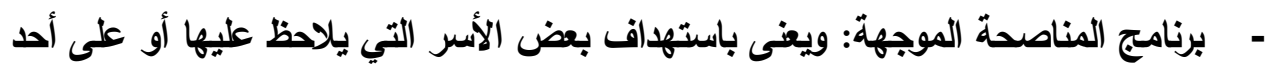

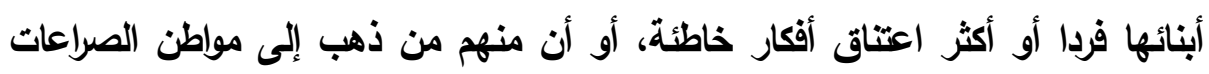

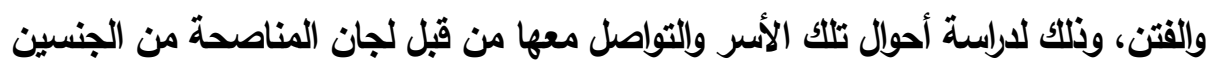
وفي تخصصات مختلفة. - برنامج المناصحة الإكترونية: يهاف البرنامج إلى تسهيل تقليم المطومات الثرعية

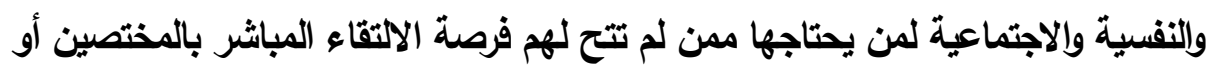

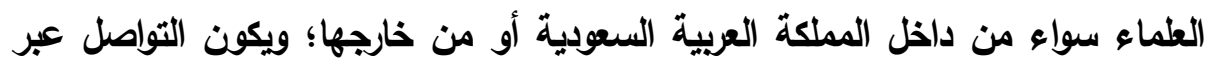
الموقع الإلكتروني اللمركز. 


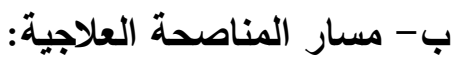

- برنامج المناصحة القربية: يهاف إلى مواجهة الأفكار الخاطئة وإحلال المفاهيم الثرعية

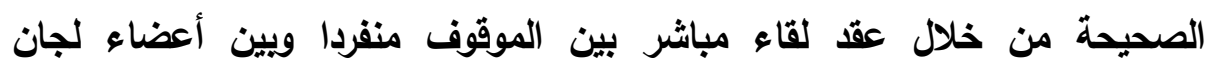

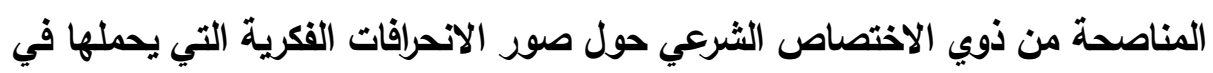

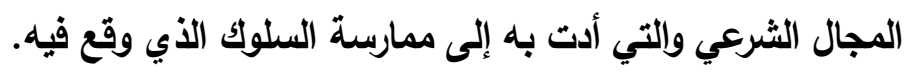

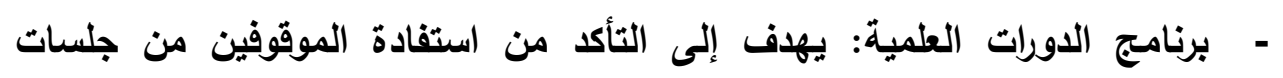

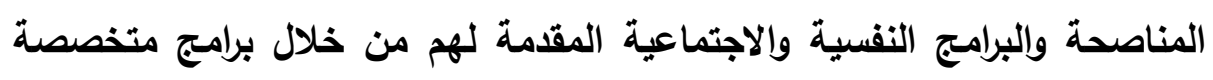

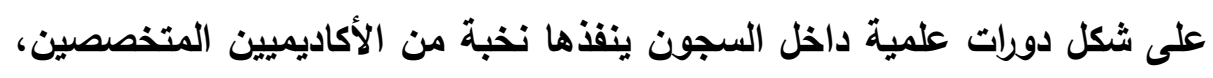
ويتم التقييم وفق معايير محددة ومن ضمنها لونها الاختبارات التحريرية. -

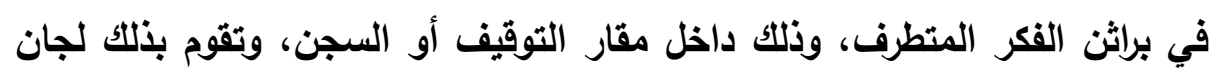
نسائية مؤهلة تأهيلا شرعيا ونفسيا واجتماعيا.

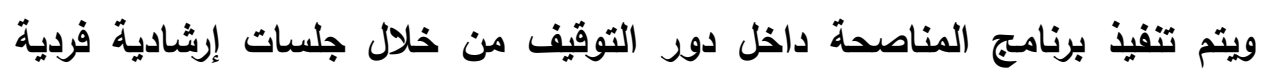

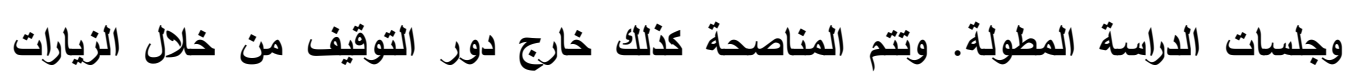

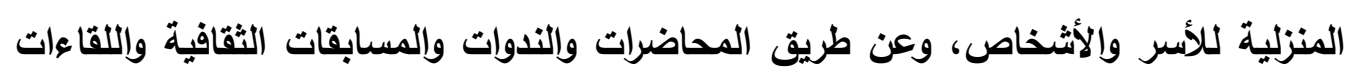

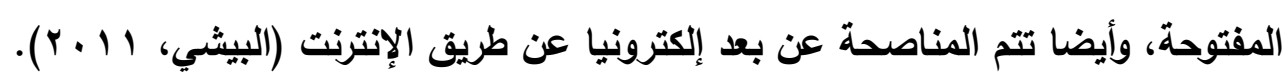

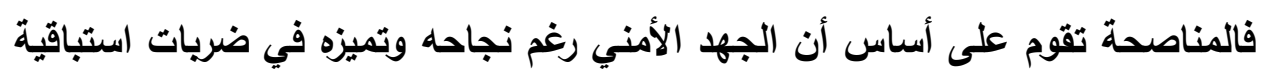

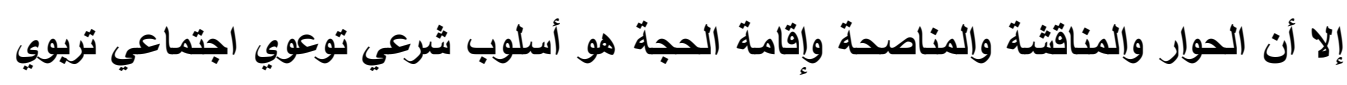

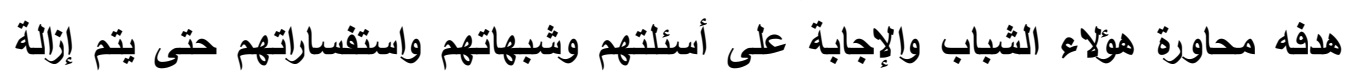

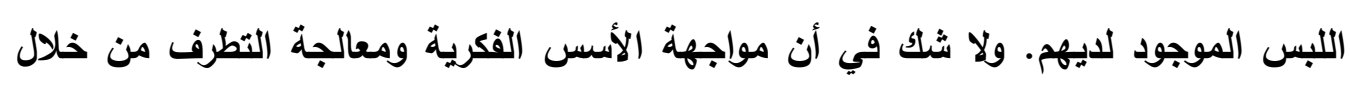

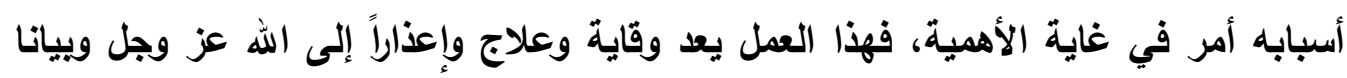

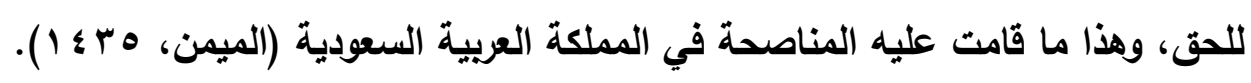

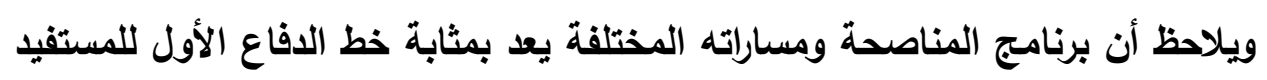

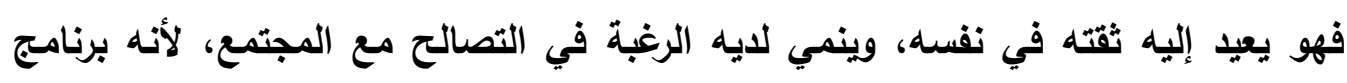

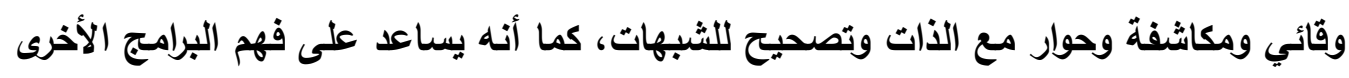
داخل المركز، فهو مدخل تمهيدي للعلاج التربوي والاجتماعي. 


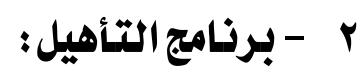

يمثل برنامج التأهيل المرطلة الثانية، وهو عبارة عن مجموعة من البرامج المتتوعة التي

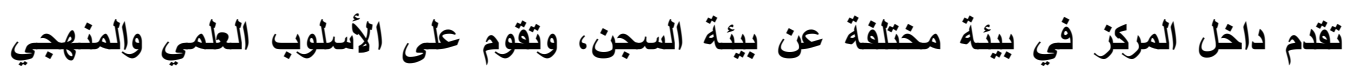

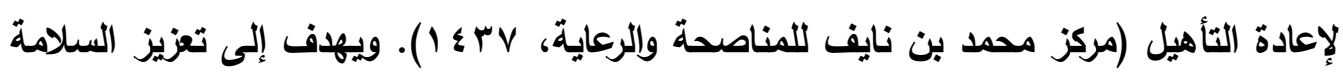

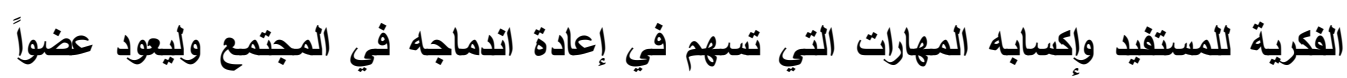

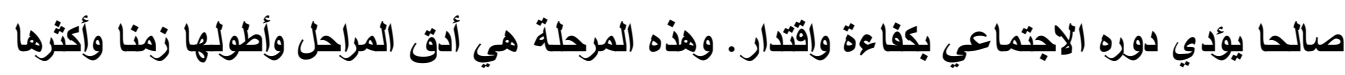

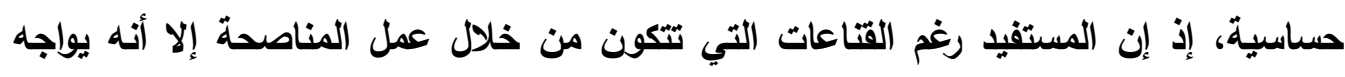
متغيرات وأحوالا وظروفا تتثابه مع تلكات التي مر بها وكانت سبيا في إيقافه (الميمن، هب كـ (1).

$$
\text { أ- المسار التعليمي: }
$$

يتضمن عدداً من البرامج التعليمية التي تهدف إلى تعزيز السلامة الفكرية وإعادة

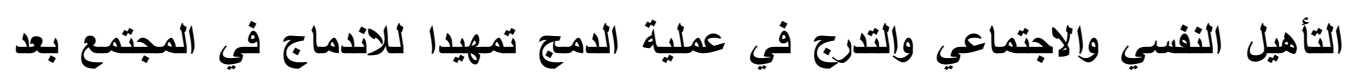

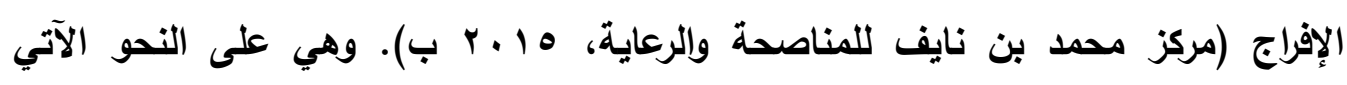

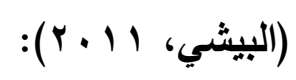

- البرنامج الثُرعي: تعزيز بناء المفاهيم الثرعية الصحيحة على منهج الوسطية والاعتدال، وتقويم المفاهيم الخاطئة لاى المستفيدين من خلال إقامة الدروس والمحاضرات في دورات المبري

علمية.

- البرنامج النفسي: يقوم الأخصائيون النفسيون بدراسة حالة المستفيد وتعليمه مهارات بناء الذات والتخلص من المخاوف وضبط الانفعال وخطوات التفكير الإيجابي وأثره

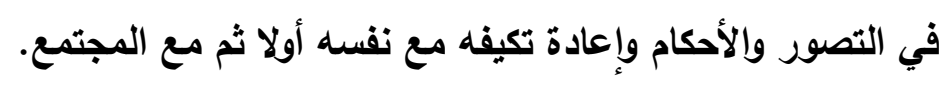

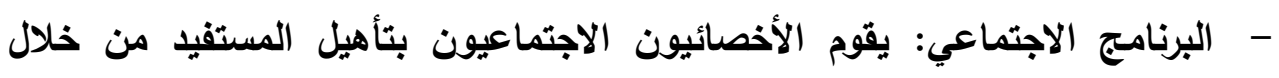

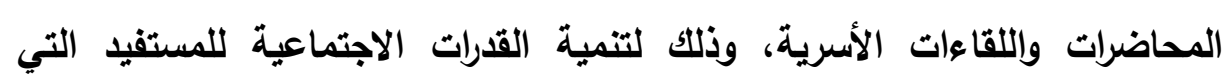

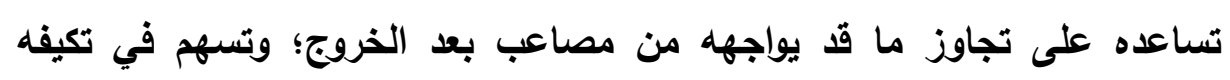
وإندماجه في المجتمع وتوفير الدعم الاجتماعي لده ولأسرته.

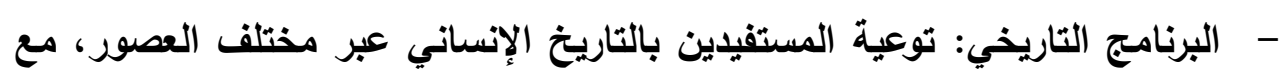
محاولة ريط الأحداث التاريخية بالأحداث الجارية. 
- - البرنامج الاقتصادي: تأهيل المستفيد معرفيا ومهاريا في مجال التعامل الاقتصادي

$$
\text { بما يحقى له حياه كريمة بعد خروجه. }
$$

- البرنامج السياسي: تعريف المستفيد بالعلاقات الدولية وآلية الانضمام للمنظمات

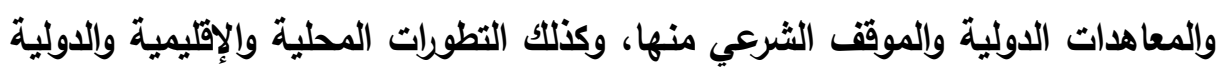

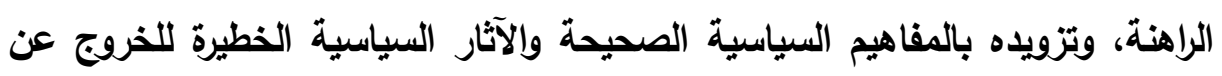
الخط السياسي العام. - برنامج الإرشاد بالفن التثكيلي: هو برنامج معرفي، يدمج بين نظريات التأهيل

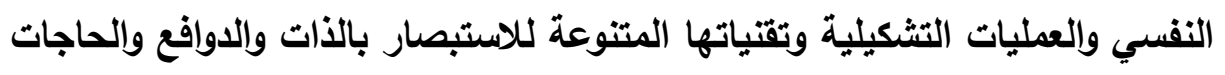
النفسية، والبنى المعرفية وأثرها على سلوكياته.

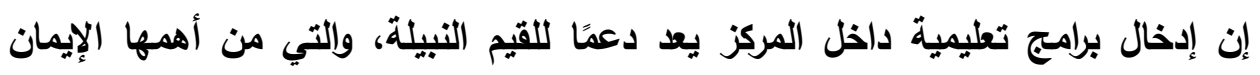

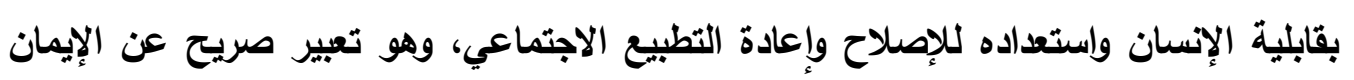

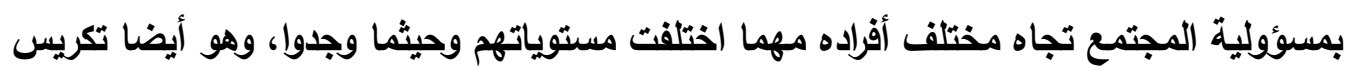

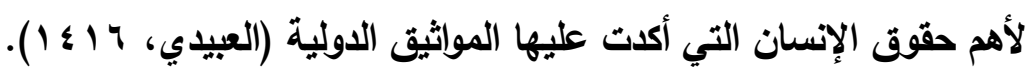

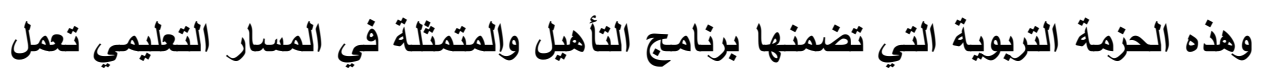

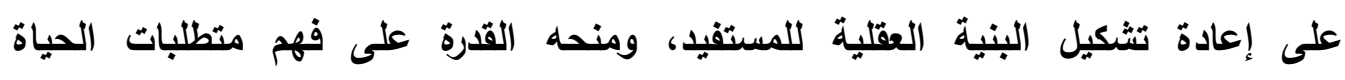

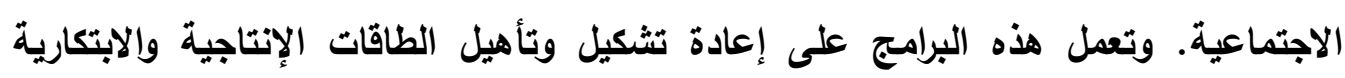
للمستفيدين اجتماعيا ونفسيا وسياسيا واقتصاديا وشرعيا وتاريخيا.

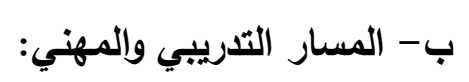

يهاف إلى التأهيل السلوكي والمهاري والمهني للمستفيد بما يكون عونا له على الانخراط

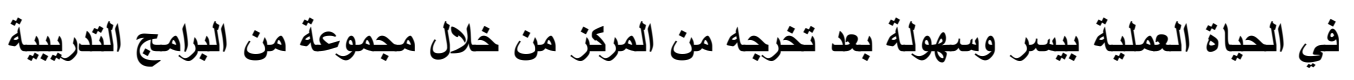

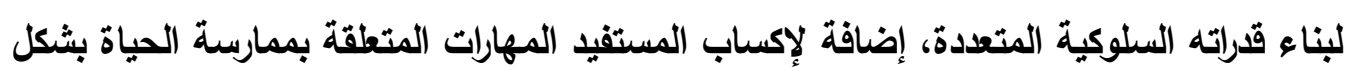

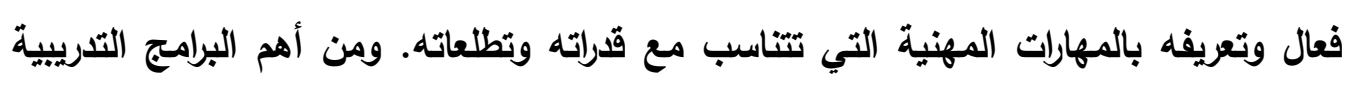

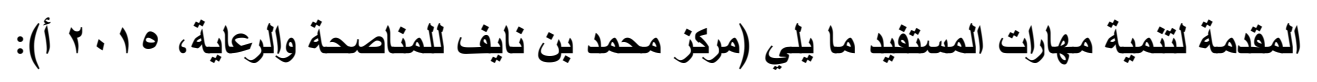

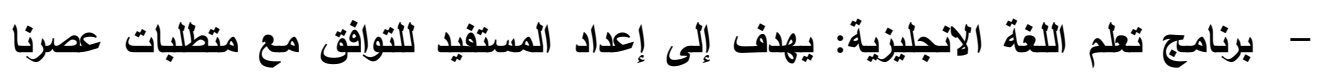

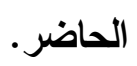


- برنامج استخدام الحاسب الآلي: لتأهيل المستفيد في مهارات الحاسب الآلي المرتبطة بممارسة الأعمال المختلفة للتعامل مع متطبات الحياة اليومية.

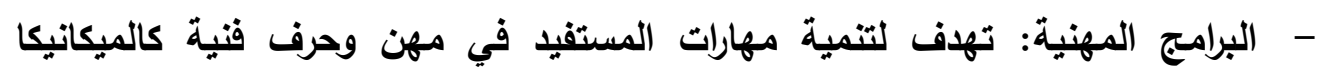
والكهرياء والإكترونيات وأعمال النجارة، وغيرها.

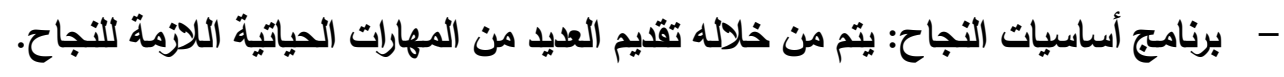

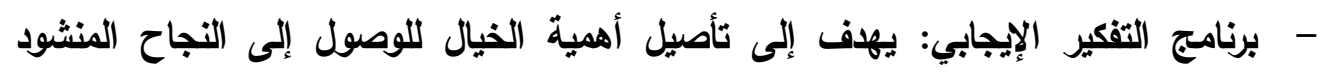
لللمستفيد. - برنامج إدارة الوقت: يهدف إلى استخدام المستفيد للوقت المتوفر بالطرق المثلى لتحقيق أهدافه الثخصية والمهنية.

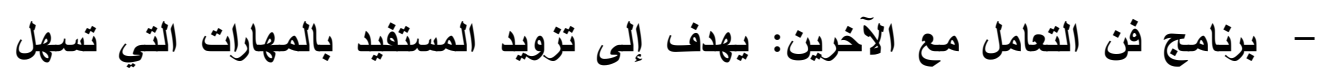
تفاعله وتواصله ميع الآخرين.

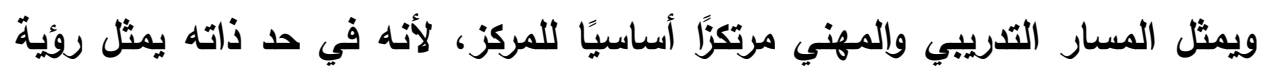

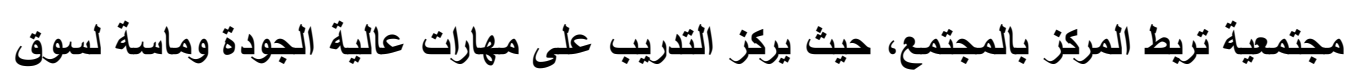
العمل وهذه البرامج ذات بعد اقتصادي واجتماعي بامتياز.

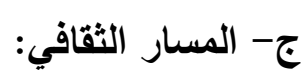
يتضمن العديد من الفعاليات التثقيفية التي تسهم في تصحيح المفاهيم المغلوطة ورفع

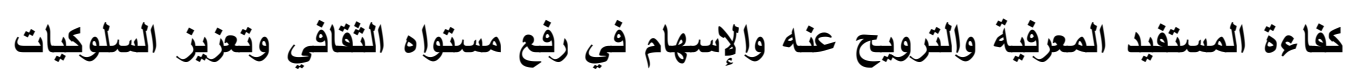

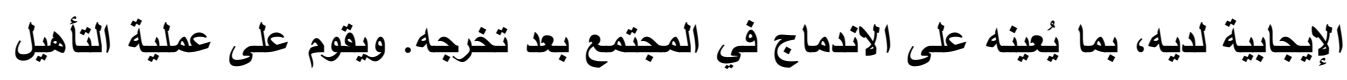

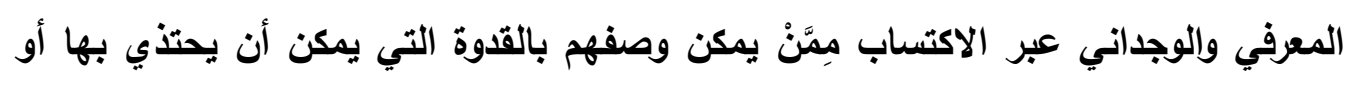

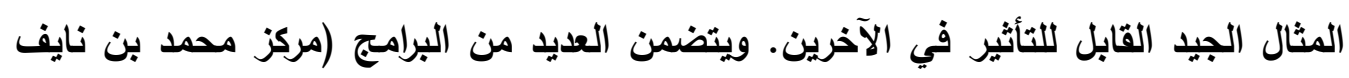

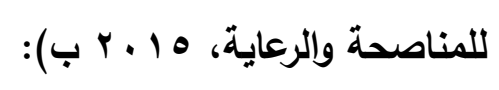

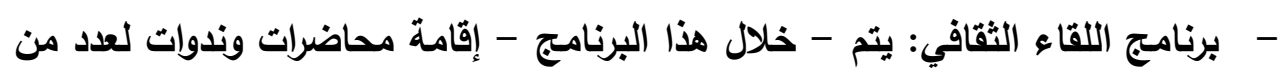
الثخصيات المرموقة في المجتمع للالتقاء بالمستقيدين.

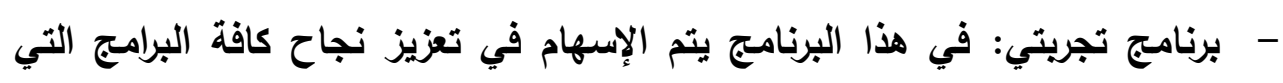

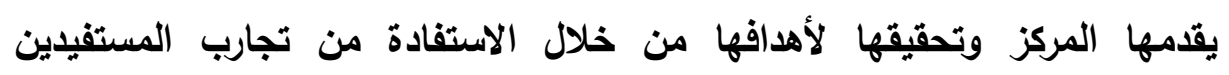


السابقين الذين تخرجوا من المركز، حيث تتاح لهم فرصة طرح تجاريهم عبر لقاءات مفتوحة مع المستفيدين الجداد.

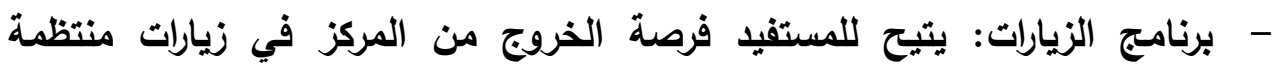

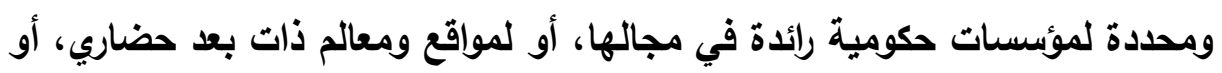

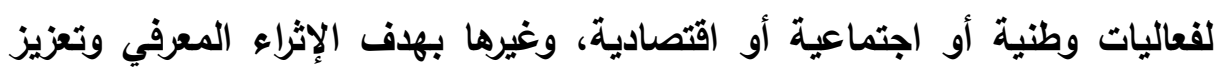
البواعث الإيجابية لايهم وتحقيق التتوع في برنامجهم اليومي.

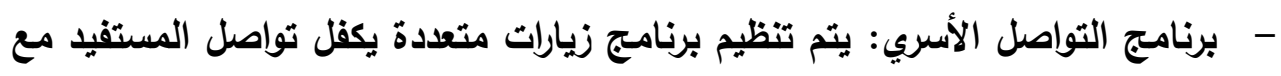

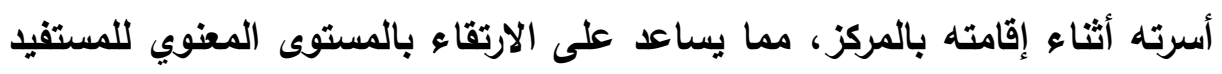

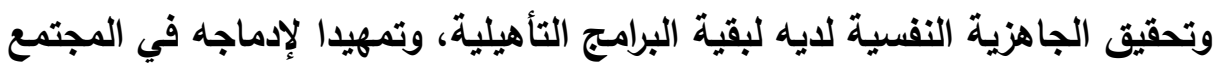

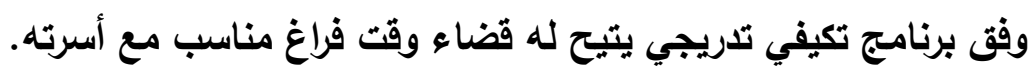
وتعمل هذه البرامج على تنمية الطاقات الفكرية للمستفيدين من خلال تنمية الهوايات

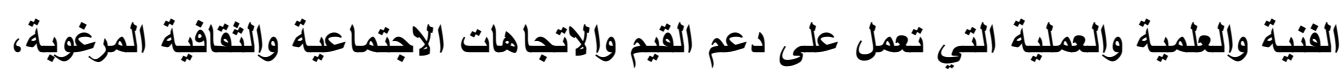

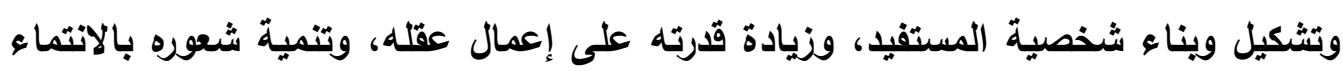
والولاء لوطنه وقيادته ومجتمعه (متولي، 14 أو 1 ).

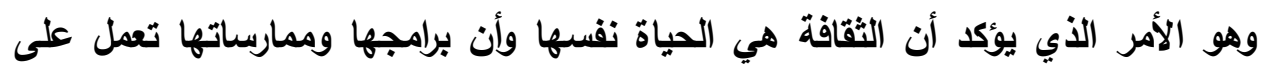

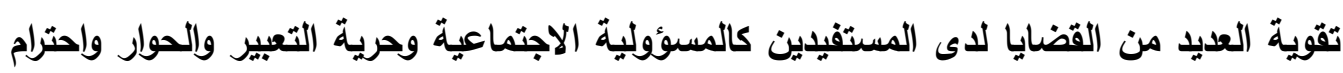

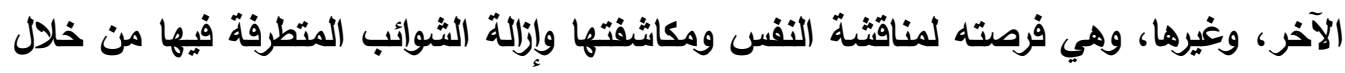
هذا البرنامج.

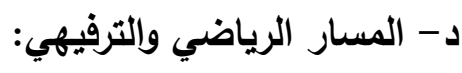
يمارس المستفيدون بثكل يومي ومنتظم أنثطة رياضية وترويحية متتوعة بما يتناسب مع الوعاضي مختلف الأعمار والرغبات والأوضاع الصحية.

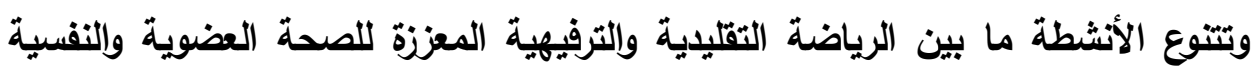

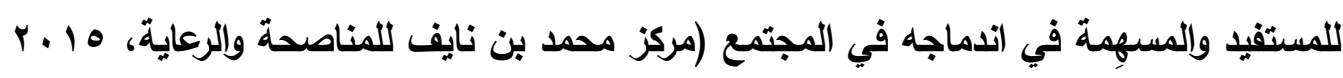

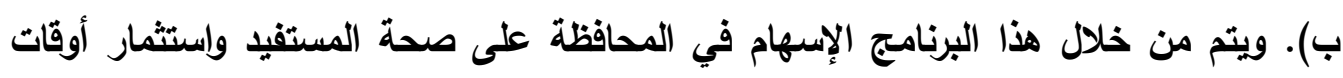

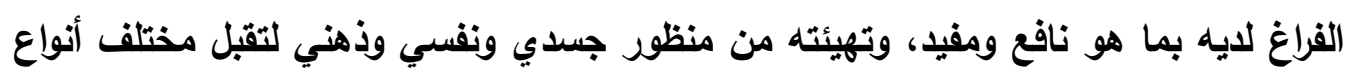




\section{الجهود التربوية لمركز محمد بن نايف للمناصحة والرعاية في مواجهة التطرف الفكري: رؤية مقترحة}

برامج المركز التأهيلية الأخرى، مثل تمارين اللياقة وألعاب الكرة بأنواعها والسباحة والمسابقات الترفيهية، إضافة إلى أنها وسيلة تريوية تسهم في تخفيف آثار السمات السلبية. وهنا بمكن القول إن الترويح نشاط تربوي فعال يمنح المستفيل الفرصة لاحترام النظام والامتثال للقيم المجتمعية وتكوين علاقات ذات صبغة اجتماعية مع الناس.

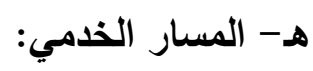

يهذف إلى توفير كافة مقومات البيئة المتكاملة والطبيعية للمستفيدين الأعمة لإعادة التأهيل، من خلال تقليم مجموعة من الأنثطة الخدمية الموجهة لتحقيق احتياجات المستفيدين

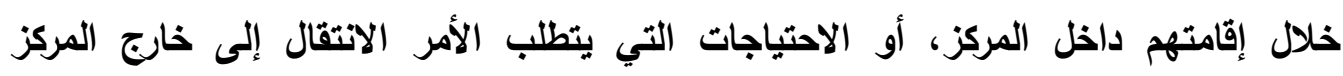

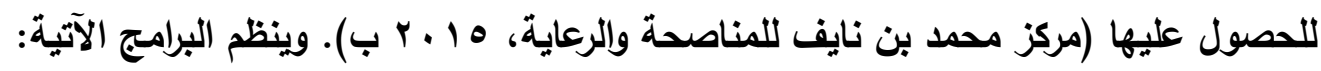

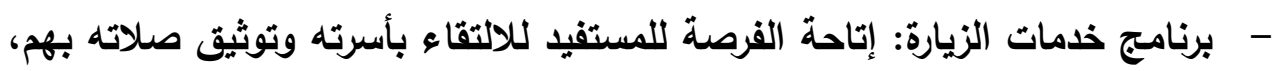
وذلك بثكل منتظم داخل المركز، كما يتضمن مجموعة من الخدمات الفرعية كالزيارة العائلية والزيارة العامة والزيارة الخاصة (الخلوة الثرعية) والزيارة الاستثنائية.

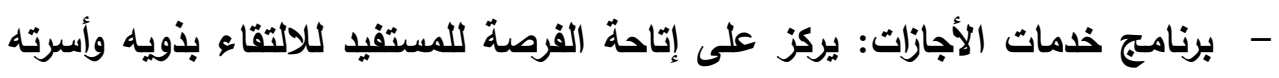

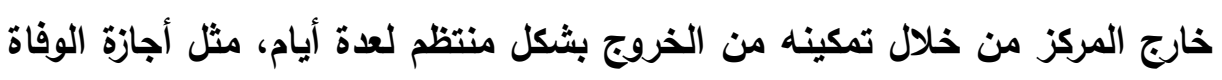

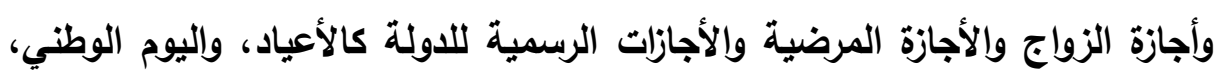

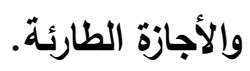
- برنامج الخدمات الاخلية: تقديم جميع الخدمات اللازمة للمستفيدين داخل المركز

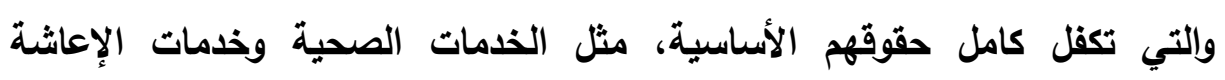
وخدمات الضيافة وخدمات الاتصال بأنواعها وخدمات المكتبة.

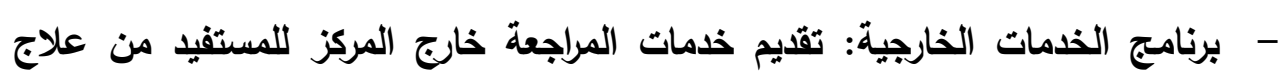
وتصحيح للأوضاع الأسرية والمراجعات الحكومية وفتح الحسابات البنكية، وغيرهات

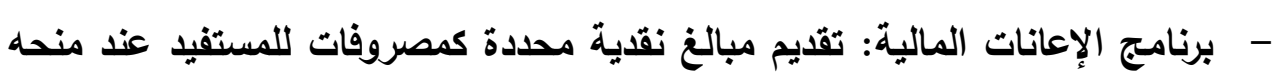

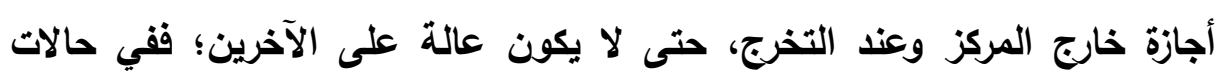

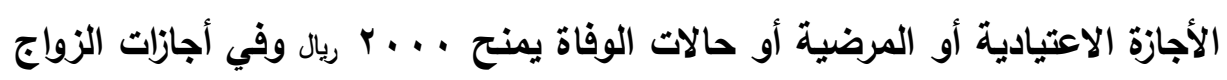
وعند التخرج يمنح ...... 
ويستطيع الفاحص لبرنامج التأهيل بالمركز أن يرى أنه من العطليات التربوية والاجتماعية

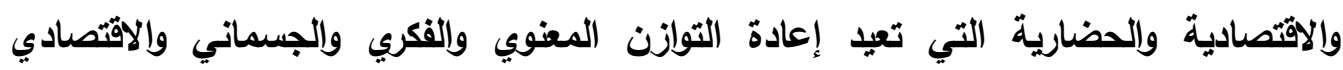

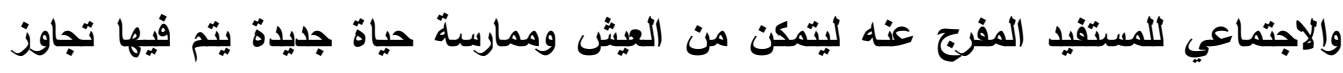

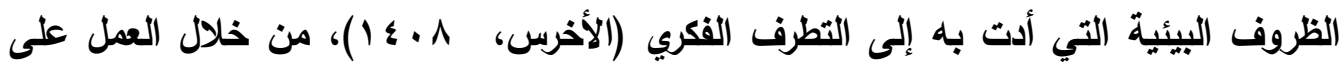

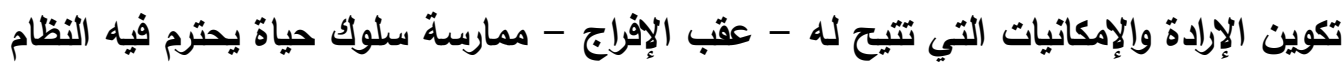

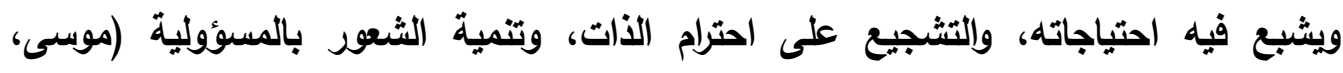
. (r... T

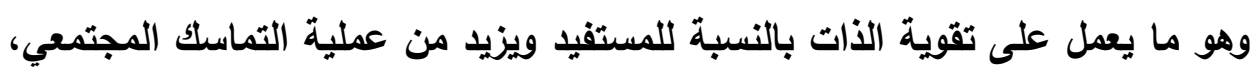

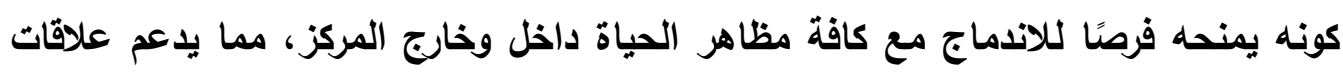
التوازن بكل أجزائها في سبيل إعادة الحياة الطبيعية للمستفيد.

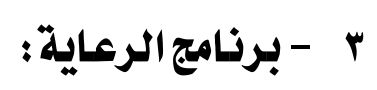

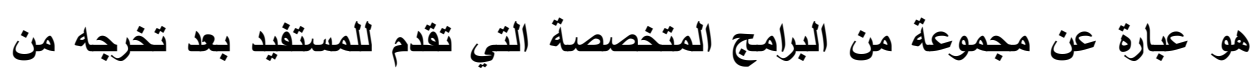

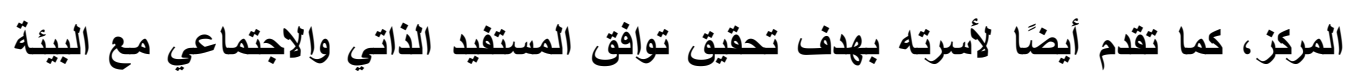

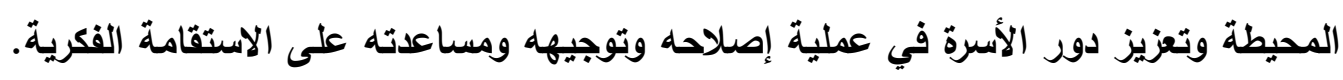

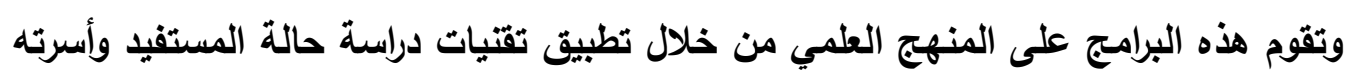

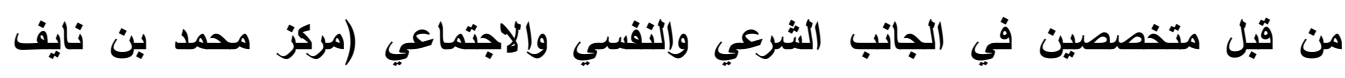

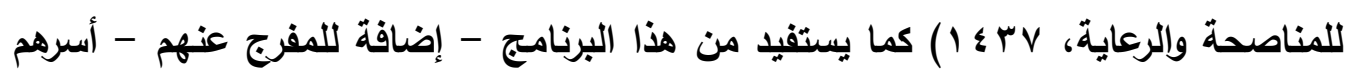

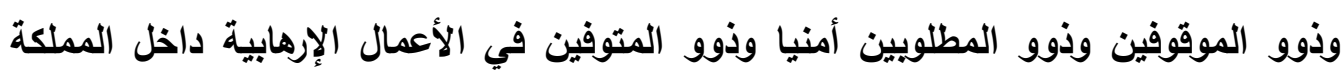

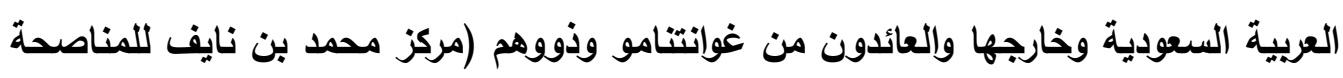

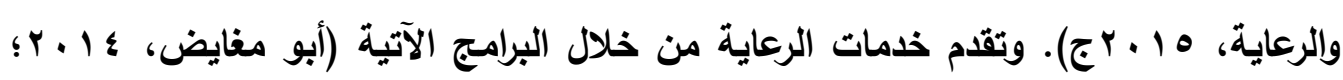
:(Striegher, 2013 أ- برنامج الرعاية الأسرية: يهدف إلى احتواء أسرة المستفيد وتعزيز دورها في عملية إصلاحه

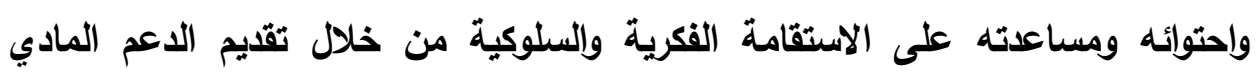

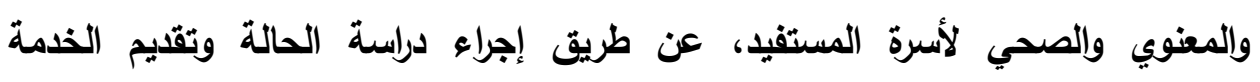

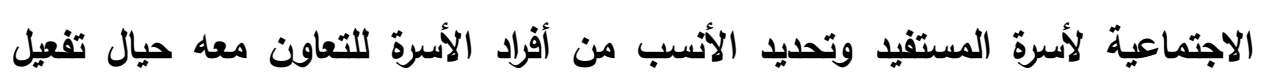
جهودها في احتواء المستفيد. 
ب- برنامج رعاية الخريجين: يهلف إلى مساعدة المستفيدين في تجاوز ما يواجههم من

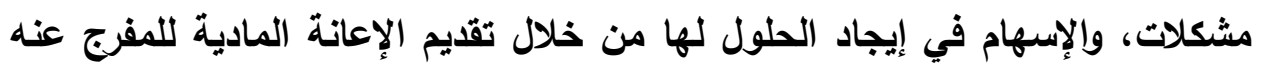

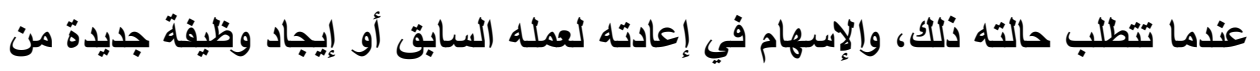

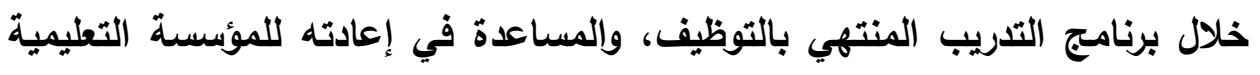

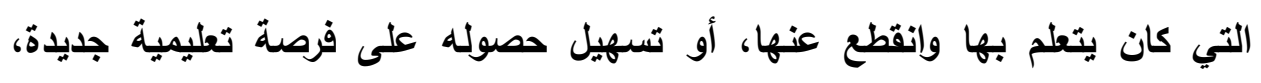

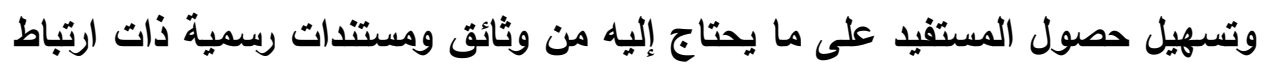

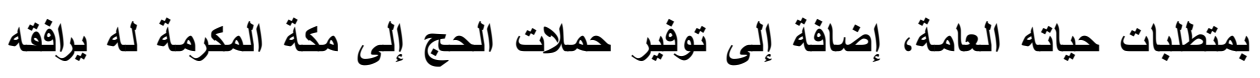

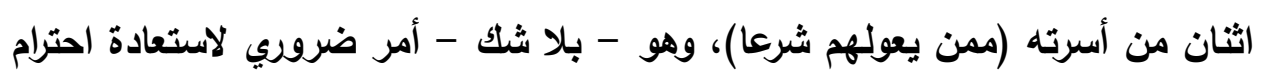
المفرج عنه لذاته.

ج- برنامج التكيف والاندماج: يهلف إلى مساعدة المستفيد المفرج عنه على التوافق الذاتي

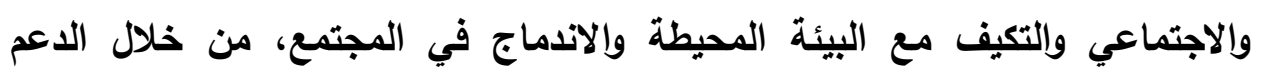

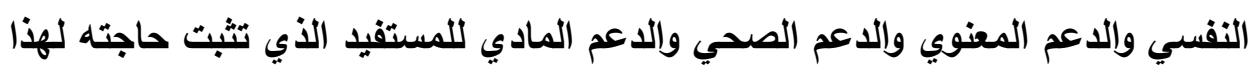

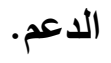

وتنفَّ مهام الرعاية للمستفيدين المتخرجين وأسرهم من خلال تكوين أكثر من فريق يناط

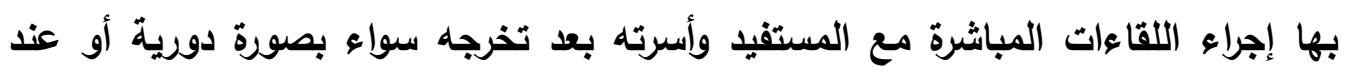

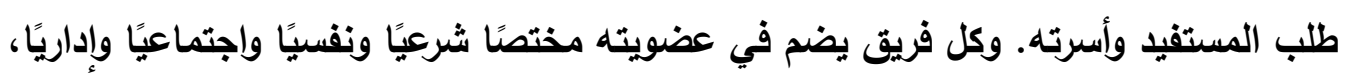

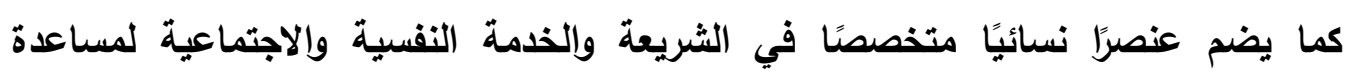

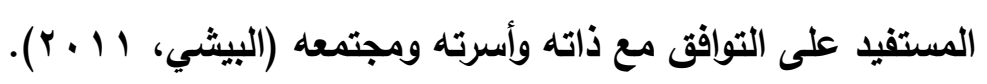

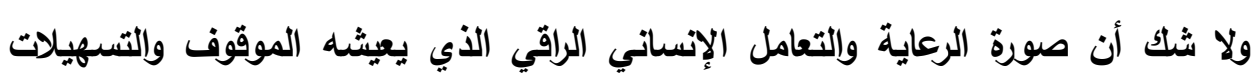
والخدمات التي توفر له هي من أهم العناصر التي تكسر ما لديه من حدة أو احتقان (الميمن،

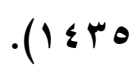

وفي ضوء ذلك يمكن القول بأن الرعاية اللاحقة لم تكن عملية عشوائية يمكن إسنادها لأي

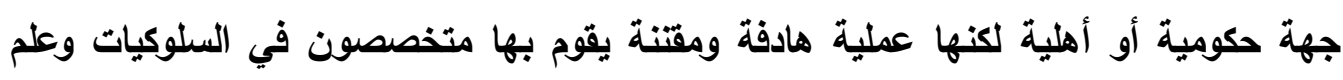

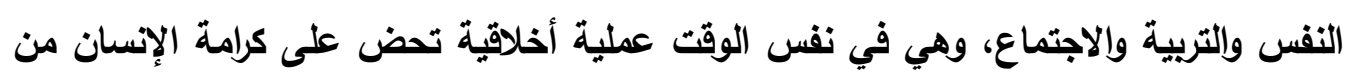

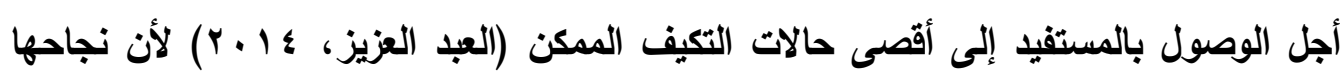

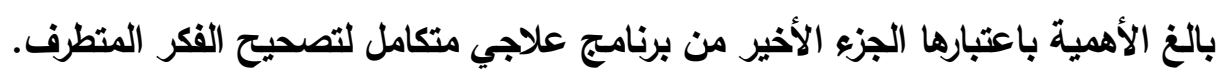


والحقيقة أن هذه البرامج الثلاثة (مناصحة - تأهيل - رعاية) تتعدد الجهات المسهمة

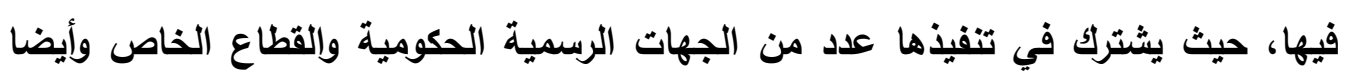

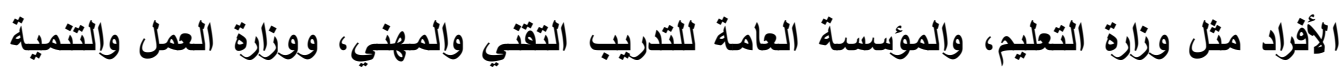

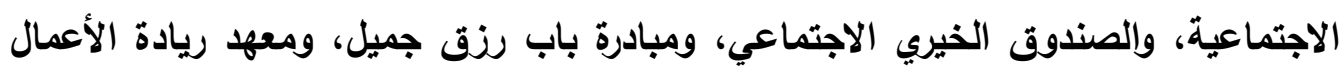

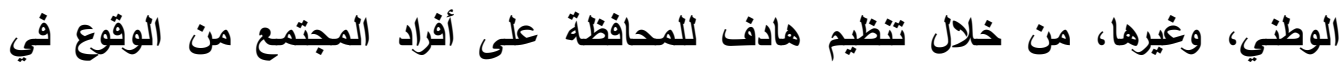
الاتحرافات الفكرية، وكذلك المحافظة على من سبق وأن أوقف أمنيا على خلفيات قضايا الفكر

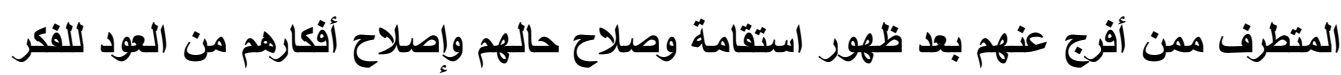
الضال مرة أخرى. لذا، فالأمر يتطلب التأكيد على أهمية مؤسسات التهات التشئئة الاجتماعية

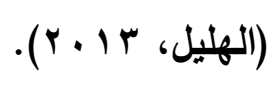

وهذا النهج المتعدد الجوانب الذي تبنته المملكة العربية السعودية يحتوي على عداد

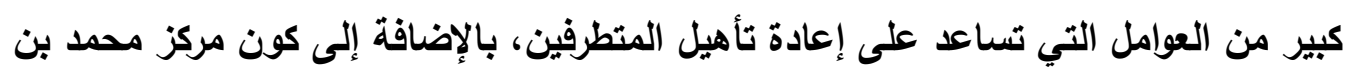

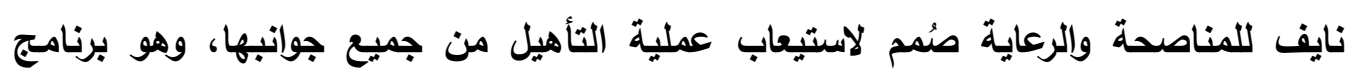

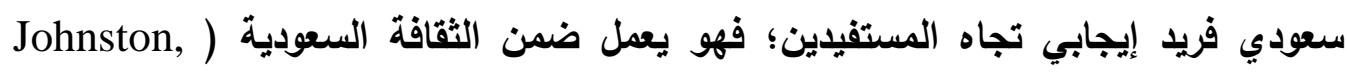
(2009

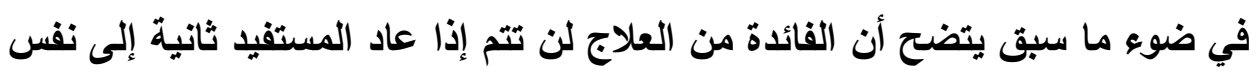

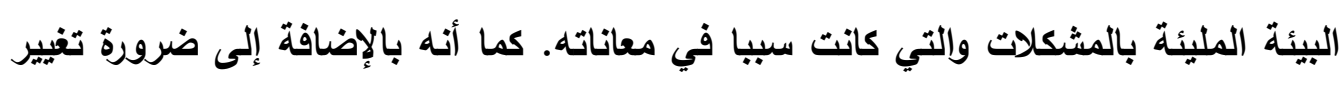

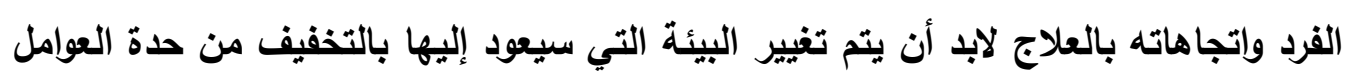

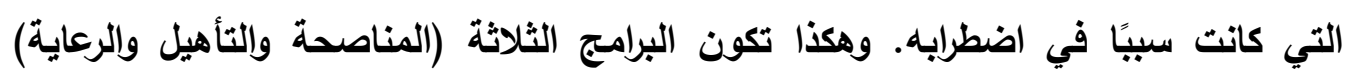
حلقات متصلة ومتفاعلة ومتكاملة من أجل نجاح البرنامج العلاجي لتصحيح الفكر المتطرف.

\section{خامسًا : خبرات بعض الدول في مواجهة التطرف الفكري والسمات المثتركة بينها}

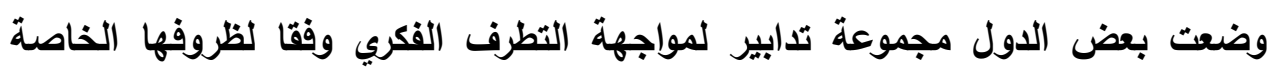

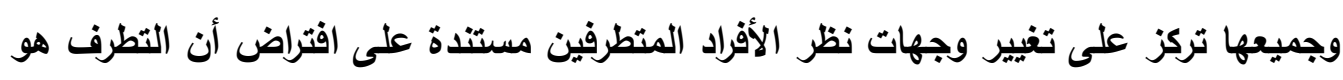

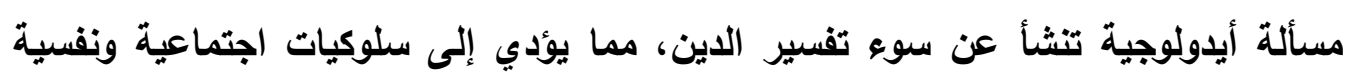
منحرفة (Saba \& Shagufta, 2009). وسوف نعرض لبعض أهم تلكت التدابير على النحو الآتي: 


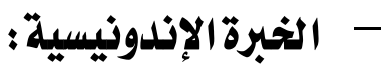

تقدم الوكالة الوطنية الإندونيسية لمكافحة التطرف جهودًا مهمة في مكافحة التطرف

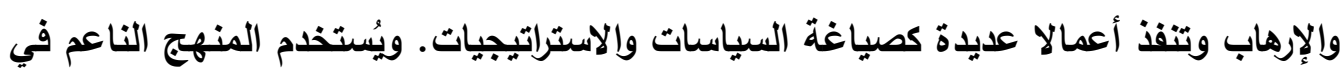

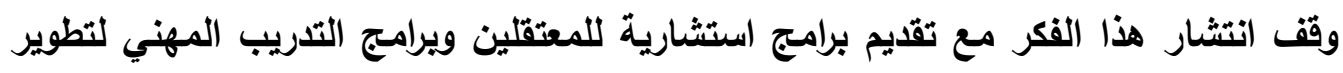

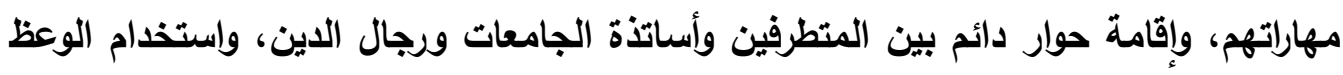

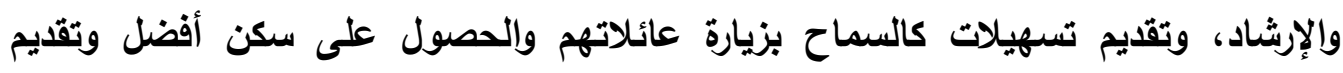
الرعاية الصحية والدعم المالي خلال فترة الاحتجاز (Horgan \& Braddock, 2010). واستخدمت الوسائل الخشنة وإناعمة للتأكد من إمكانية عودة المعتقل إلى مجتمعه والعيش العان بعيدا عن الفكر المتطرف، إضافة لذلك، فإن المتطرف المعتقل عليه أن يجتاز أريع مراحل حتى يطلق سراحه، وهي (Aslam et al., 2016): المرحلة الأولى: مرحلة المراقبة وهذه المرحلة يتم فيها إجراء مقابلة مع المتطرف لجمع

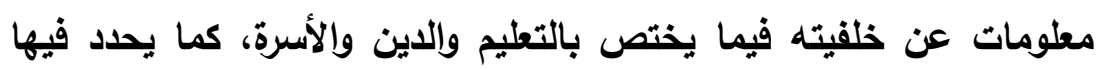

$$
\text { السبب الرئيس الذي دفعه إلى التطرف. }
$$

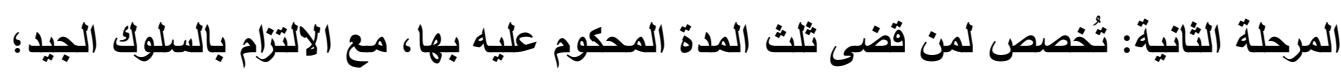

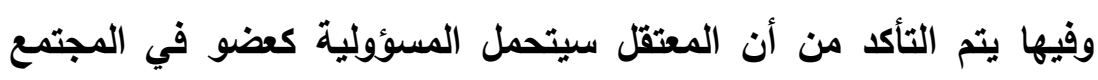

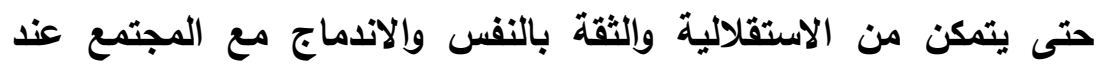

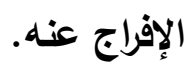

المرحلة الثالثة: تُخصص لمن قضى نصف المدة المحكوم عليه بها، وفي هذه المرحلة يمكن

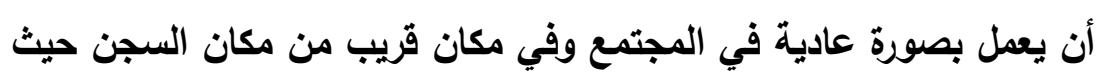

$$
\text { يخضع للمراقبة من جانب السلطات الرسمية. }
$$

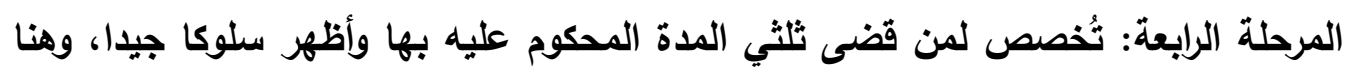
يمنح خروجا يمكنه من الذذمة لباقي المدة كعضو في المجتمع.

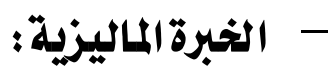

يرتكز معظم برنامج مواجهة التطرف في ماليزيا على التطليم وإعادة التأهيل، حيث يركز التعليم على تصحيح المفاهيم الخاطئة عن السياسة والدين. بينما تتبنى استراتيجية إعادة التأهيل 
الرصد والمراقبة الثاملة للمتطرفين المعتقلين بعد إطلاق سراحهم. وتدعم ماليا أفراد أسرة المعتقل

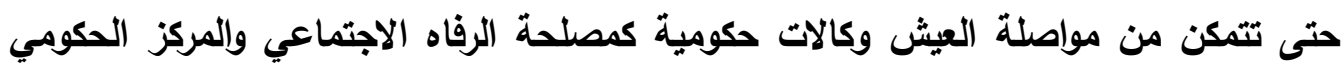

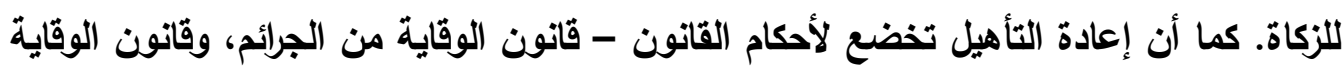
من الإرهاب - ويطلق عليها جميعا مصطلح النظام الإنتاجي (2009, Saba \& Shagufta). ولكي يطلق سراح المتثلين المتطرفين يجب عليهم إنهاء برنامج إعادة التأهيل، والذي يتضمن أريع مراحل هي (Aslam et al., 2016): المرحلة الأولى: تقوم فيها مجموعة من الاستثاريين والثرطة بعملية اجتثاث الفكر المتطرف

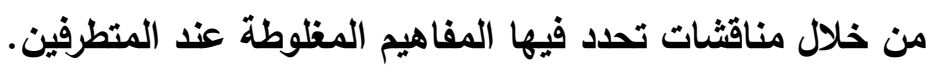

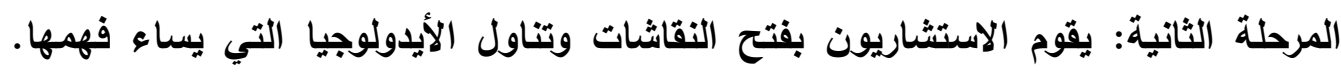
ويواجه كل استثاري مهمة صعبة بسبب مقاومة المتطرف.

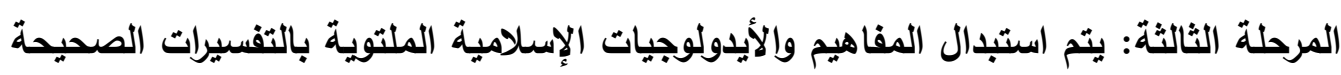

$$
\text { من القرآن الكريم والسنة النبوية. }
$$

المرحلة الرابعة: تبأ عملية إعادة تأهيل المعتقلين؛ وتوضح التربة الحكومة الماليزية لأسر

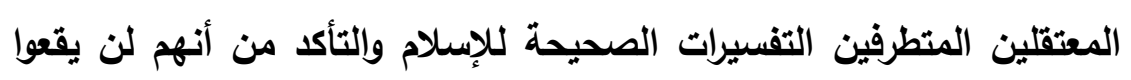

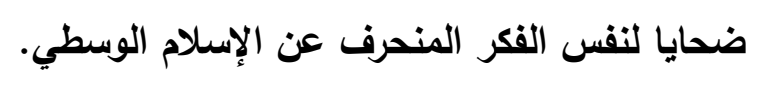

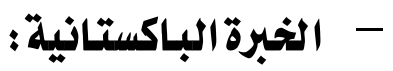

يوجد في باكستان برنامج لمواجهة التطرف تثارك فيه مجموعة من المتخصصين: أطباء

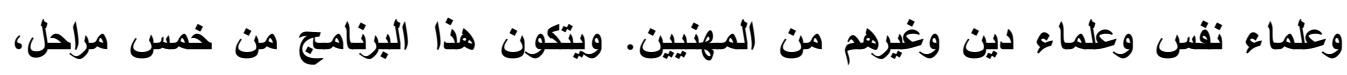

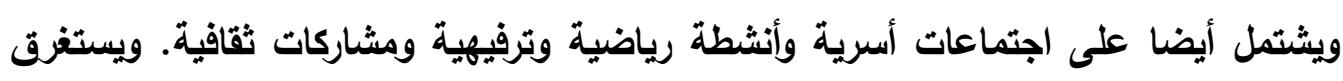

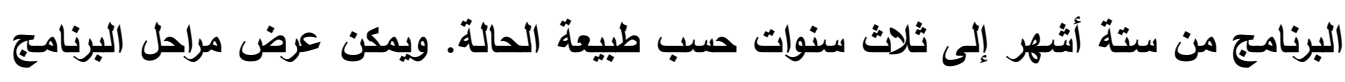
كما يلي (Basit , 2015): المرحلة الأولي: يخضع فيها المتطرفون لإعادة التأهيل النفسي من قبل خبراء متخصصين في

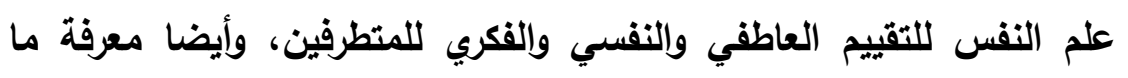
يدفعهم للميل نحو التثدد.

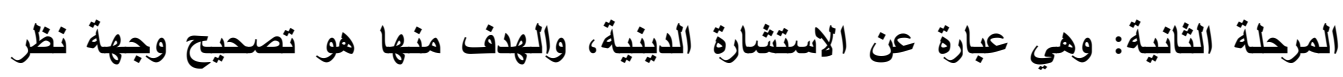
المتطرفين من خلال تغيير معتقاتهم الدينية المتثددة وتعديل السلوك. والكو 
المرحلة الثالثة: يتم تقديم التعليم النظامي من الصف الأول الابتدائي إلى المرحلة الثانوية

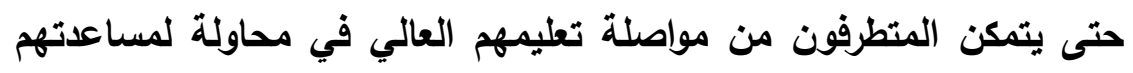
على تبني وجهات النظر المستنيرة وزرع قيم التسامح والتعدية تعنية الدينية.

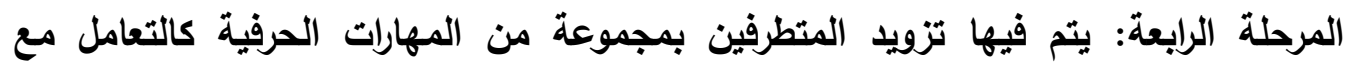

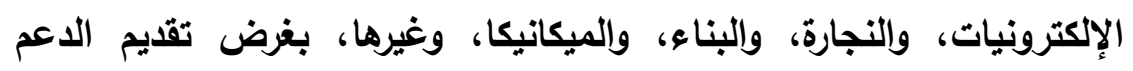

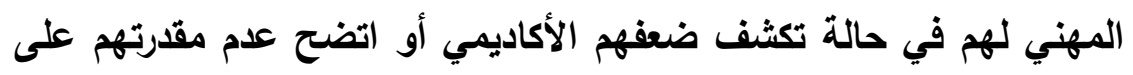
العثور على عمل حتى يتسنى لهم إيجاد وظيفة فعلية عند خروجهم.

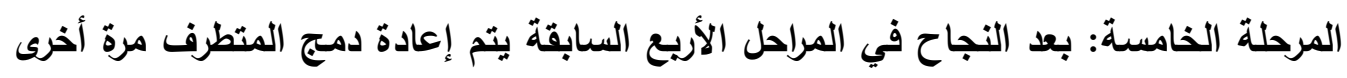

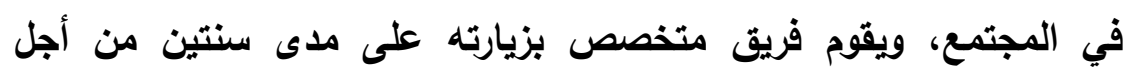
التصدي لخطر عودة المفرج عنه إلى التطرف مرة أخرى.

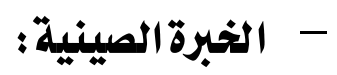

تع قضية القضاء على التطرف إحدى السياسات التي اتخنتها السلطات الصينية مؤخرا لمعالجة تصاعد الغف والتطرف، خصوصا وأن التدابير العكرية وتطبيق القانون لانيات يكفيان

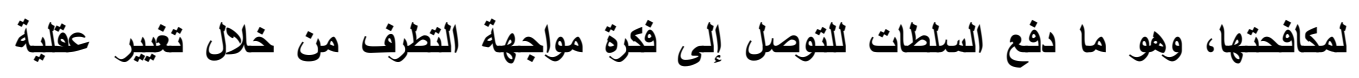

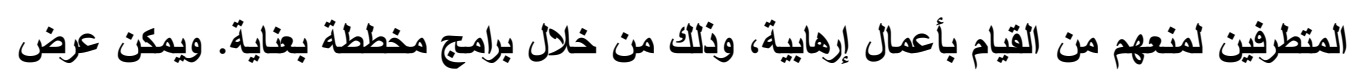
مراحل تلك البرامج كما يلي (Zhou, 2017):

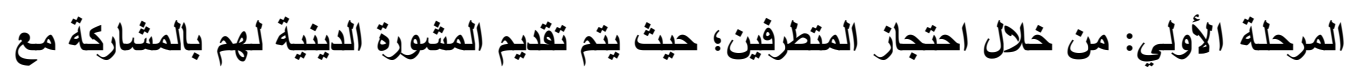

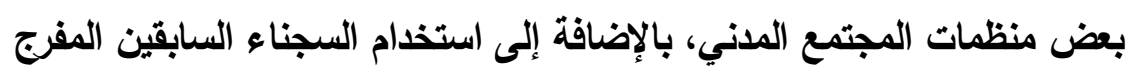

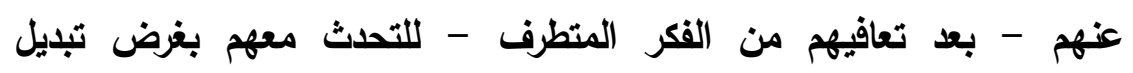

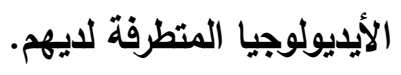

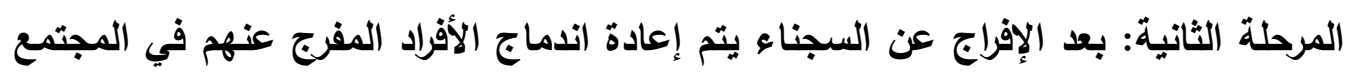

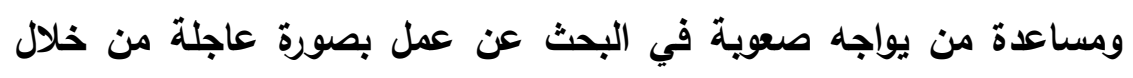

$$
\text { شراكات وثيقة مع منظمات المجتمع المدني. }
$$

المرحلة الثالثة: الرعاية الاجتماعية؛ ويقوم بها مركز التأهيل الاجتماعي والجمعيات الإسلامية

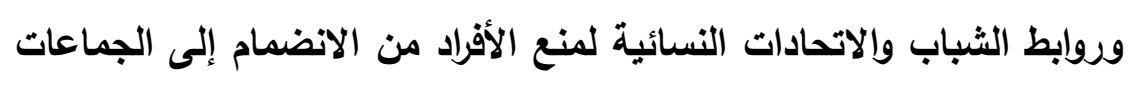


المتطرفة أو دعمها. وتهدف إلى تثقيف من شاركوا في التطرف ولكنهم لا يستحقون عقوية جنائية، أو أولئك المعرّضين للتطرف.

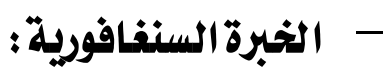

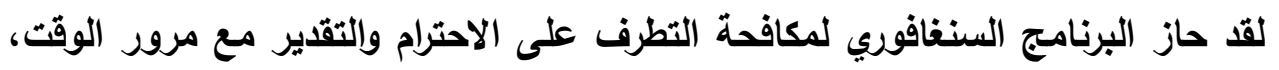

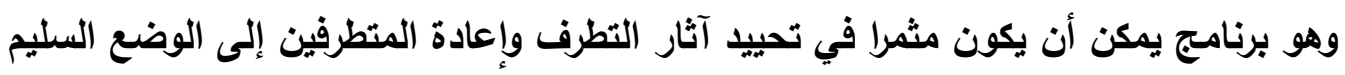
والاندماج في المجتمع. ويمكن عرض مراحل البرامج على النحو الآتي ( International :Peace Institute , 2010 المرطلة الأولى: يتم احتجاز المتطرف، ويتم تحديد الطريقة المناسبة للتعامل معه من خلال

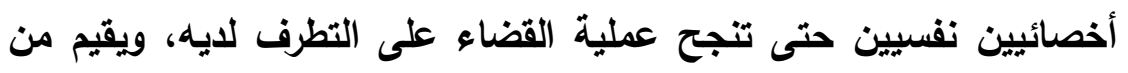

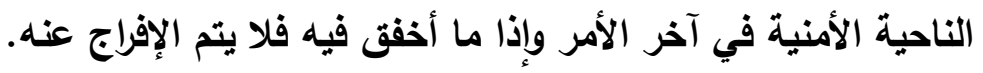

المرحلة الثانية: يخضع المفرج غنهم لنظام دقيق للمتابعة يجدل كل عامين ويتم تمديده أو إنهاؤه وفقا لنتيجة التقييم السنوي. ويعد أن يتحرر المستقيد من برنامج المتابعة يكون

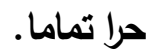

المرحلة الثالثة: يتم دمج المفرج عنهم في المجتمع بصورة كاملة من خلال برنامج الرعاية اللاحقة وتقليم الدعم اللازم له ولأسرته.

\section{السمات الشتركة للخبرات الدولية في مواجهة التطرف الفكري:}

1- استخدام المنهج الناعم مع أساليب الأمن القائمة على الضبط والمحاكمة وتطبة التطبيق

$$
\text { القانون في القضاء على التطرف الفكري. }
$$

ץ- استخدام التدابير لمواجهة التطرف عملية مستمرة سواء في مرحلة الاحتجاز أو الفوب

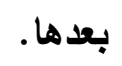

r- تطبيق القاعدة التريوية "إنسانية العقاب تخدم أهاف العدالة أكثر مما تخذمها

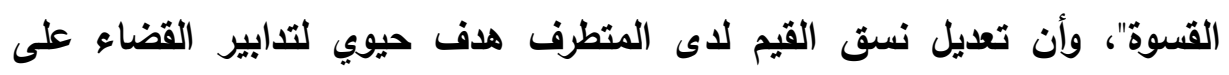
التطرف.

؟ - الاستعانة بالاستثاريين والخبراء للحوار مع المتطرفين وتقديم المشورة لهم قبل ويعد

$$
\text { الافراج عنهم ومساعدة أسرهم. }
$$


ه- تقايمها لبرامج مهنية ومهارية وتعليمية للنزلاء ومساعدة المفرج عنهم في عملية التأهيل وإندماجهم في المجتمع.

צ- الاستعانة بالأخصائيين النفسيين والمتخصصين الثرعيين كجزء رئيس لا يتجزأ من البرامج

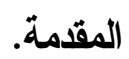

\section{سادسًا : الرؤية المقتز حة لتعزيز الجهود التربوية لمركز محمدل بن نايف} للنناصحة والرعاية في مواجهة التطرف الفكري بـالمملكة العربية السعودية

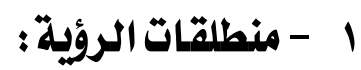

- الاقتصار على الجانب العقابي وحده في مواجهة سلوك التطرف والعنف غير مجد بالارجة الكافية لمواجهة التطرف.

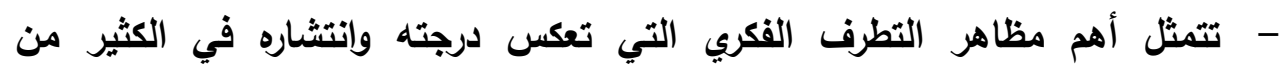

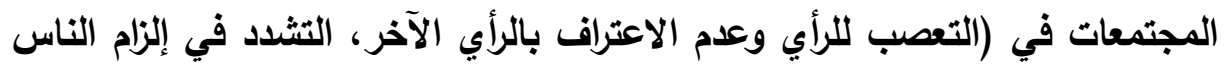

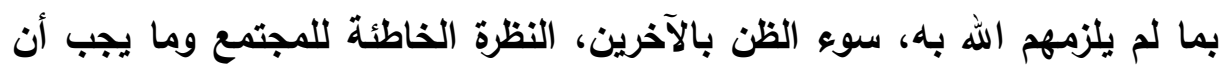
يكون عليه، التقليد الأعمى، والسقوط في هاوية التكفير).

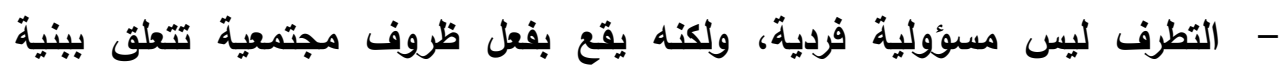

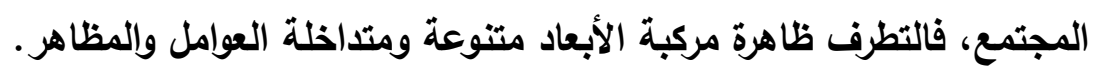

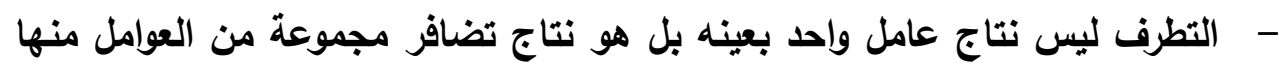

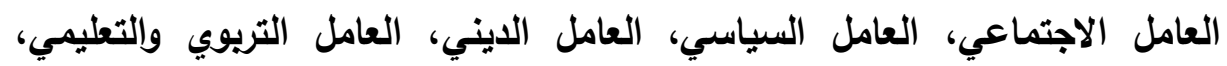

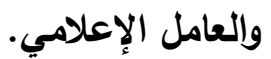
- إعادة تأهيل المتطرفين عملية من الصعب تنفيذها إجباريا فهي في حاجة إلى بناء جسر من التعاون والثقة بين العاملين بمؤسسات مواجهة التطرف والنزلاء.

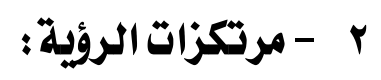

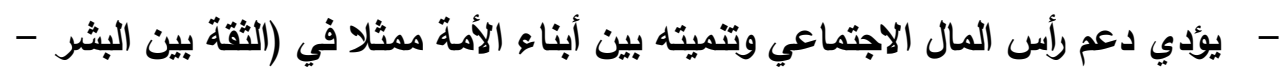
نفي الخوف من العلاقات التبادلية بين أبناء المجتمع - توثيق الرئية التباءيط الاجتماعية

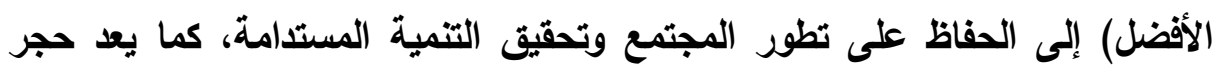
الأساس في مواجهة التطرف. 
- وجود اهتمام كبير - من قبل أولي الأمر بالمملكة - بضرورة الإيلاف والتآلف بين

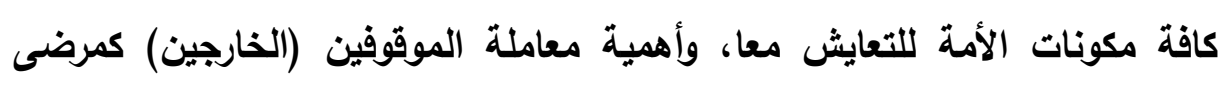

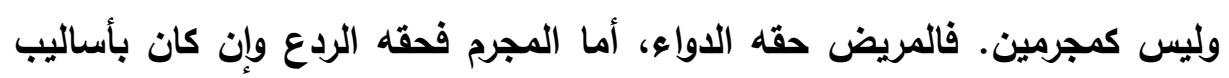

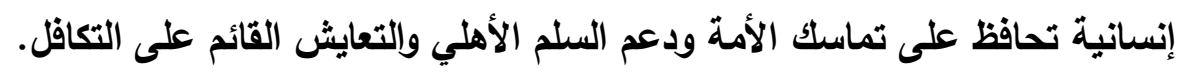

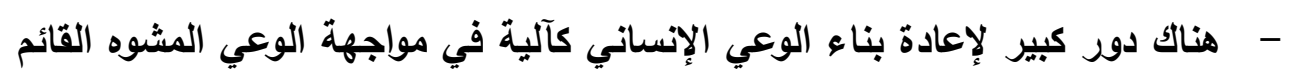

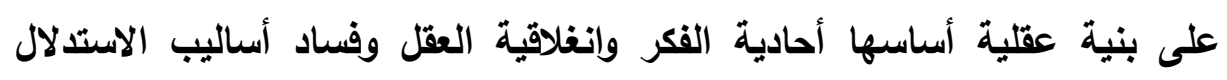

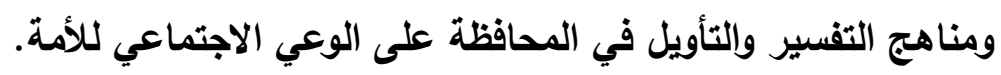

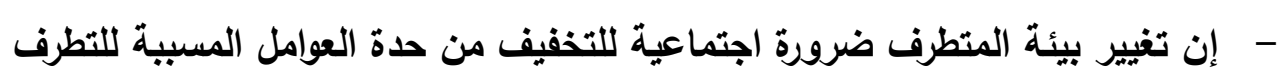
بمظاهره المختلفة. علمي متخصص تثارك فيه جهات مختلفة من المجتمع.

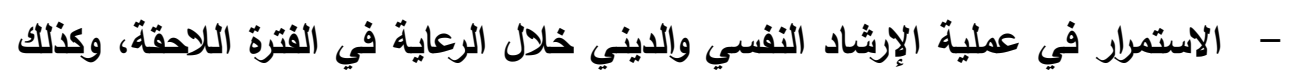

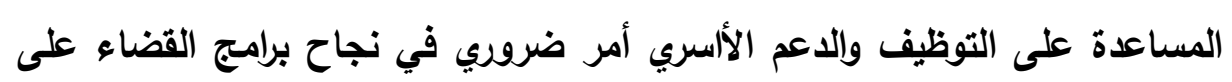
التطرف.

- - دعم مشاركة الثباب في الحياة المجتمعية.

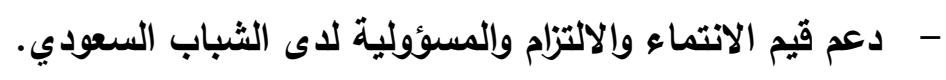

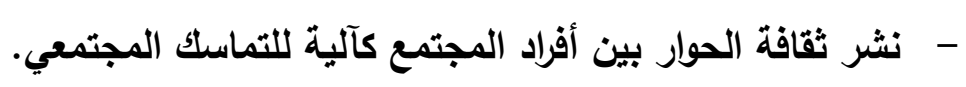
- - استخدام المنهج العلمي في مواجهة قضايا التطرف الفكري. - - مراجعة البرامج بثكل دوري مع قابلية تعديلها وفق الأعراف والتقاليد المجتمعية. - - - إسهام منظمات المجتمع المدني في تنفيذ برامج مواجهة التطرف الفكري.

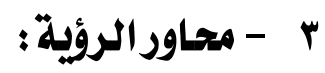

بالنظر إلى البرامج التي قدمها المركز لمواجهة التطرف يتضح أنها تتضمن العديد من

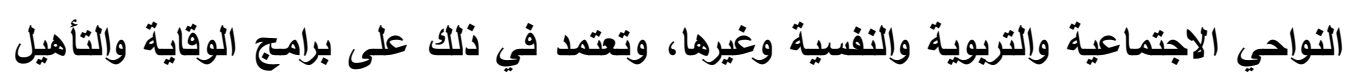

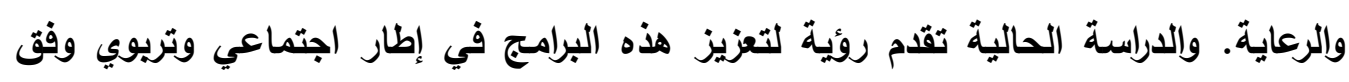
المحاور الآتية: 
المحور الأول: إصلاح الظهير المجتمعي

- تغزيز التحالفات الاستراتيجية لمكافحة هذه الظاهرة على الصعيد العالمي من خلال مبادرات ثائية وإقليمية وجماعية عبر حزمة من التثابير المرتكزة على ركائز ثقافية وتريوية واجتماعية واقتصاية.

- دعم التواصل الحضاري والثقافي بين المملكة العربية السعودية ودول الجوار خاصة اللدول العربية، والعمل على التلاقح الثقافي بين هذه الدول ضئ الدمن أجندة عمل محددة ومتوافق عليها أساسها التكامل الثقافي والاقتصادي والتوجه نحو المستقبل.

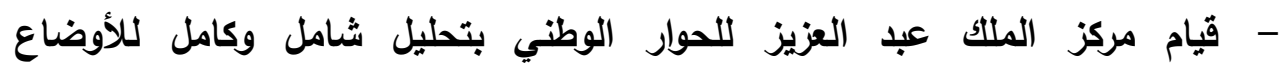
الاجتماعية والثقافية والاقتصادية والسياسية للمجتمع السعودي لصياغة خطاب لإني ديني مبني على وسطية الإسلام الصحيح. - تأسيس قناة فضائية وحسابات إلكترونية في وسائل التواصل الاجتماعي بلغات متنوعة لنشر الخطاب الايني الوسطي.

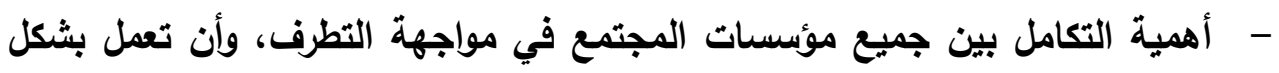
ديناميكي متزامنة ومتواكبة ويكل وسائلها المختلفة.

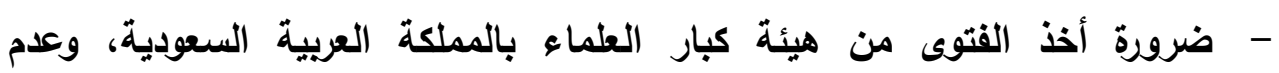

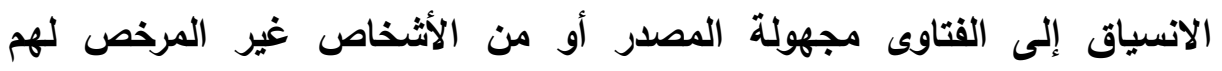
بالفتوى. - تطوير الإعلام ليصبح أكثر فاعلية لتوعية الأفراد من خلال البرامج المعدة بثكل

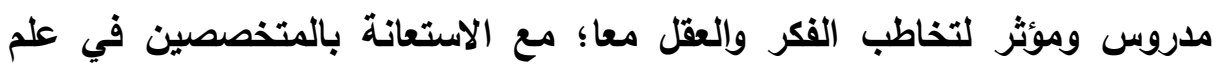
النفس والتربية وعلم الاجتماع ليتحدثوا - عبر وسائل الإعلام - عن خطر غسئ بالفيل

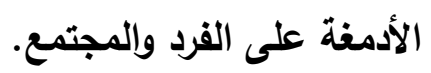
- ضرورة إبراز دور المفكرين الإسلاميين المؤهلين في العلوم الثرعية والرافضين لفكر التطرف والإرهاب. - ضرورة العمل على تهيئة الظروف المجتمعية لتمكين المتنفيد من سرعة الاندماج في المجتمع بعد خروجه من المركز. 
- التتسيق مع اللجنة الوطنية (تراحم) من أجل الاستفادة من برامجها المتعدة لخدمة المستفيدين.

- - ضرورة الاستفادة من الطاقات والإمكانات البشرية والمادية التي تمتلكها مؤسسات التربية والتعليم المختلفة في مجال توعية الطلاب من أجل تدعيم القيم الدينية الوسطية.

- ضرورة تحمل الأسرة مسؤولية الإسهام في إعادة المستفيد إلى تيار الحياة

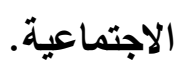

- الاستفادة من نتائج البحوث والدراسات وتوظيفها في مجال التوعية والتأهيل والرعاية.

\section{المحور الثاني : تنويع الأنشطة التربوية}

- الارتقاء بالممارسة التريوية في مؤسسات التعليم النظامي، خاصة في مرحلة التعليم قبل الجامعي باعتبارها مرحلة الإعداد من أجل المواطنة.

- وضع سياسة تربوية شاملة يمكن من خلالها تحقيق التكامل بين أهداف التربية النظامية والتربية غير النظامية. - دعم الدور الثقافي للجامعات في تثكيل وتكوين الوعي بمختلف مستوياته وأنواعها

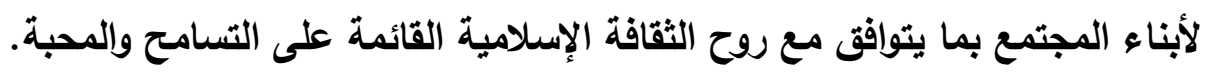
- تضمين الخطط والأنثطة الاراسية بالمدارس والجامعات موضوعات حيوية تكثف التفائ الحقائق والخبرات التربوية التي تسهم في تعديل سلوك المتطرف.

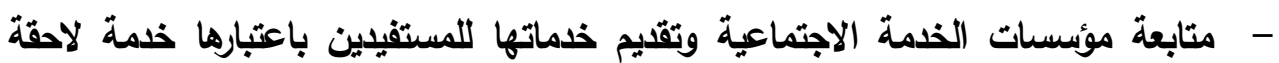
ضرورية.

- - عقد ندوات في مؤسسات التعليم لتوضيح أضرار الفكر المتطرف على الفرد والمجتمع. - ت تمية وتحفيز الثباب للخدمة التطوعية في المجتمع لاستثمار وقت فراغهر. - تقوية المهارات الإيجابية التي يتمتع بها المستفيدون أولا، ثم إكسابهم مهارات جليدة. - التركيز على ثقافة الحوار ووسائله بدلا من الإلقاء والتلقين في المؤسسات التعليمية. 
المحور الثالث: تعزيز أداء مركز محمد بن نايف للمناصحة والرعاية

- تنمية روح المسؤولية لاى القائمين على برامجه، وتكثيف البرامجاجئ الموجودة

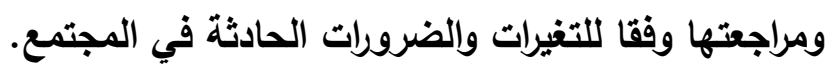

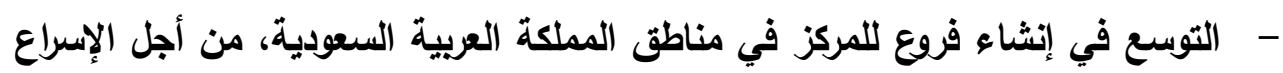
في إجراءات القضاء على ظاهرة التطرف الفكري. - - استقطاب المتخصصين من أساتذة الجامعات لوضع آليات ويرامج إبداعية مبتكرة للمناصحة والرعاية والتأهيل تتفق وروح الثريعة الإسلامية.

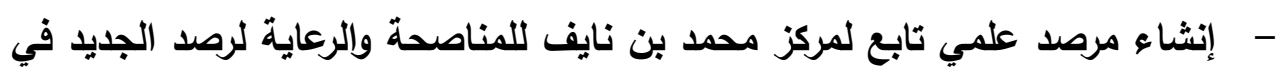
مجال تطور ظاهرة التطرف والإرهاب محليا وإقليميا وعالميا. - تعزيز الجدارة المهنية لأعضاء المركز المتخصصين، عن طريق عقد الحلقات الاراسية وورش العمل وحلقات التدريب والمؤتمرات.

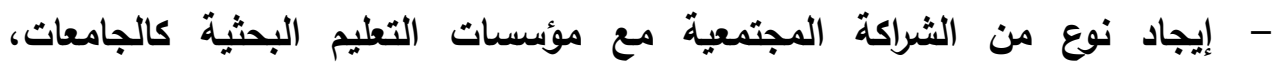
والاستفادة من الجهود البحثية في هذا المجال.

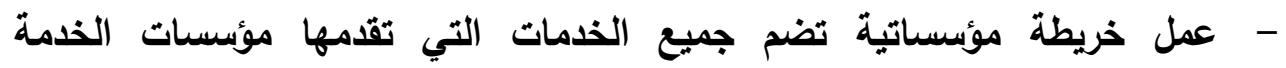

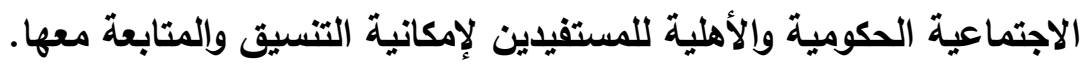

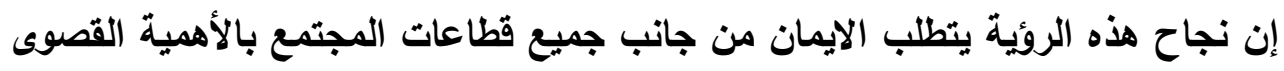

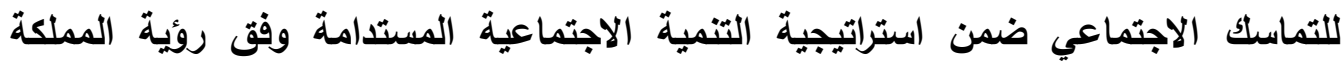

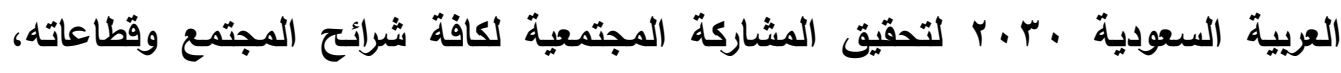
خاصة المرأة والمناطق النائية والثباب، لاسيما في مرحلة التحول الاجتماعي والثقافي الحالية التي تمر بها المملكة بقيادة رشيدة لتحقيق مشروع التقلدم والانطلاق نحو آفاق مستقبلية

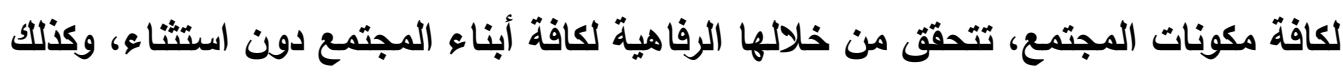

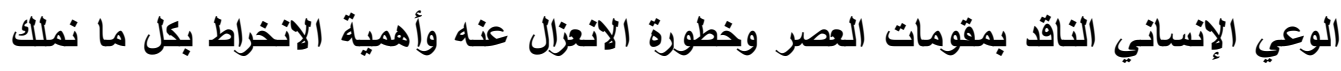
من قدرات في تحمل تكلفة التنمية؛ وكل ذلك تحقيقا لمقومات المواطنة العئة وقيم الانتماء. 


\section{المراجـع}

أولاً : المراجع العربية

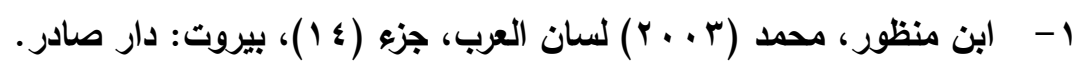

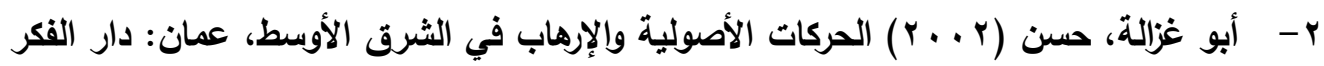

للطباعة والنثر والتوزيع.

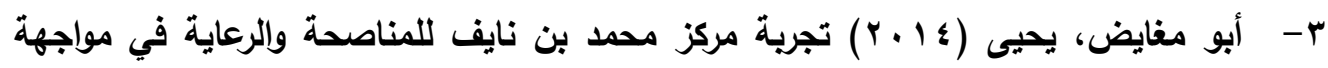

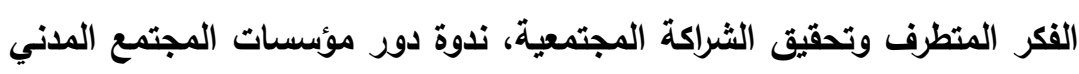

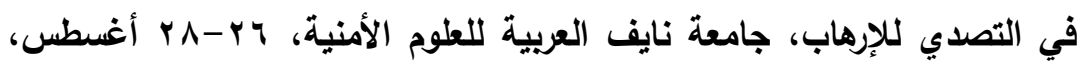
الجزائر.

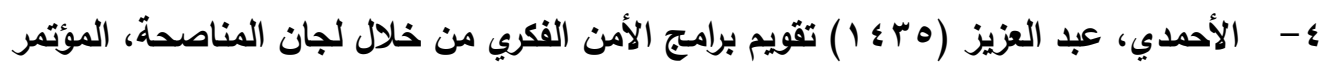

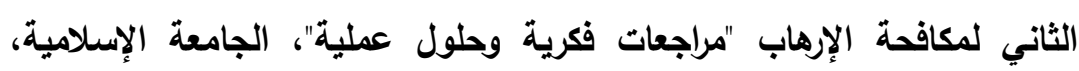

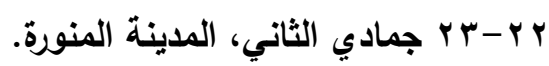

ه- الأخرس، محمد (1 • ؛ 1) البرامج التأهيلية وتحقيق الرعاية النلاحقة للمفرج عنهم (في الرعاية

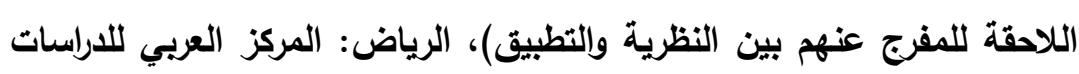

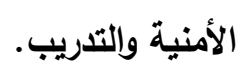

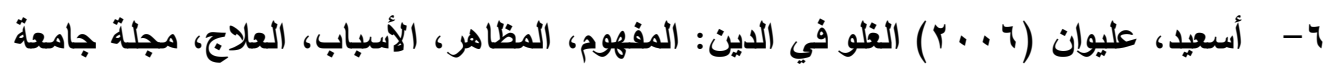

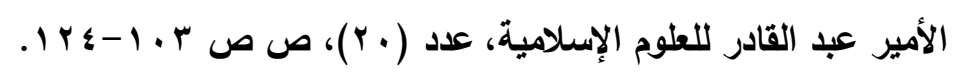

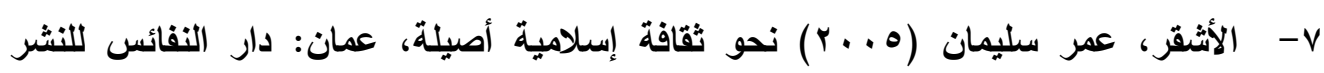
والتوزيع.

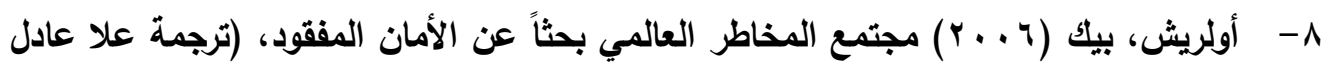
وآخرون)، القاهرة: المركز القومي للترجمة.

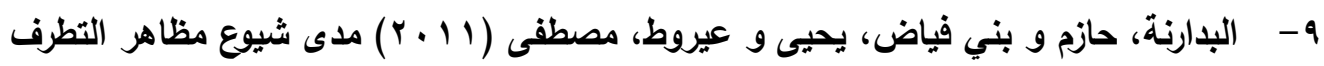

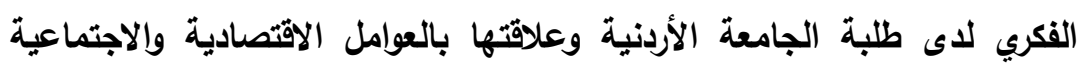

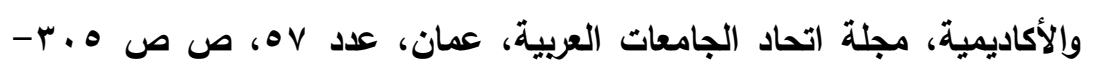
q

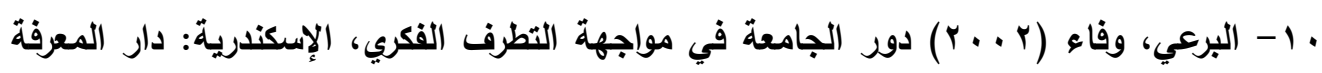
الجامعية. 
1 - 1 بورني، نسيم (r ا • ץ) الدور التربوي للمؤسسات العقابية وعلاقته بإعادة تأهيل المساجين،

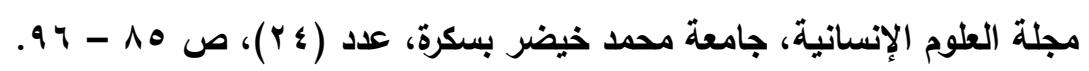

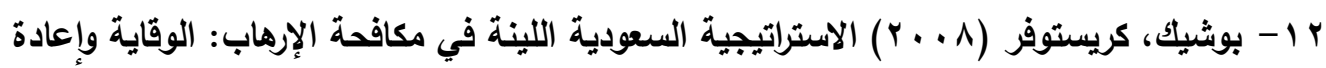

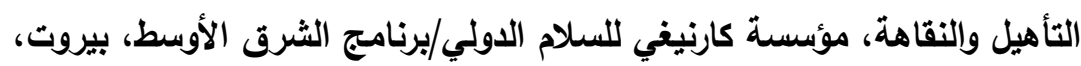

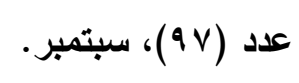

r ا - البيثي، سعيد (11 + r) عرض تجربة الملكة العربية السعودية في المناصحة والتأهيل، ندوة

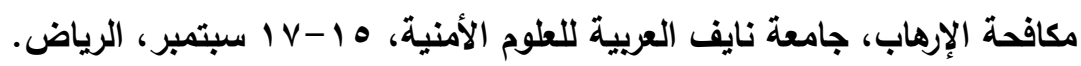

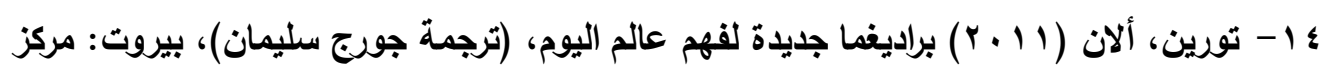
دراسات الوحدة العربية.

10

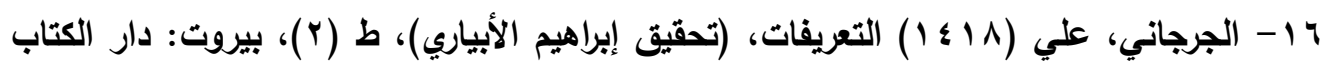
العربي.

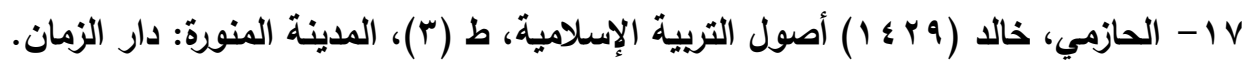

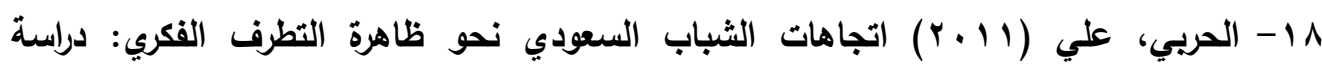
اجتماعية على عينة من طلبة جامعة القصيم، رسالة ماجستير، الجامعة

\section{الأردنية.}

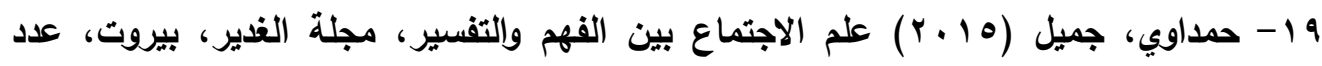

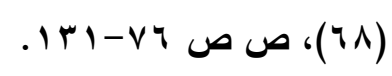

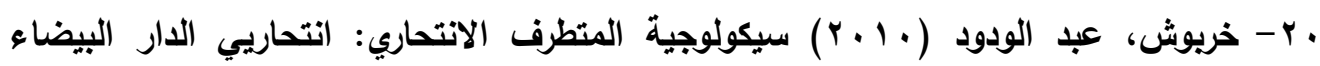

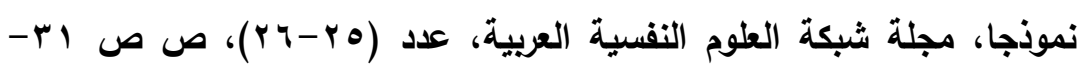

$$
\text { مo }
$$

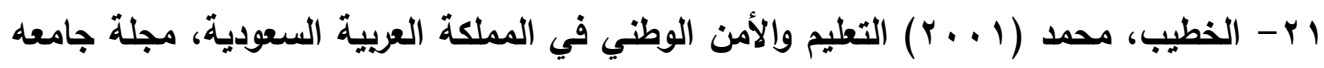

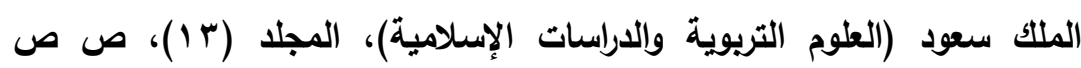

$$
.191-17 \mathrm{~V}
$$

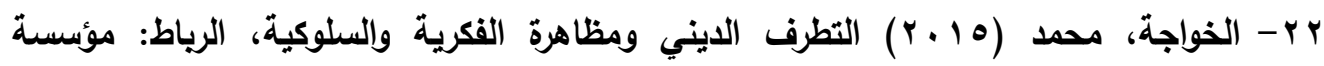
مؤمنون بلا حدود للاراسات والأبحاث.

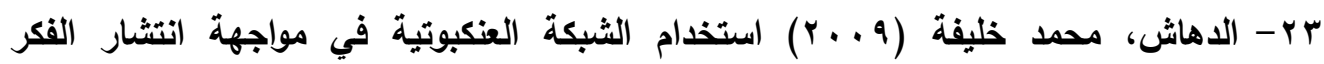
المتطرف، رسالة ماجستير غير منثورة، جامعة نايف العربية للعلوم الأمنية. 


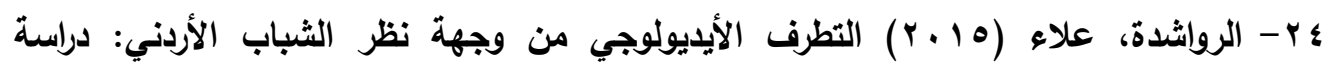

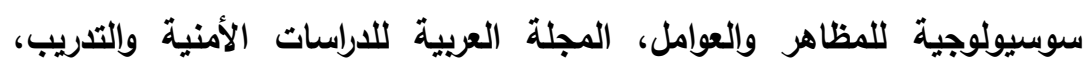

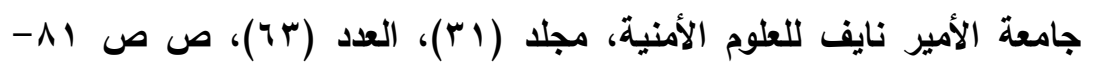
$.1 \%$.

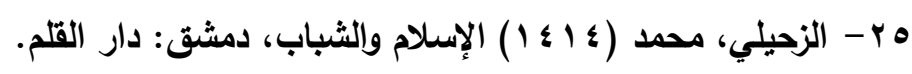

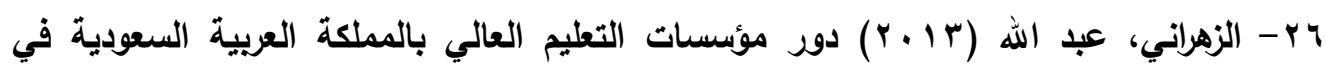

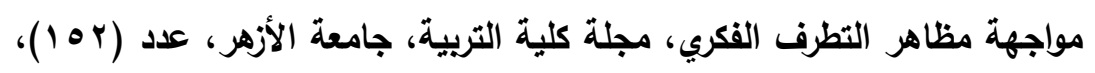

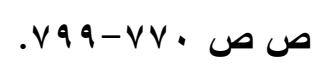

V V - السحمراني، أحمد (991 1) العنف والإرهاب: الجذور والتحديات وسبل العلاج، المؤتمر الدولي

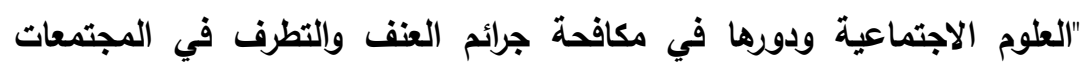

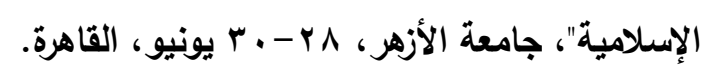

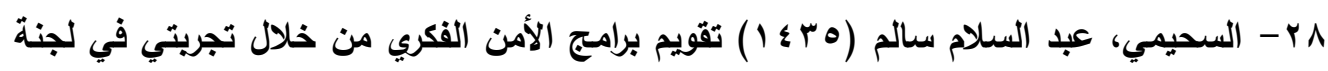

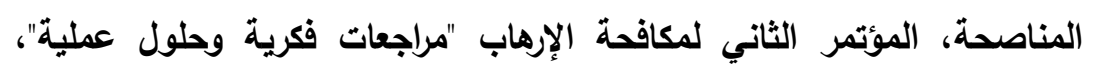

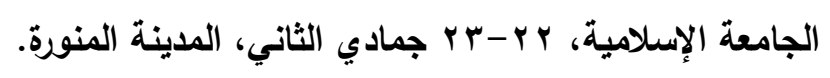

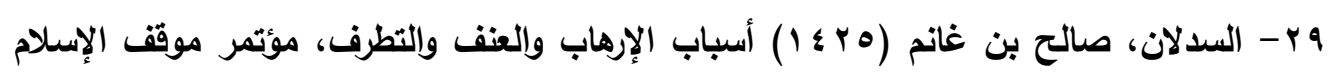

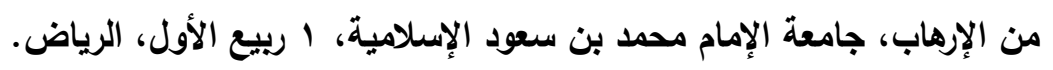

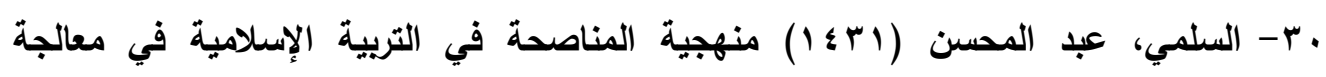

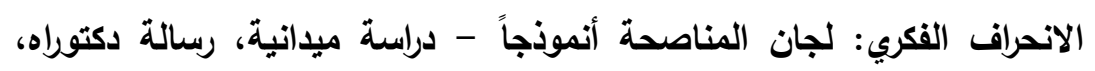

\section{الجامعة الإسلامية.}

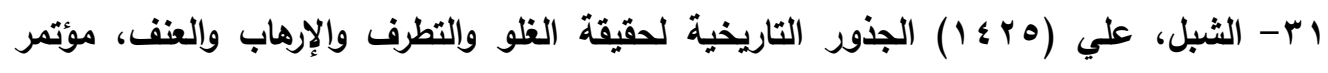

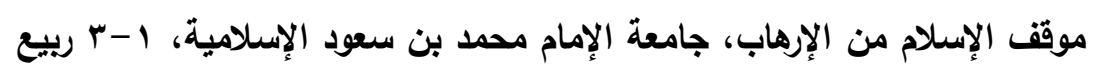

$$
\text { الأول، الرياض. }
$$

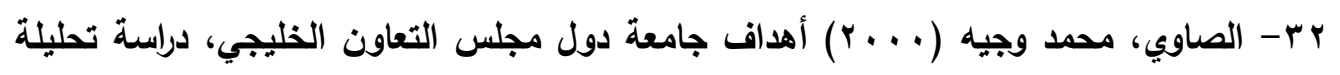

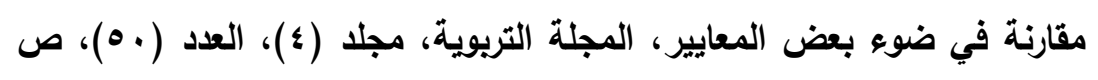

$$
.1 r \Lambda-V 0
$$

rr- الضحيان، سعود (991) البرامج الإششادية في السجون ودورها في الحد من العود

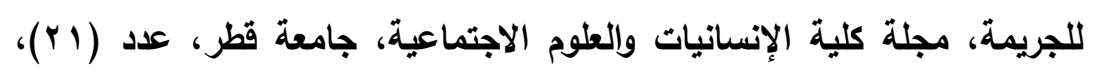

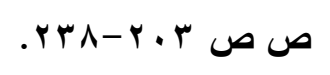




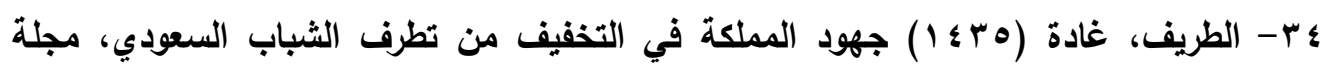

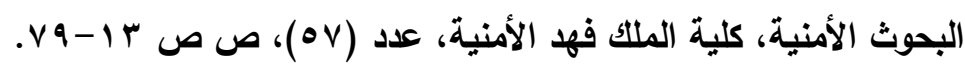

هr- طعيمة، سعيد (999) التعليم المصري والاخترلق الثقافي: دراسة تحليلية، مجلة كلية

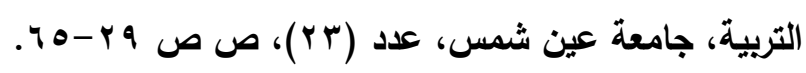

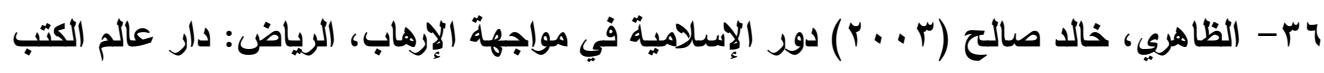
للنشر والتوزيع.

V V - عبد العال، عبد الحليم (1 ـ 1) تجارب وخبرات محلية ودولية في الرعاية، الرياض: المركز

$$
\text { العربي للاراسات الأمنية والتدريب. أجارب وخبرات }
$$

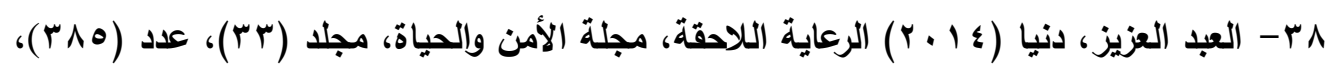

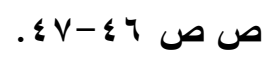

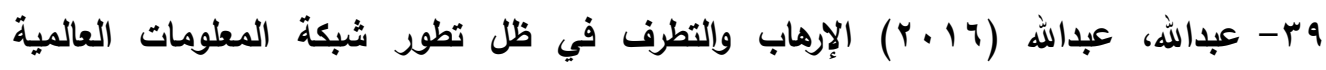

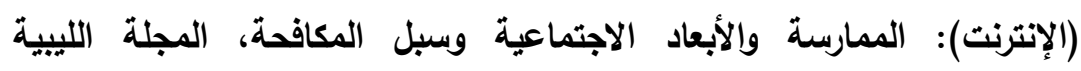

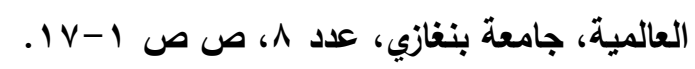

• ـ - العبيدي، الأسعد (1 1 1 1) دور الخصائص النفسية والاجتماعية لنزلاء المؤسسات الإصلاحية

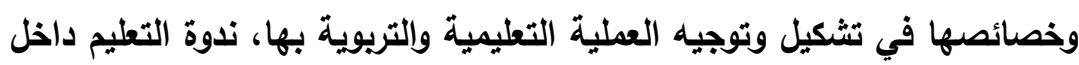

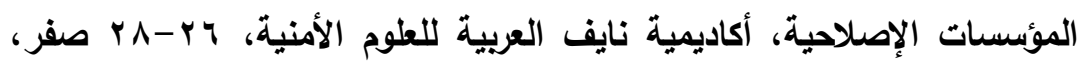

$$
\text { الرياض. }
$$

اء - عتريسي، طلال (10 + r) الأبعاد الاجتماعية لظاهرة التكفير، مجلة الغدير، العدد (^؟)، ص

$$
\text { ص }
$$

r ع - عفيفي، محد الهادي (91911) في أصول التربية: الأصول الثقافية للتربية، القاهرة: مكتبة الأنجلو المصرية.

r ؟ - عمران، عفاف (؟9 9 1 ) الأبعاد الاجتماعية والاقتصادية لظاهرة التطرف الديني بحث تطبيقي

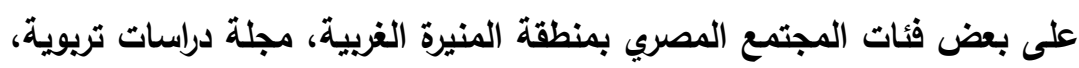

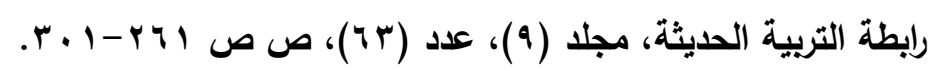

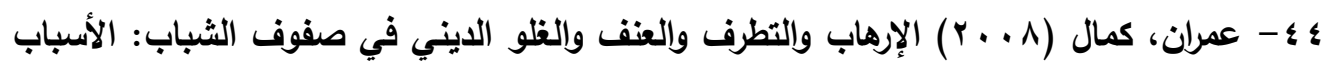

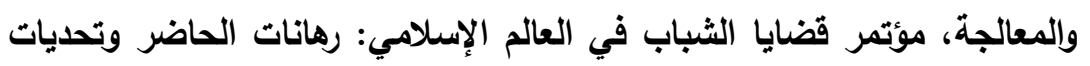

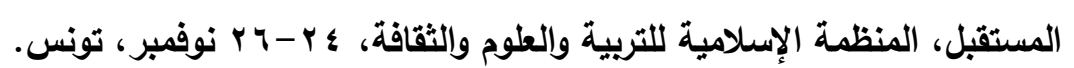




\section{الجهود التربوية لمركز محمد بن نايف للمناصحة والرعاية في مواجهة التطرف الفكري: رؤية مقترحة}

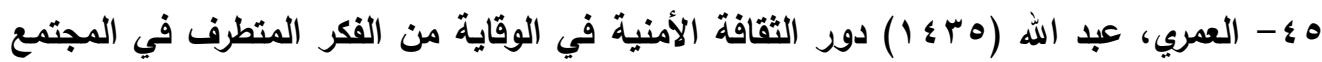
السعودي، رسالة ماجستير، جامعة نايف العربية للعلوم الأمنية.

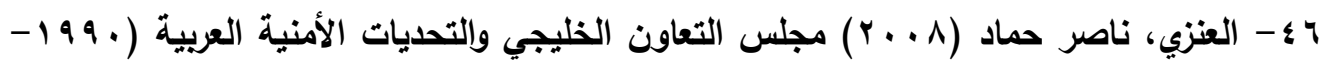

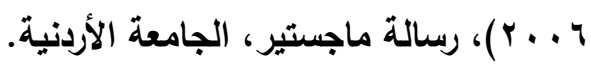

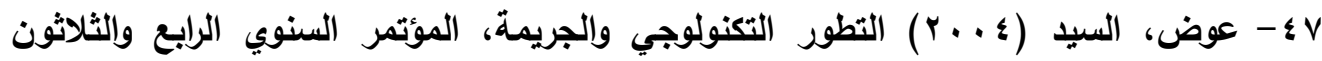

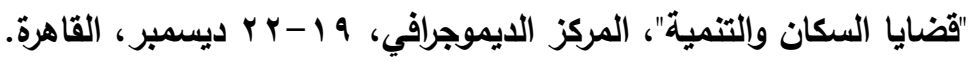

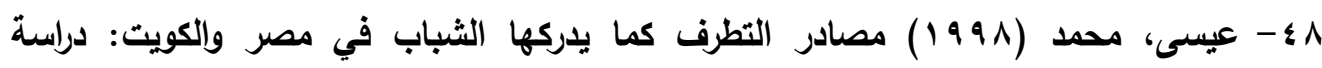

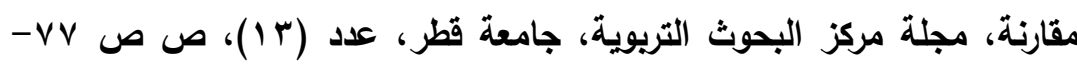
$.1 \cdot r$

9 ؟ - الفاربي، عبداللطيف و الغرضاف، عبدالعزيز و موحي، محمد و غريب، عبدالكريم ( 99 ( )

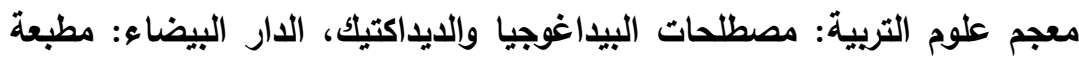

$$
\text { النجاح الجديدة. }
$$

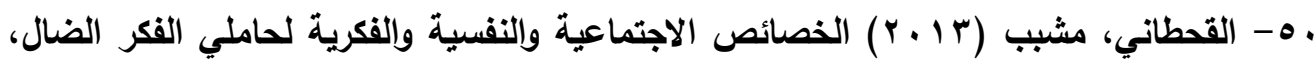
رسالة دكتوراه، جامعة نايف العربية للعلوم الأمنية.

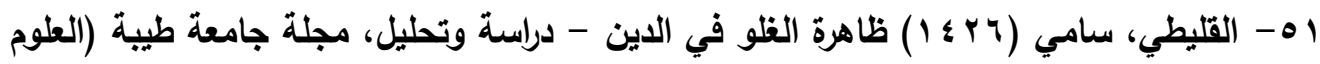

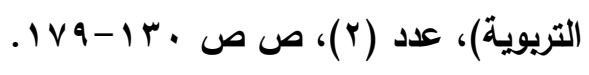

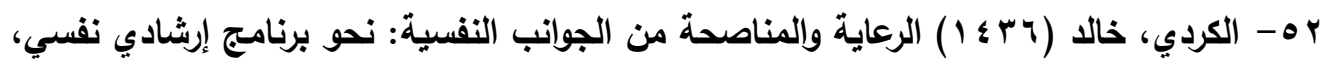

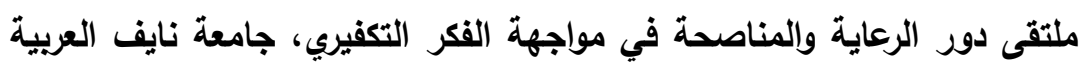

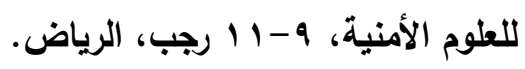

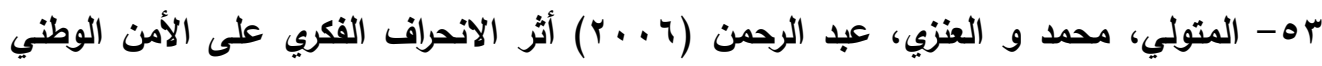

$$
\text { الخليجي، الكويت: دار الإيمان للطباعة. }
$$

؛ ه - متولي، مصطفى (7 1 أ 1) نموذج مقترح لبرامج تعليمية تريوية داخل المؤسسات الإصلاحية

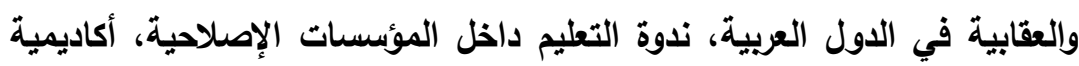

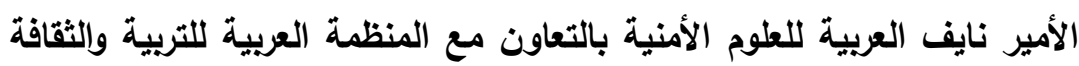

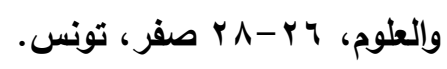

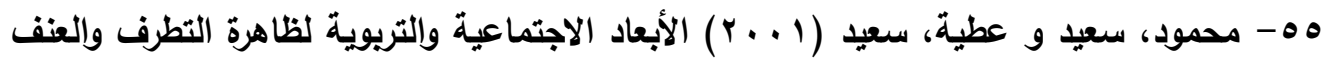

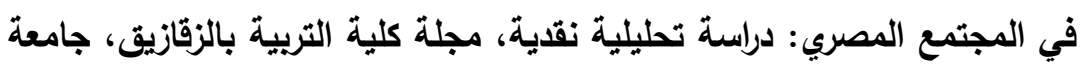

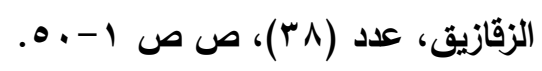




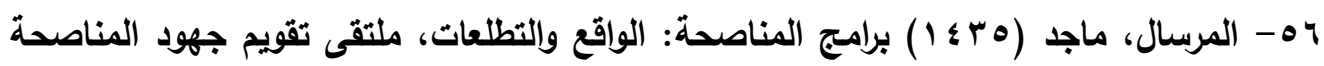

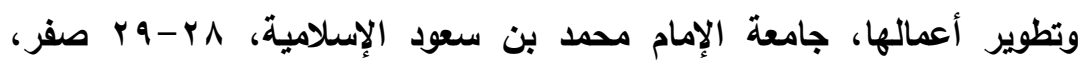
الرياض.

V- V - مرسي، فؤاد (9V9 ) أزمة المجتمع هي أزمة المثقفين، الندوة الدولية "المثقفين والتغير

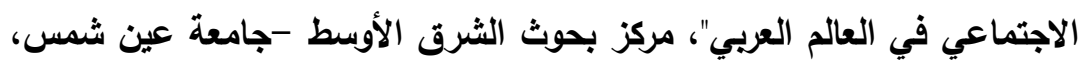

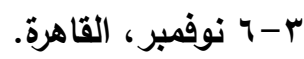

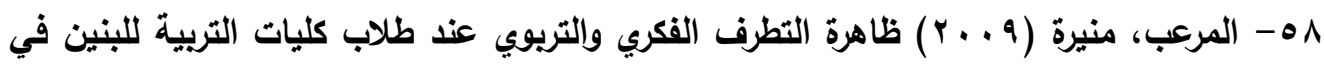

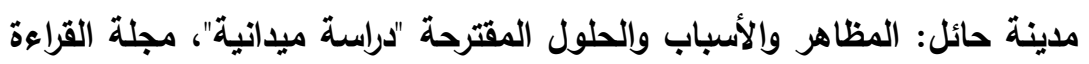

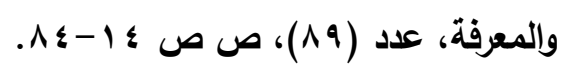

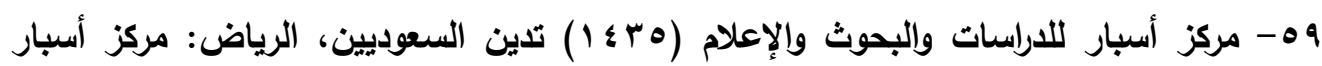

$$
\text { للاراسات والبحوث والإعلام. }
$$

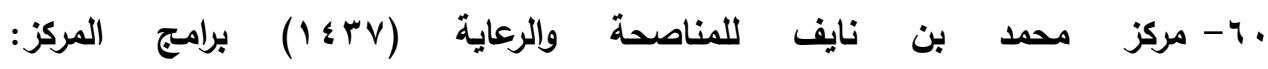
http://www.mncc.org.sa/wps/wcm/connect/main/Counseling+c enter+AR/Main/Home/?presentationtemplate=Design/MNCC/ \#MNCC+AR (8-10-1437) آ- مركز

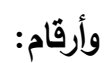
http://www.mncc.org.sa/wps/portal/!ut/p/z1/04_iUlDg4tKPAFJ ABjKBwtGPykssy0xPLMnMz0vM0Y_Qj4wyizfwNDHxMDQ x8vb39jc3cDR18vNyswwwNPA31Q9HVWBgGuRs4GhmFup uYhZkYOJjqB9FlH4cwNGASP24FUThN96LsAVRqEoMTIx dgUrMnUICA7wMDYxN0RWgmeGOoQBLIBFyZnBikX5Bb mhoRGWwZ5aJoyIAerozHw!!/dz/d5/L2dJQSEvUUt3QS80T mxFL1o2XzBJNDRIMTQySzA0M0UwQTU3QIRRUEoxMEs

$$
\text { /y (21-9-1438) }
$$

r r - مركز محمد بن نايف للمناصحة والرعاية (10 ب ب ب) منشور عن برنامج التأهيل، الرياض: مركز محمد بن نايف للمناصحة والرعاية.

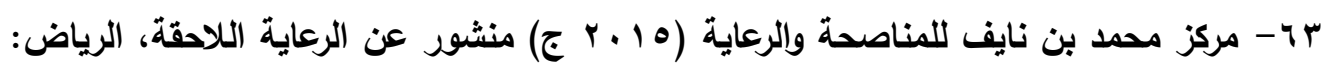
مركز محمد بن نايف للمناصحة والرعاية.

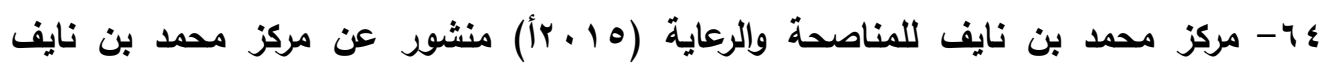
للمناصحة والرعاية، الرياض: مركز محمد بن نايف للمناصحة والرعاية. 
ه - المرواني، نايف (11 ب) تجربة المملكة العربية السعودية في مكافحة الإرهاب، مجلة الفكر

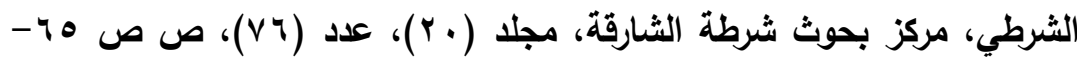

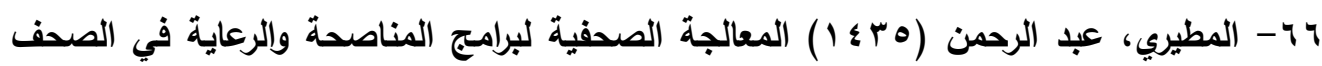

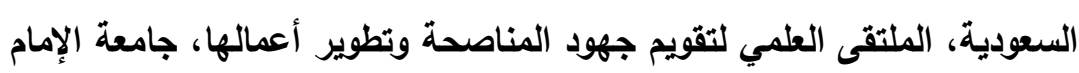

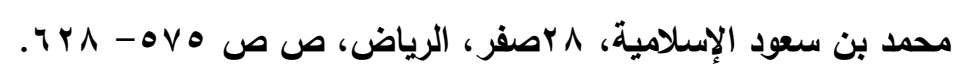

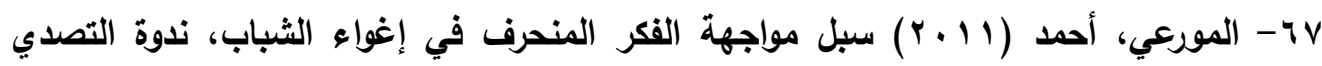

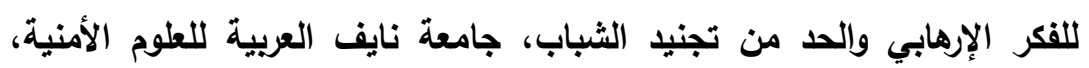

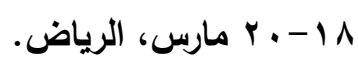

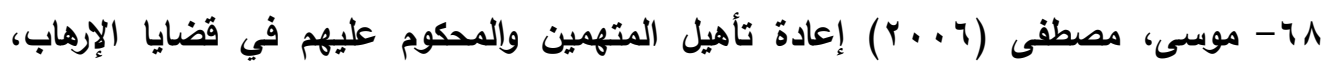
الرياض: جامعة نايف العربية للعلوم الأمنية.

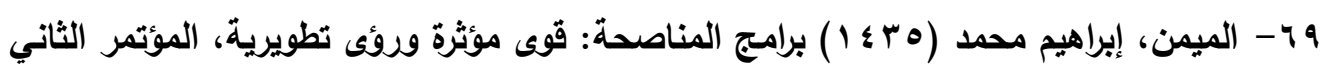

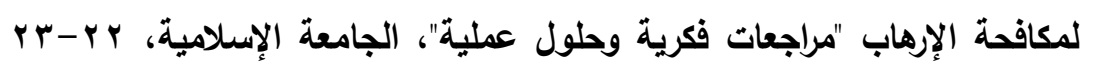

$$
\text { جمادي الثاني، المدينة المنورة. }
$$

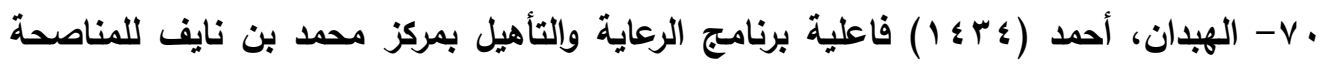

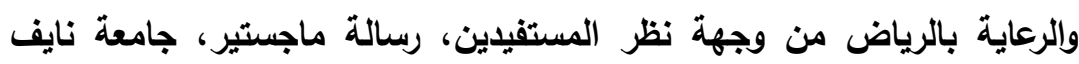

$$
\text { العربية للعلوم الأمنية. }
$$

ا - الهليل، عبد العزيز ( ا I I I) واقع الرعاية اللاحقة للمفرج عنهم من الموقوفين امنيا في مركز

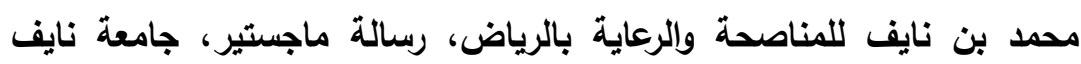

\section{العربية للعلوم الأمنية.}

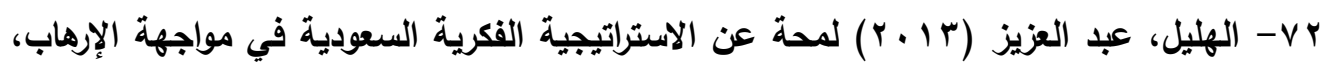

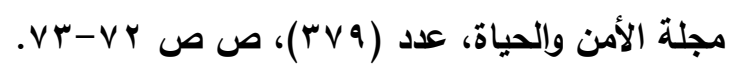

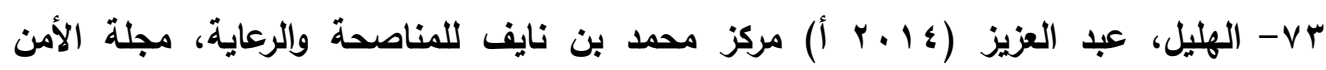

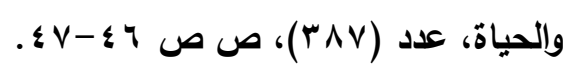

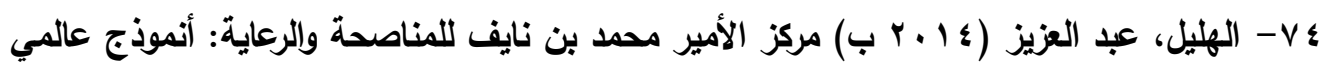

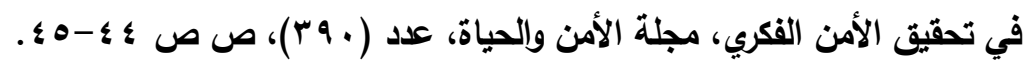




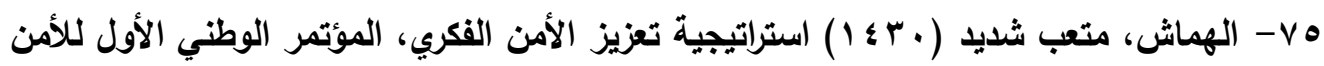

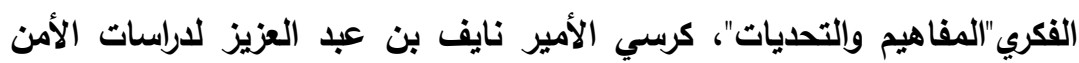

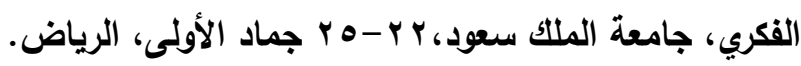

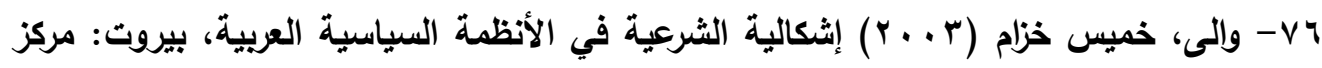

$$
\text { الوحدة الوطنية والدراسات. }
$$

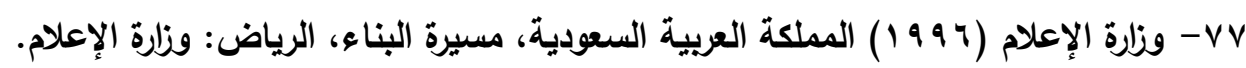

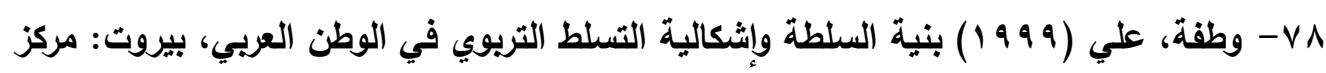

$$
\text { دراسات الوحدة العربية. }
$$

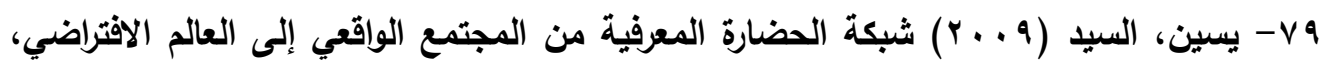
سلسلة العلوم الاجتماعية، القاهرة: الهيئة المصرية العامة للكتاب.

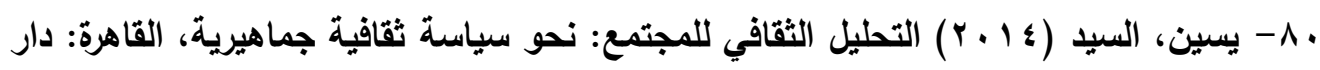
نهضة مصر للنشر.

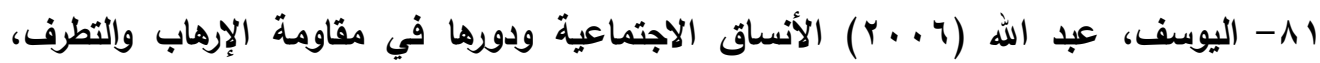
الرياض: جامعة نايف العربية للعلوم الأمنية.

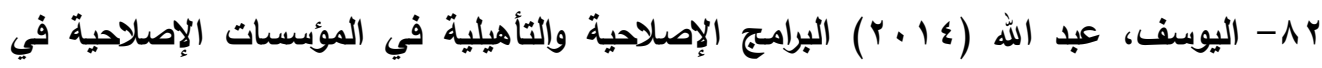
المملكة العربية السعودية، ط (ب)، الرياض: كلية الملك فهر الأمنية.

ثانيًا : المراجع الإنجليزية

83- Alsayat, N. (2014) the Contributions of the Rehabilitation and Care Programs for Terrorists, Masters of Criminal Justice, University of Colorado Denver.

84- Anderson, G. \& Arsenault, N. (2000) Fundamentals of Educational Research, 2nd Edition, New York: Routledge Taylor \& Francis Group.

85- Aslam, M. \& Othman, L. \& Rosili, N. (2016) DE-Radicalization Programs in South-East Asia: A Comparative Study of Rehabilitation Programs in Malaysia, Thailand, Indonesia \& Singapore, Journal of Education and Social Sciences, (4), pp. 154-160.

86- Basit, Abdul (2015) Countering Violent Extremism: Evaluating Pakistan's Counter-Radicalization and De-radicalization Initiatives, IPRI Journal, XV (2), Pp. 44-68. 


$$
\text { الجهود التربوية لمركز محمد بن نايف للمناصحة والرعاية في مواجهة النطرف الفكري: رؤية مقترحة }
$$

87- Crenshaw, M. (2005) Political Explanations, The International Summit on Democracy, Terrorism and Security, 8-11 March, Madrid.

88- Gendron, A. (2010) Confronting Terrorism in Saudi Arabia, International Journal of Intelligence and Counter Intelligence, 23(3), pp. 487-508.

89- Gunaratna, R. (2008) Understanding the Challenge of Ideological Extremism, UNISCI Discussion Papers, (18), pp. 113-126

90- Horgan, J. \& Braddock, K. (2010) Rehabilitating the Terrorists?: Challenges in Assessing the Effectiveness of Deradicalization Programs, Terrorism and Political, (22), pp. 267-291.

91- International Peace Institute (2010) A New Approach? Deradicalization Programs and Counterterrorism, Countering Violent Extremism: Learning from Deradicalization Programs in Some Muslim-Majority States, March 16-17, Amman.

92- Johnston, A. (2009) Assessing of Effectiveness of De-radicalization Programs of Isamist Extremists, Master of Arts in Security Studies, Naval Postgraduate School.

93- Jones, M. (2013) Rehabilitating Islamist Extremists: Successful Methods in Prison-Centered De-radicalisation Programmes, Journal of Politics and International Studies, (10), pp. 171-221.

94- Saba, N. \& Shagufta, H. (2009) Deradicalization: Approaches and Models, PAK Institute for Peace Studies, April. http://sanpips.com/download.php?f=116.pdf $(\mathbf{2 2 - 8 - 2 0 1 6})$

95- Spencer, A. (2006) Questioning the Concept of New Terrorism, Peace Conflict \& Development, (8), pp. 1-33.

96- Striegher, J. (2013) the Deradicalisation of Terrorists, Salus Journal, 1(1), pp. 19-40.

97- Zhou, Z. (2017) Chinese Strategy for De-radicalization, Terrorism and Political Violence, (16), pp.1-23. 